\title{
COMET NUCLEUS SAMPLE RETURN MISSION
}

PRESENTATION TO

SSEC SUMMER STUDY

SNOWMASS, COLORADO

2 AUGUST 1983

UNDER CONTRACT NO. NASW-3622 STUDY NO. 1-120-340-M20 
Report No. SAI $-83 / 1152$

\title{
COMET NUCLEUS SAMPLE RETURN MISSION
}

\author{
by \\ Science Applications, Inc. \\ 1701 East Woodfield Road \\ Schaumburg, Illinois 60195

\section{for} \\ Solar System Exploration Division \\ Office of Space Science and Applications \\ NASA Headquarters \\ Washington, DC 20546
}

Contract NASW-3622

Study No. 1-120-340-M20

September 1983 


\section{Page intentionally left blank}

\section{Page intentionally left blank}


This study was conducted between May and August 1983 as part of the work performed by Science Applications, Inc. under Contract No. NASW-3622 for the Solar System Exploration Division, Code EL, NASA Headquarters. Total technical effort expended on this study task was 48 man-weeks. The purpose of this effort has been to assist NASA planners and the planetary science community in defining a comet nucleus sample return mission in terms of its relevant science objectives, candidate mission concepts, key design/technology requirements and programmatic issues. Results of the study were presented at the Solar System Exploration Committee (SSEC) Summer Study held in August 1983 in support of the committee's focus on potential augmentations to their recommended core program.

Harvey Feingold served as study leader for this effort with very significant contributions provided by the following SAI staff members: Alan Friedlander, Steve Hoffman, Deanna Limperes, John Niehoff, Kevin Schaefer, John Soldner, Dan Spadoni and Bill Wells. Special acknowledgement and thanks are also due Dr. David Morrison of the University of Hawaii, our science consultant on this study, for his valuable contributions relating to the mission science objectives and guidelines. 
INTRODUCTORY STATEMENT OF SCIENTIFIC OBJECTIVES............. 1

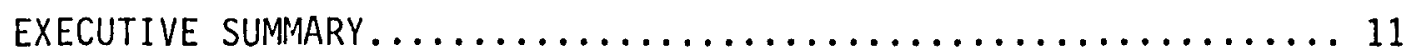

OBJECTIVES AND SCOPE.............................. 13

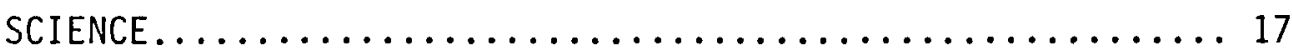

COMET SELECTION.................................. 27

MISSION CONCEPT................................ 35

ENCOUNTER STRATEGY...............................41 4

SAMPLING....................................... 53

THERMAL CONTROL.............................. 63

FLIGHT PERFORMANCE.............................. 71

COST....................................... 83

CONCLUSIONS.................................. 91

APPENDIX: SUPPORTING DATA......................... 95 


\section{INTRODUCTORY STATEMENT OF SCIENTIFIC OBJECTIVES}




\section{Page intentionally left blank}

Page intentionally left blank 


\section{COMET SAMPLE RETURN}

by

David Morrison, University of Hawaii

\section{Objectives of Cometary Exploration}

The small, chemically primitive objects in the solar system represent today the most important remaining frontier for planetary exploration. During the past twenty years, spacecraft have repeatedly visited the inner planets, and the Pioneer and Voyager missions have provided a strong beginning toward the study of the outer planets with their systems of rings and satellites. However, to date no spacecraft have visited the smaller, primitive bodies: comets, main-belt asteroids, or Earth-approaching asteroids.

In its 1980 report on a Strategy for the Exploration of Primitive Solar System Bodies, the Space Science Board noted that investigations of these small bodies "will provide understanding of a kind that is qualitatively distinct from that provided by studies of the planets and their satellites...As a group these objects provide an important link in our understanding of solar system evolution. This conclusion...reflects the general belief that many are composed of condensed.material from the primitive solar nebula, which is either essentially unaltered or at least has not been altered to the extent of material on planetary and satellite surfaces." The Board therefore recommended that "the primary goal of investigations of asteroids, comets, and dust during approximately the next decade, be to determine their composition and structure and to deduce their history in order to increase our knowledge of the chemical and isotopic composition and physical state of the primitive solar nebula and to further our understanding of the condensation, accretion, and evolutionary processes that occured in various parts of the nebula before and during planet formation."

Comets play a particularly central role in this strategy because they represent the most chemically primitive solid matter known to have survived in the planetary system. A. H. Delsemme, for instance, in his 1977 paper "The Pristine Nature of Comets", noted that "the present results seem at least to have established the fact that the comets are much less depleted in $H, C, N, 0$, and CI chondrites, and that they are probably the most primitive bodies still in the inner solar system." It is now generally accepted, and was implicit in Delsemme's discussion, that most of the cometary material is in the form of ices, which have only been able to survive for nearly 5 billion years because they have spent nearly all of their lifetime far from the sun, in the 0ort cometary cloud some 50,000 AU from the center of the solar system. In this essentially interstellar environment, they have been preserved nearly unaltered until deflected from their place of storage into the inner solar system. They represent, therefore, in the words of the NASA Comet Working Group of 1978, "messengers from the distant past". 
The first cometary space mission will begin the exploration of these bodies in 1985 , when the U.S. ISEE-3 interplanetary spacecraft will pass through the tail of Comet P/Giacobini-Zinner. of potentially much greater interest will be the results expected in 1986 from several spacecraft flybys planned for Comet P/Halley. These include sophisticated remote-sensing instruments on board the European Giotto and the two USSR/Hungarian/French VEGA spacecraft, each of which is expected to pass within a few thousand kilometers of the cometary nucleus. Although these will represent fast flybys $(\simeq 70 \mathrm{~km} / \mathrm{sec})$, some data, at least in the form of a few images, can be expected from the nucleus of Halley. Because of the relatively large size and high level of activity for this comet, interesting results can be expected in spite of the unfavorable circumstances of the spacecraft encounters.

Beyond the fast-flybys of Halley, the next step in cometary exploration identified by the NASA Solar System Exploration Committee (1983) is a rendezvous with a short period comet. In a rendezvous, the spacecraft can fly in formation with the comet for several months, maneuvering about the nucleus and studying it and its activity with a variety of powerful remote sensing instruments. Indirectly, the rendezvous spacecraft can also investigate the chemistry of the nucleus through analysis of the cometary atmosphere, which consists of gas evaporating from the nucleus under the influence of solar heating. It is the premise of this report that such a rendezvous will take place during the mid1990s. It is also probable that the second-priority SSEC comet mission, a fast-flythrough with return to Earth of an atomized or plasmatized sample of the coma dust and gas, will be flown; however, such a collection of an atmomized sample is not considered a necessary precursor to the missions being discussed in this report.

\section{Significance of Sample Return}

A variety of scientific advisory groups, including particularly the Space Science Board in its 1980 report on a Strategy for the Exploration of Primitive Solar-System Bodies, have focused on the nucleus as the most critical part of a comet. Even for early missions, the Space Science Board gave first priority to the objective of determining the composition and physical state of the nucleus. However, a flyby or even a rendezvous mission has limited capability to meet this objective with any high degree of precision. Most remote sensing techniques are restricted to analysis of the uppermost parts of the surface, parts that are typically subject to heating, outgassing, and rapid evolution at the very time the remote measurements are being made. Additional inferences concerning the composition of the nucleus can be made from direct analysis of the dust and gas of the coma, but the very processes that make this gas and dust accessible erase most of the information on its physical state and possibly introduce substantial chemical modifications as well. The only way to be certain that we are truly investigating the physical and chemical nature of the primitive material of the nucleus is to acquire a pristine sample before it has been subjected to alteration by solar heating. 
Perhaps even more important than the acquisition of a sample in a pristine state is the advantage of being able to study it in terrestrial laboratories. No spacecraft analysis technique can approach the precision and sophistication of laboratory analysis. In addition, the presence of a sample in the laboratory permits experimentation, rather than pure observation. The results of one set of measurements can be used to develop a strategy for subsequent tests. Nor is one confined to the state of the art as it existed at the time of flight instrument definition; once a sample is acquired and safely archived, it can be studied by each new technique that future developments may make available.

Although the Space Science Board, in its 1980 report, did not make recommendations for sample return (since such missions clearly fell outside the decade of initial missions under consideration), it seems clear that many of the specific objectives it adopted, even for an initial comet mission, could be much more reliably accomplished through sample return. These include the determination of the abundance to $10 \%$ accuracy of the elements $\mathrm{H}, \mathrm{C}, 0, \mathrm{Na}, \mathrm{Mg}, \mathrm{Al}, \mathrm{Si}, \mathrm{S}, \mathrm{Ca}, \mathrm{Fe}$, and $\mathrm{Ni}$; establishment of the concentrations of ices such as water and carbon dioxide; determination of surface mineralogy; and establishment of the physical state of the surface material and its degree of local inhomogeneity. The Space Science Board further stressed a number of additional goals that almost surely require sample return, including determination of detailed molecular abundances and, most important, the measurement of a number of critical isotopic ratios of elements whose isotopic composition should reflect the preaccretionary compositional mix of the solar nebula and the chronology of its subsequent evolution.

\section{GENERAL OBJECTIVES OF COMET SAMPLE RETURN}

The considerations outlined above lead us to the basic objectives that should govern the planning and execution of the first comet sample return mission.

A sample should be acquired from the subsurface of an active comet in such a way as to preserve its chemical and, to the degree possible, its physical integrity. Further, the environment of the sample should be characterized with sufficient precision to permit the sample to be related to the comet as a whole and to other comets investigated by remote sensing techniques only.

The sample should be maintained in its pristine state during transit to Earth and recovery, and it should be carefully archived so as to preserve its integrity indefinitely.

These objectives will be amplified upon and interpreted below. 


\section{Selection of Comet Target}

The sample return comet should be judged using the same criteria established for the selection of a rendezvous target. It should be a currently active comet that clearly has retained much of its volatile inventory. It must have a well-defined nucleus, of course, but this may be a trivial requirement; it is presumed today that all comets have a solid nuclei. At present, three cometary nuclei have been detected by radar, and plausible claims have beem made for the measurement of the bare nuclei of at least two others, P/Halley and P/Schwassmann-Wachmann 1 . Within the next decade, it is probable that improvements in radar and possibly the use of the Space Telescope to study comets far from the sun should make this criterion easy to satisfy. For practical reasons the target comet must have a low-inclination orbit and reasonable short period. It is desirable, but not necesasry, that the comet be well placed for Earth-based viewing during the period of sample acquisition.

Ideally, the target conet should have been one already visited by a rendezvous spacecraft. In that case, we could be sure of its suitability, and the problem of global characterization and of selection of a sampling site would already have been largely accomplished. But it is unduly restrictive to require a precursor mission to the sample return target itself, so long as one or more previous rendezvous missions to similar comets have taken place.

The location within the cometary orbit in which the sampling takes place is not critical and could be selected on engineering and operational grounds. However, if the sample acquisition does not take place while the comet is active, it is essential that observations be continued (perhaps by a station left in orbit or on the surface of the nucleus) through the next perihelion passage in order to provide the required characterization of the environment from which the sample was obtained.

\section{Characterization of the Comet}

The objectives for the characterization of the target are similar to those associated with a comet rendezvous mission. These include the determination of the size, shape, and bulk density of the nucleus; mapping of the surface optical properties and temperature distribution over the nucleus; high resolution stereo imaging to produce a topographic map of the nucleus and locate the regions of the activity; measurement of the major elemental and mineralogical composition of the surface; and direct analysis of the coma gas and dust. If the sample is to yield its full value, our knowledge of the comet as a whole must not be inferior to that demanded from a rendezvous mission. 


\section{Site Selection and Documentation}

It is very unlikely that a target comet will be even approximately homogeneous over its surface. Particularly for the more evolved, short-period comets, there is ample evidence that the most active regions are localized on the surface. Further, the recent measurements of low albedo for several cometary nuclei suggest the presence of a lag deposit over much (perhaps all) of the surface that may provide some resistance to outgassing of volatiles from the undisturbed subsurface regions. Seen at close range, such a comet may bear little resemblance to the classic "snow-ball". In an extreme case the actual sources of most of the material ejected to form the coma and tail might be so localized as to be analogous to volcanoes or geysers.

Under such circumstances the selection of a sample site takes on great significance. The primary objective in site selection should be to ensure that the sample is representative of the undisturbed subsurface material of the comet. With our present level of ignorance, it is not possible to specify what the visible characteristics of such an ideal site might be. But it seems safe to conclude that a careful and deliberate orbital study of the comet should be made before the site is selected.

Once the sampling site has been selected, a new set of measurements must be made to provide information on the site at close range. These must include close-up imaging of at least the quality achieved by the Viking landers. Characterization of surface temperature and insolation are also required. Determination of the gas production rate and possibly the gas composition would be of great scientific interest from the surface station but are not strictly required for site documentation. It seems probable that these measurements could be made using an instrument package that might be left on the surface after the main sample-return spacecraft has departed, providing a long-term surface "weather station" on the coniet.

During the acquisition of the sample, additional data must be obtained, such as the depth from which it is taken, the temperature, and the mechanical properties of the material. Undoubtedly these would be classed as engineering data, in any case, required to document the performance of the sample collection device. In the case that a core sample is obtained, a properly preserved core will itself contain much of the essential stratigraphic data for its documentation. 


\section{Sample Acquisition}

In order to meet the requirement of a chemically pristine material, the sample must be acquired from a substantial depth. If possible, this depth should be such that the material acquired should never have been heated substantially above the mean temperature of the cometary interior. Thus we must penetrate below. not only the surface lag deposit but also to the depth of greater than one thermal skin depth; that is, the depth of penetration of the thermal wave associated with solar heating during one perihelion passage. For a loose, porous material, the thermal skin depth might be tens of centimeters; for a more compact material, it could be as much as a meter. The lag deposit itself can not be thicker than a thermal skin depth. Although we lack the data on surface thermophysical properties required for a precise calculation, we estimate that a relatively pristine sample can be acquired if we can bore to a depth of a meter.

If the sample is to be pristine, it is necessary to protect it as much as possible from alteration caused by the coring process itself. Primarily, this means that we must avoid contaminating the sample with the drill and avoid heating it so as to produce a fractionation of the volatile component.

These are difficult and demanding requirements, but they would appear to be essential if the mission is to accomplish its overall objectives.

Probably the ideal sampling technique would be to obtain a core sample several centimeters in diameter and approximately a meter long. We would hope that central parts of such a core would be little disturbed by the coring process, and the stratigraphy of the core would permit detailed studies of the evolutionary processes influencing the crust as well as the analysis of more pristine material from the deeper sections.

\section{Additional Samples}

The acquisition of a single sample, if it is representative of the pristine and primitive subsurface material of the comet, will satisfy the minimum objectives of the mission. However, it is desirable as a secondary objective to obtain additional samples from different depths. In a drilling process, a core might be acquired that would yield a profile of the upper meter or so of the cometary surface. Alternatively (or additionally) it may be possible to scoop up a sample from the upper few centimeters without the degree of mechanical deformation produced by drilling. Such a surface sample would provide important additional data on the formation of lag deposits as well as establishing "ground truth" for the remote sensing measurements of the comet. 
It is unlikely to be a requirement of the mission that samples be brought back from a variety of surface locations. In a large and highly evolved planet such as the Moon or Mars, geological processes create a diversity of geochemical regimes, and a range of sites must be investigated to decipher the complex history of the planet. On a comet, however, there is less reason to expect fundamentally different geological provinces, and accordingly less need for samples from multiple sites.

\section{Size of the Sample}

It is characteristic of modern geochemical analysis to be able to learn more and more from smaller and smaller samples. The recent example of the Antarctic lunar sample demonstrates that only a few grams of material are required to satisfy the needs of all the major laboratories in this country. However, it is equally true that, other things being equal, a larger sample is better than a smaller one. This is particularly true if the sample contains a heterogeneous collection of mineral grains, perhaps of very different origins. It is, for instance, extremely important to search for interstellar or pre-solar-system grains in any cometary sample, even though such materials may constitute a very small fraction of the total sample. The more material we can return for terrestrial analysis, the more likely we are to find rare but significant materials that may provide profound insights into the origin of the solar system.

The precise requirements for sample size should be subject to a detailed cost-benefit analysis, once a sample-acquisition and return technique has been specified. For the present it seems appropriate to suggest $1 \mathrm{~kg}$ as a nominal sample size. A one-meter-deep core with a cross section of a few centimeters would yield a sample of this size, and it seems likely that it would be sufficient to meet the minimum requirements of the mission.

\section{Protection of the Sample}

After acquisition, the sample must be hermetically sealed to ensure against any contamination or loss of volatiles. Its temperature should be held at about the same value as at the location where it was acquired. Efforts should also be made to protect it against undue radiation exposure from either natural sources such as cosmic rays or from an RTG power source, if the spacecraft has one.

While it is important to maintain the physical and mechanical integrity of the sample as much as possible, no speical requirements need be placed on $\mathrm{g}$ forces. Even accelerations of $10 \mathrm{~g}$ or so are not likely to cause damage, and they are in any case negligible in comparison with the forces associated with the coring process itself. 


\section{Surface Monitoring Station}

Our understanding of the nature of cometary activity would be greatiy increased by the operation of a surface monitoring station, somewhat analogous to the Viking landers on the surface of Mars. A surface monitoring station is not required in direct support of comet sample return. However, it appears at this stage of analysis that the capabilities of such a surface station are not very different from those already required for site and sample documentation, and that therefore it should be relatively easy to incorporate a long-lived surface station as a part of the sample return mission.

The surface station should include instruments to measure surface (and possibly subsurface) temperature, insolation, gas production rate, and gas composition, as well as some surface imaging. (In the likely case that only very limited data rates can be supported, the imaging could be designed to transmit only information on alteration of the scene, or it could even be omitted altogether). The station should be designed to operate through one apparition, or at least until the comet has moved far enough frorn the sun for its activity to subside (roughly, to beyond the orbit of Mars).

A possible alternative to a surface station might be an orbital station. This too could provide extremely useful data, but as it. would not differ much from the investigations carried out on precursor rendezvous missions, such an orbital station would have considerably lower priority than surface studies. 


\section{EXECUTIVE SUMMARY}


Page intentionally left blank

Page intentionally left blank 
OBIECTIVES AND SCOPE 
Page intentionally left blank

Page intentionally left blank 
- mission rationale

- SSEC CuRRENTLy assessing potential "Augmentations" to its RECOMMENDED CORE PLANETARY PROGRAM FOR THE PERIOD 1985 - 2000

- A COMET NUCLEUS SAMPLE RETURN MISSION IS CONSIDERED A REPRESENTATIVE AUGMENTATION TO THE CORE PROGRAM PRIMITIVE BODY EXPLORATION

- STUdY OBJECTIVES AND SCOPE

O TO CONDUCT AN ASSESSMENT STUDY OF RELEVANT SCIENCE OBJECTIVES, CANDIDATE MISSION CONCEPTS, KEY DESIGN/TECHNOLOGY REQUIREMENTS, AND PROGRAMMATIC ISSUES

O CONSIDER IN SCOPE:

- A REPRESENTATIVE SET OF SHORT-PERIOD COMETS, E,G, THREE

- PERIHELION VS. APHELION ENCOUNTER AND SAMPLING

- BALLISTIC AND LOW-THRUST FLIGHT MODES 
Page intentionally left blank

Page intentionally left blank 


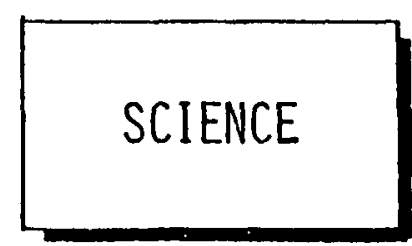




\section{SCIENCE GUIDELINES}

The primary objective of this mission is to collect a sample of undisturbed comet material from beneath the surface of an active comet in such a way as to preserve its chemical and, if possible, its physical integrity; and return it to the Earth in a minimally altered state. Secondary objectives are to: (1) characterize the comet to a level consistent with a rendezvous mission, (2) monitor comet dynamics through perihelion and aphelion with a long-lived lander and (3) determine the subsurface properties of the nucleus in an area local to the sampled core.

The science guidelines reflect an amplification of the above objectives by Dr. David Morrison. In essence they have provided the basis for the mission concept and design decisions that are presented in this report.

Guidelines suggested for comet characterization are similar to those associated with a rendezvous mission and basically guide the selection of remote instrumentation. In addition to satisfying the objectives for full global characterization of the comet, a nearly complete complement of rendezvous instruments would be needed for selection and characterization of the sampling site.

With respect to site selection it is clear that ample information and time be provided the scientists on Earth to enable them to carefully study the comet characteristics and choose a site location where they are confident that the collected sample would be representative of the pristine, undisturbed comet material. Once the site is selected, close-up imaging and surface characterization would be needed to document the site.

The essential guideline for sample acquisition is that the sample contain material that has never been heated substantially above the mean temperature of the cometary interior. It is postulated that this could be achieved by sampling below one thermal skin depth, which is estimated to be a meter or slightly less below the surface. Protection of the sample from all forms of contamination, both during the sampling process and during the return transit to Earth is of utmost importance. 
- COMET CHARACTERIZATION:

- Site SELECTION AND DOCUMENTATION:

- SAMPLE ACQUiSition:
- DETERMINE SIZE, SHAPE AND BULK DENSITY OF NUCLEUS

- MAP SURFACE OPTICAL PROPERTIES AND TEMPERATURE DISTRIBUTION

- PRODUCE HIGH RESOLUTION TOPOGRAPHIC MAP OF NUCLEUS AND LOCATE REGIONS OF ACTIVITY

- MEASURE MAJOR ELEMENTAL AND MINERALOGICAL COMPOSITION OF SURFACE

- ANALYZE COMA GAS AND DUST

- SELECT SITE(S) MOST LIKELY TO PROVIDE SAMPLES(S). REPRESENTATIVE OF THE PRISTINE UNDISTURBED COMET MATERIAL

- DOCUMENT SITE THROUGH HIGH RESOLUTION IMAGING, SURFACE TEMPERATURE, GAS PRODUCTION RATE AND INSOLATION

- ACQUIRE SAMPLE BELOW THERMAL SKIN DEPTH TO ENSURE MATERIAL HAS NOT BEEN HEATED SUBSTANTIALLY ABOVE MEAN TEMPERATURE OF INTERIOR

- PROTECT SAMPLE AGAINST THERMAL AND CHEMICAL CONTAMINATION 


\section{SAMPLING DEPTH}

The question relating to the depth at which the nucleus sample must be collected in order to obtain material that is essentially unaltered by heating is one that is not easily answered. There is no guarantee that material even at the very center of a comet nucleus has not been heated to some extent during its orbits about the Sun (Klinger, 1981). The mean temperature of a comet's interior, which can be related to the depth at which heating has occurred, depends upon several factors including: the thermal conductivity of the nucleus material, its mean orbital temperature and its age or number of perihelion passages it has experienced. The issue of sampling depth has therefore been made more pragmatic by relaxing the heating requirement to ensure only that the collected sample has not been heated substantially above the mean interior temperature of the comet.

Attenuation of the diurnal temperature wave through the interior of the rotating nucleus can be measured in terms of its thermal skin depth (the point at which the termperature variation is attenuated by a factor 1/e). Weissman and Kieffer (1981) derived a thermal skin depth of $0.72 \mathrm{~cm}$ for Comet $\mathrm{P} / \mathrm{Halley}$ based on a rotation period of 10.3 hours and nuclear material modeled as a porous mixture of uncompacted snow and dust. Using the same parameters, thermal skin depths corresponding to 1/e attenuation of temperature variations over more extended periods of time can be computed as well. Consider the time interval about perihelion during which there may be significant heat flow to the comet's interior. If such heating occurs out to, for example, $3 \mathrm{AU}$, this interval can be on the order of $\mathrm{T}_{\mathrm{P}} \pm$ 300 days. The thermal skin depth for the above conditions is approximately 27 cin. If however, the material were more compact and thermally conductive the skin depth could be as much as 1 meter or more.

Assuming that a sample collected below 1 thermal skin depth can provide material that is relatively unaltered by the short-term solar heating, it can be roughly estimated that the sample depth should be at least one meter. A meter is probably more than adequate for loose porous material, but may be less than needed for crystallized ice.

Klinger, J. (1981), "Some Consequences of a Phase Transition of Water Ice on the Heat Balance of Comet Nuclei", Icarus, $47,320$.

Weissman, Paul R., and Kieffer, Hugh H., "Thermal Modeling of Cometary Nuclei", Icarus, 47, 302. 
ISSUE: TO WHAT DEPTH BELOW NUCLEUS SURFACE MUST SAMPLE BE COLLECTED TO ENSURE THAT MATERIAL HAS NOT BEEN. HEATED SUBSTANTIALLY ABOVE THE MEAN TEMPERATURE OF THE COMETARY INTERIOR?

RATIONALE: MEAN TEMPERATURE OF COMET INTERIOR DEPENDS UPON ITS THERMAL CONDUCTIVITY, MEAN ORBITAL TEMPERATURE AND AGE. (KLINGER, 1981)

SIGNIFICANT HEAT FLOW TO THE COMET'S INTERIOR OCCURS ONLY WITHIN A RELATIVELY SHORT TIME PERIOD NEAR PERIHELION

SAMPLING BELOW 1 THERMAL SKIN DEPTH WILL PROVIDE MATERIAL THAT IS RELATIVELY UNALTERED BY SHORT-TERM SOLAR HEATING

LAG DEPOSITS ARE LESS THAN 1 THERMAL SKIN DEPTH

ANALYSIS: THERMAL SKIN DEPTH OF POROUS MIXTURE OF UNCOMPACTED SNOW \& DUST WRT NUCLEUS ROTATION PERIOD*, $\delta \simeq 0.7 \mathrm{CM}$ (WEISSMAN \& KIEFFER, 1981)

OVER TIME INTERVAL $T_{P} \pm 300^{d}, \delta \simeq 27 \mathrm{CM}$

$\delta$ SCALES AS [THERMAL DIFFUSIVITY] ${ }^{\frac{1}{2}}$ AND FOR MORE COMPACT ICY MATERIALS COULD BE AS MUCH AS 1 METER (OR MORE)

CONCLUSION: DESIGN FOR SAMPLE DEPTH OF AT LEAST 1 METER

* 10.3 HOURS - HALLEY 


\section{SCIENCE GUIDELINES (CONCLUDED)}

The guideline pertaining to the number and size of the samples returned suggests that a single sample taken from the appropriate depth would be adequate for scientific purposes, but that additional samples, particularly if taken from different sites, could deliver the dual benefit of reducing mission risk while providing data by which comparisons could be made. In view of these advantages, the sampling strategy proposed for this mission is based on the collection of two samples from two different sites, if possible.

With regard to sample size, the study has assumed 1 meter length cores with $8 \mathrm{~cm}$ diameters. Depending on the density of the material, such samples may range from 0.5 to $5 \mathrm{~kg}$ which is probably more than adequate from a mass standpoint.

Once the samples are collected they must be carefully protected against contamination and the loss of their volatiles. For this purpose, the science guidelines recommend hermetic sealing, thermal control and radiation shielding. All such measures have been incorporated in the baseline mission concept.

The final science guideline suggests instrumentation and lifetime requirements appropriate to a comet surface monitoring station. This station, referred to as a long-lived lander throughout this report, is considered to be an optional element in the mission analyses and costing. 
- number and size of samples:

- SAMPLE PROTECTION:

- surface monitoring station:
- PRIMARY OBJECTIVE IS 1 SAMPLE FROM DEPTH OF AT LEAST 1 METER

- ADDITIONAL SAMPLES FROM OTHER SITES/ DIFFERENT DEPTHS PROVIDE COMPARATIVE DATA AND REDUCE MISSION RISK THROUGH REDUNDANCY

- MAINTAIN ACQUISITION TEMPERATURE; PREFERABLY $\leq$ THAT AT COMET APHELION

- PROTECT AGAINST LOSS OF VOLATILES THROUGH HERMETIC SEALING

- AVOID UNDUE RADIATION EXPOSURE

- SECONDARY TO SAMPLE RETURN OBJECTIVES

- INCLUDE INSTRUMENTS TO MEASURE TEMPERATURE, INSOLATION, GAS PRODUCTION, AND GAS COMPOSITION, AS WELL AS LIMITED IMAGING

- DESIGN TO LAST THROUGH AT LEAST ONE APPARITION AND PREFERABLY THROUGH 2 SUCCESSIVE APSELINE PASSAGES 


\section{SCIENCE INSTRUMENTS \& SUPPORT REQUIREMENTS}

Characterization of the comet nucleus, selection of the landing site, and site documentation all require that the spacecraft be equipped with science instruments for remote sensing observations of solid bodies. The primary instrument for topographic mapping of the surface, determining optical properties, and locating active regions is a narrow angle solid state imager employing Galileo technology. Surface mineralogy is mapped by studying reflected solar radiation in the near spectral region where minerals and ices have characteristic absorptions. Gamma-ray and $x$-ray spectroscopy are included for measuring the elemental composition of the surface. The surface temperature is mapped by the infrared radiometer. The radar altimeter determines the shape and surface texture of the nucleus by using longer wavelengths while the electromagnetic sounder offers sensitivity to subsurface structure. The neutral and ion mass spectrometers determine the gas production rate and its molecular composition.

The dust production rate is provided by the dust counter. If sufficient resources are available on the spacecraft, then a full complement of comet rendezvous instruments should be included for studies of the gas and dust in the coma and tails and the comet solar wind interaction.

During the return of the sample to Earth the sample environment must be monitored. Sonie key environmental parameters that should be monitored are the sample temperature, the pressure in the sample container and the energetic particle radiation dose accumulated in the sample.

The station left at the nucleus should have a solid state imager for site documentation, a mass spectrometer for long-term monitoring of gas production and composition, a temperature transducer and photometer for studying the comet's response to changes in insolation, a seismoneter for detecting violent events and a tracking aid for accurate comet orbit determination. Surface mechanical properties would be determined by the system that obtains the samples.

Support requirements for the above instruments are given in terms of the total mass, power and data rate for the entire complement in each payload. The individual instrument requirements are broken out in more detailed supporting viewgraphs found in the Appendix. 


\begin{tabular}{|c|c|c|c|c|}
\hline & $\begin{array}{l}\text { S/C BUS } \\
\text { PER ENCOUNTER }\end{array}$ & $\begin{array}{c}\text { S/C BUS } \\
\text { APH ENCOUNTER }\end{array}$ & $\begin{array}{l}\text { LANDER- } \\
\text { STATION }\end{array}$ & $\begin{array}{l}\text { SAMPLE } \\
\text { MONITOR }\end{array}$ \\
\hline SOLID STATE IMAGING & $x$ & $x$ & $x$ & \\
\hline THERMAL IR RADIOMETER & $x$ & $x$ & & \\
\hline IR REFLECTANCE MAPPER & $x$ & $x$ & & \\
\hline GAMMA-RAY SPECTROMETER (1) & $x$ & $x$ & & \\
\hline$X$-RAY SPECTROMETER & $x$ & & & \\
\hline NEUTRAL MASS SPECTROMETER & $x$ & $\mathrm{x}$ & $x$ & \\
\hline ION MASS SPECTROMETER & $x$ & $x$ & & \\
\hline DUST COUNTER & $x$ & & & \\
\hline RADAR ALTIMETER (2) & $x$ & $x$ & & \\
\hline TEMPERATURE TRANSDUCER & & $=$ & $x$ & $x$ \\
\hline PHOTOMETER & & & $x$ & \\
\hline SEISMOMETER & & & $x$ & \\
\hline TRACKING & & & $x$ & \\
\hline PRESSURE TRANSDUCER & & & & $\mathrm{x}$ \\
\hline ENERGETIC PARTICLE DETECTOR & $\ldots$ & $\ldots$ & 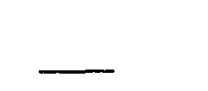 & $x$ \\
\hline MASS (KG) & 116 & 97 & 10 & 4 \\
\hline POWER (W) & 100 & 85 & 22 & 4 \\
\hline DATA RATE (BPS) & $30 \mathrm{~K}$ & $28 \mathrm{~K}$ & 910 & 1 \\
\hline
\end{tabular}




\section{Page intentionally left blank}

Page intentionally left blank 


COMET
SELECTION




\section{PROGRAMMATIC CONSIDERATIONS}

The set of comets selected as candidate targets for the Comet Nucleus Sample Return mission must necessarily be limited to those whose apparitions occur in a time period consistent with the anticipated launch date for that mission. The considerations outlined on the facing page indicate that programmatic constraints exist that would prevent such a launch from taking place before the year 2000 , and therefore the candidate comets should be selected from those whose apparitions occur after 0ctober 2003.

The major constraint to an earlier launch is the presumed need for nucleus characterization data prior to a program start for sample return. Since such information can only be supplied by a precursor rendezvous mission, the data return from that mission essentially determines the timing of the events which follow.

In cases where performance considerations dictate the need for a launch earlier than March. 2000 , it may be possible to either accelerate the Comet Sample Return flight development program, or start the program earlier and parallel the development of systems dependent upon information that would be obtained from the comet rendezvous. 
- A MAJOR CONCLUSION OF THIS STUDY IS THAT A RELIABLE SAMPLING CONCEPT CAN NOT BE SPECIFIED UNTIL A PRECURSOR COMET RENDEZVOUS MISSION PROPERLY CHARACTERIZES THE PHYSICAL PROPERTIES OF COMETARY NUCLEI,

- THE SSEC hAS RECOMMENDED A COMET RENDEZVOUS FLIGHT PROJECT BE STARTED AS PART OF ITS CORE PROGRAM BY 1987 WITH A LAUNCH IN 1990 OR 1991 AND COMET RENDEZVOUS OCCURRING IN 1995 OR 1996.

- ASSUMING THIS OBJECTIVE IS IMPLEMENTED AND ALLOWING ADEQUATE TIME FOR THE RENDEZVOUS MISSION RESULTS TO IMPACT THE PRE-PROJECT SAMPLER DESIGN, THE EARLIEST START FOR THE SAMPLE RETURN MISSION WOULD BE FY 1997.

- With A 42-MONTH FLIGHT DEVELOPMENT PROGRAM, THE EARLIEST LAUNCH DATE FOR the SAMPLE RETURN MISSION WOULD BE MARCH 2000; HOWEVER, PERFORMANCE CONSIDERATIONS COULD DICTATE AN ACCELERATED PROGRAM THAT WOULD PERMIT EARLIER LAUNCHES,

- allowing for one-way trip times of up to 3,5 years, the selection of an ACCEPTABLE COMET FOR THE SAMPLE RETURN IS CONSTRAINED TO APPARITIONS OCCURRING AFTER OCTOBER 2003, I,E. THE BEGINNING OF FY 2004. 


\section{PERIHELION VS. APHELION ENCOUNTER}

The facing page addresses the pros and cons of perihelion versus aphelion encounters regarding the suitability or special advantages offered by each to the requirements of a comet nucleus sample return mission. It is seen that the advantages of one are generally the disadvantages of the other and vice-versa.

For example, perihelion encounters almost always assure that the comet would be recovered prior to spacecraft acquisition, whereas this would be unlikely at aphelion distances. 0ther perihelion advantages include better ability to select sampling sites because of comet activity, the opportunity to view the encounter and calibrate the science measurements at Earth, shorter communication times which permit interactive control during the encounter and perhaps the most important of these advantages, the ability to use SEP propulsion if available.

The advantages offered by aphelion encounters include reduced risk resulting from the comet's relatively benign environment. This allows closer spacecraft approaches to the comet and more relaxed encounter profiles. Other advantages are less complex thermal control problems due to the greatly reduced solar constant and the opportunity to view an inactive comet nucleus for the first time.

Comparing the two encounter conditions it appears that the advantages offered by perihelion encounter far outweigh those for aphelion. Even if the advantage consisted of nothing more than the ability to use SEP, perihelion encounter would be preferred, since this may be the most important of the considerations discussed above. It will be shown later that ballistic performance is severely tested by the sample return mission and the development of NEP by the time period considered is uncertain at best. This leaves SEP as possibly the only viable transportation mode for this mission. 


\section{PERIHELION}

PRO :

- COMET RECOVERY/ACQUISITION ASSURED

- ACTIVITY PROVIDES BETTER BASIS FOR SITE SELECTION

- OPPORTUNITY FOR EARTH VIEWING/ CALIBRATION

- COMMUNICATION TIME PERMITS LIMITED INTERACTION

- SEPS OPTION IS AVAILABLE

CON :

- POTENTIALLY MORE HAZARDOUS ENVIRONMENT

O SPACECRAFT APPROACH LIMITED BY ACTIVITY

O ENCOUNTER PROFILE IS TIME/ DISTANCE CONSTRAINED

- THERMAL PROTECTION OF SAMPLE IS COMPLICATED BY COMET ENVIRONMENT

\section{APHELION}

PRO:

- BENIGN ENVIRONMENT REDUCES MISSION RISK

O CLOSE APPROACH TO COMET POSSIBLE

O SIMPLER ENCOUNTER PROFILE

- LESS COMPLEX THERMAL CONTROL PROBLEMS

- FIRST VIEWING OF INACTIVE COMET NUCLEUS

CON:

- UNCERTAIN ABILITY TO RECOVER/ACQUIRE COMET

- LIMITED INFORMATION FOR SITE SELECTION

- COMMUNICATION TIME RESTRICTS EARTH INTERACT I ON

- LOW ILLUMINATION LEVELS

- SEPS OPTIONS ARE FORECLOSED

- INACTIVITY LIMITS REMOTE SCIENCE INTEREST 


\section{SELECTED COMETS}

Three comets were selected as potential candidates for the sample return mission: Encke, Tempel 2 and Wild 2. In addition to having apparitions satisfying the programmatic launch date constraints, they satisfy the criteria normally established for rendezvous targets, i.e:

- they are currently active with a clearly retained volatile inventory as evidenced by their gas production rates,

- they have well-identified nuclei,

- they have low-inclination orbits,

- they have short orbit periods, and

- except for Tempel 2, have good Earth-based viewing during the encounter (although while not necessary would certainly be an advantage).

Ideally, the sample return target should be the same comet as selected for the rendezvous mission. However, this is considered to be unduly restrictive if program planning flexibility is to be maintained.

The lone aphelion encounter investigated is the Wild 2 opportunity in July 2000. This obviously violates the programmatic restrictions stated previously; however, it was the only aphelion mission that could be captured ballistically and was therefore accepted for that reason. It should be considered as only a representative example of such a mission and not as a viable candidate. 
COMET

APSE PASSAGE

PEAK OH PROD RATE

PERIHELION

INCLINATION

PERIOD

(MOLECULES/SEC)

(AU)

(DEG)

(YEARS)

$\begin{array}{cccccc}\text { ENCKE } & 10 / 03 \text { PERIHELION } & 1.5 \times 10^{29} & 0.33 & 11.9 & 3.28 \\ & & & & & - \\ \text { TEMPEL-2 } & 3 / 05 \text { PERIHELION } & 1.3 \times 10^{28} & 1.48 & 12.0 & 5.47 \\ \text { WILD-2 } & 10 / 03 \text { PERIHELION } & 2.5 \times 10^{28} & 1.58 & 3.3 & 6.39 \\ \text { WILD-2 } & 7 / 00 \text { APHELION } & 2.5 \times 10^{28} & 1.58 & 3.3 & 6.39\end{array}$


Page intentionally left blank

Page intentionally left blank 


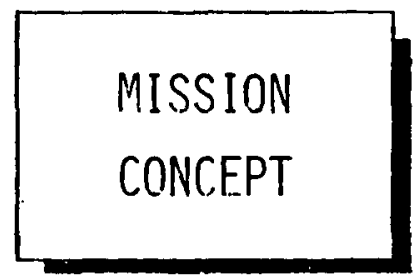




\section{COMET SAMPLE RETURN MISSION OVERVIEW}

The concept proposed for the comet nucleus sample return mission consists of several elements:

The spacecraft bus would be responsible for providing round-trip interplanetary transfer for all system elements with the exception of the long-lived lander which would be left on the comet's surface. This spacecraft would also carry a science payload to carry out the nucleus characterization and site documentation objectives, and would provide relay control and communication during the sampling process.

Two sampling devices are required to collect two l-meter cores of the nucleus. These are to be separately deployed from the spacecraft and recovered through an automated rendezvous and docking procedure. It is recommended that two samples be collected rather than one in order to enhance the reliability of the sampling process; e.g., the first sampler could be used to calibrate the deployment of the second sampler. Also if the first sample is successfully collected, the second sampler provides the opportunity to investigate another site.

Optionally, the second sampler would carry with it a long-lived lander that would be anchored to the comet's surface upon impact. The lander should be capable of monitoring nucleus surface activity over one orbital period of the comet or at least through two successive apseline passages.

After recovery by the spacecraft, the core samples would be hermetically sealed in an environmentally controlled capsule to prevent thermal, chemical or radiation contamination during the return trip to Earth. At Earth approach, solid retro motors would be used to inject the capsule into a circular shuttle-compatible orbit to increase the probability of quick recovery. 
- PROVIDE a SPACECRAFt bUS FOR ROUND-TRIP INTERPLANETARY TRANSIT, NUCLEUS CHARACTERIZATION SCIENCE, AND RELAY CONTROL OF SAMPLING PROCESS

- provide remiote sampling devices capable of collecting two (2) one-meter CORES OF THE NUCLEUS AND RETURNING THEM TO THE ORBITING SPACECRAFT BUS

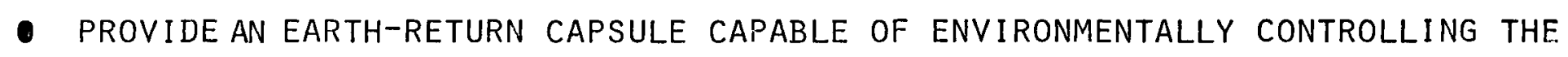
COLLECTED CORES, AND EQUIPPED TO RETRO FROM EARTH APPROACH INTO A CIRCULAR, SHUTTLE-COMPATIBLE RECOVERY ORBIT

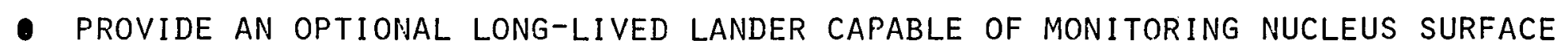
ACTIVITY THROUGH TWO SUCCESSIVE APSELINE PASSAGES

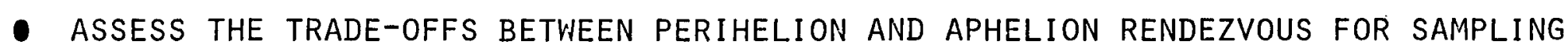
THE NUCLEUS 


\section{MISSION OPTIONS}

The table lists 12 mission options that were examined in detail in this study. These were culled from a total set of 48 possible options covering 4 different comet encounters, 3 propulsion modes and 4 sampling concepts. The basis for selecting these 12 is as follows:

- All feasible ballistic missions were included (3)

- Since all NEP missions had substantial performance margins only those missions entailing the most demanding sampling concept were included (3)

- Two SEP missions employing penetrator samples were included for each perihelion comet encounter; one mission considered only the use of samplers and the second considered the optional lander (6)

Due to time limitations we were unable to examine NEP aphelion encounter missions.

The blank columns seen in this table will be filled out as the supporting information is subsequently presented. 


\section{MISSION OPTIONS}

\begin{tabular}{|c|c|c|c|c|c|c|c|c|c|c|c|c|}
\hline \multirow{2}{*}{ OPTION } & \multirow{2}{*}{ COMET/YR } & \multicolumn{2}{|c|}{ TOTAL $T_{M}$} & \multirow{2}{*}{$\begin{array}{l}\text { FLIGHT } \\
\text { MODE }\end{array}$} & \multicolumn{3}{|c|}{ SAMPLER CONCEPT } & \multirow{2}{*}{ 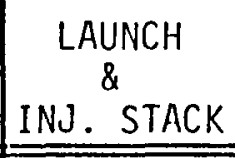 } & \multicolumn{2}{|c|}{ INJECTED MASS (KG) } & \multicolumn{2}{|c|}{ COSTS (' $84 \$ M)$} \\
\hline & & $R_{p}$ & $R_{A}$ & & PEN. & DRL. & LDR. & & REQ'D & MARGIN & PROJECT & TOTAL \\
\hline 1 & ENCKE/03 & $6.1^{Y}$ & & SEP & $x$ & & & & & & & \\
\hline 2 & ENCKE/03 & $6.1 Y$ & & SEP & $x$ & & $x$ & & & & & \\
\hline 3 & ENCKE $/ 03$ & $6.9^{Y}$ & & NEP & & $x$ & $x$ & & & & & \\
\hline 4 & TEMPEL-2/05 & $11.1^{Y}$ & & $\begin{array}{l}\text { BAL. } \\
\triangle V E G A\end{array}$ & $x$ & & & & & & & \\
\hline 5. & TEMPEL -2/05 & $4.9^{Y}$ & & SEP & $x$ & & & . & & & & \\
\hline 6 & TEMPEL - 2/05 & $4.9^{Y}$ & & SEP & $x$ & & $x$ & & & & & \\
\hline 7 & TEMPEL - 2/05 & $6.8^{Y}$ & & NEP & & $x$ & $x$ & & & & & \\
\hline 8 & WILD -2/03 & $6.0^{Y}$ & & SEP & $x$ & & & & & & & \\
\hline 9 & WILD-2/03 & $6.0 \mathrm{Y}$ & & SEP & $x$ & & $x$ & & & & & \\
\hline 10 & WILD-2/03 & $7.0^{\gamma}$ & & NEP & & $x$ & $x$ & & & & & \\
\hline 11 & WILD-2/03 & $8.9 Y$ & & $\begin{array}{l}\text { BAL. } \\
\text { DIR. }\end{array}$ & $x$ & & & & & & & \\
\hline 12 & WILD-2/03 & & $6.1^{Y}$ & $\begin{array}{l}\text { BAL. } \\
\text { DIR. }\end{array}$ & $x$ & & & & & & & \\
\hline
\end{tabular}


Page intentionally left blank

Page intentionally left blank 


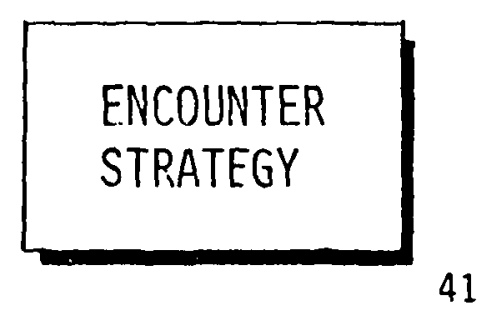




\section{HAZARDS}

The hazards presented to the spacecraft during its near encounter operations have been identified as the dust and gas emitted by the active nucleus and the thermal background within the coma. Their potential effects on the spacecraft are stated on the facing page. Of these three hazards, dust appears to be the most constraining to this mission. Given the particular set of objectives to be accomplished during the encounter which require operations at different altitudes for specified periods of time, the integrated effect of the dust layering hazard dictates a maximum allowable level of comet activity, i.e. gas production, during the near encounter phase. For example, to limit probable dust impacts to less than $20 \%$ of the spacecraft surfaces, the maximum coverage accepted for this analysis, requires that the gas production rate average less than $6 \times 10^{26}$ molecules/sec (or an $0 H$ rate less than $5 \times 10^{26}$ ) over the duration of the near encounter operations for Tempel 2 and Wild 2 . During an Encke encounter, taking place post-perihelion, the average gas production rate could be substantially higher - as much as $4 \times 10^{27}$ molecules/sec ( $0 \mathrm{H}$ rate $\approx 3 \times 10^{27}$ ). The reason for this is that the proposed encounter strategy has a time profile that complenents comet activity after perihelion; i.e., remote operations are performed early while comet activity is high, and close-in sampling and site characterization are performed late, after activity has drastically subsided. By reference to comet gas production data such as that compiled by M. Festou (see Appendix) acceptable encouriter starting times (for post-perihelion encounter) or ending times (for pre-perihelion encounters) can be determined.

The timing constraint imposed by the dust hazard on the starting/ending time of the encounter impacts all related mission design requirements as well. The required arrival/departure time at the comet is directly affected by the encounter strategy time constraint. This in turn influences the selection of the interplanetary transfer mode, which in turn impacts the performance requirements and this drives mission cost. 
- IMPACT ON MISSION DESIGN

- THE HAZARDS PRESENTED BY THE COMA ENVIRONMENT IMPOSE A TIMING CONSTRAINT ON THE ENCOUNTER STRATEGY THAT IMPACTS ALMOST ALL MISSION DESIGN REQUIREMENTS AS A RESULT OF THEIR INTERACTIVE NATURE, IE, HAZARD $\rightarrow$ ENCOUNTER STRATEGY $\rightarrow$ ARRIVAL TIME $\rightarrow$ IP TRANSFER $\rightarrow$ PERFORMANCE $\rightarrow$ COST

- DUST

- A COMET PRODUCING GAS AT A RATE OF $6 \times 10^{27} \mathrm{MOL} / \mathrm{SEC}$ WITH A DUST/GAS RATIO OF 0.5 , CAN COVER A SPACECRAFT ORBITING AT 10 RN WITH ONE LAYER OF IMPACTS IN ONE DAY (DIVINE MODEL OF COMA ENVIRONMENT), CONSTRAINING DUST IMPACT COVERAGE TO LESS THAN 20\% OF THE S/C SURFACES REQUIRES THAT GAS PRODUCTION AVERAGE LESS THAN APPROXIMATELY $6 \times 10^{26} \mathrm{MOL} / \mathrm{SEC}$ DURING THE NEAR ENCOUNTER PHASE FOR PRE-PERIHELION MISSIONS (TEMPEL 2, WILD 2) AND LESS THAN $4 \times 10^{27} \mathrm{MOL} / \mathrm{SEC}$ DURING THE ENCKE POST-PERIHELION ENCOUNTER

- GAS

- GAS PRESSURES gREATER THAN 10-3 TORR CAN CAUSE "PUMPING" OF MULTI-LAYER INSULATION IN SPACECRAFT, HOWEVER AT A DISTANCE OF $10 \mathrm{R}_{N}$, GAS PRESSURE WAS COMPUTED TO REACH ONLY $10^{-5}$ TORR EVEN WHEN GAS PRODUCTION REACHED $10^{28} \mathrm{MOL} / \mathrm{SEC}$

- tHERMAL

- A COMA THERMAL BACKGROUND OF 185 - 200\% WILL CAUSE OVER-HEATING UNLESS SUFFICIENT THERMAL INERTIA IS BUILT INTO SPACECRAFT 


\section{PHASE I: GLOBAL CHARACTERIZATION}

The near encounter strategy proposed for the comet nucleus sample return mission is comprised of three major phases:

1) Global Characterization

2) Regional Site Mapping

3) Sample Collection and Site Characterization

In describing all three phases, the assumption will be made that the diameter of the comet nucleus is $2 \mathrm{~km}$. Rotation periods assumed for the three comets of interest are: Encke, 6 hours; Tempel 2, 4.8 hours; and Wild 2, 10 hours. The narrow-angle imaging system is presumed to have a $10 \mu$ rad angular resolution and 0.6 deg FOV. The maximum data transmission rate is assumed to be 30 kbps.

During the 6 day global characterization phase of the encounter, the spacecraft would be stationed at $200 \mathrm{~km}$ above the nucleus surface where its imaging system would obtain full-nucleus images at a spatial resolution of $2 \mathrm{~m} / \mathrm{pixel}$. At each of three different phase angles it would be planned to take full nucleus images at 8 sub-satellite longitudes with 9 different filters, for a total of 216 frames. This should provide sufficient information to enable the selection of regions on the surface as candidate sampling sites. Two days are allowed for region selection and one more day is allowed to perform the spacecraft transfer to a $50 \mathrm{~km}$ altitude where the regional site mapping is to take place. 


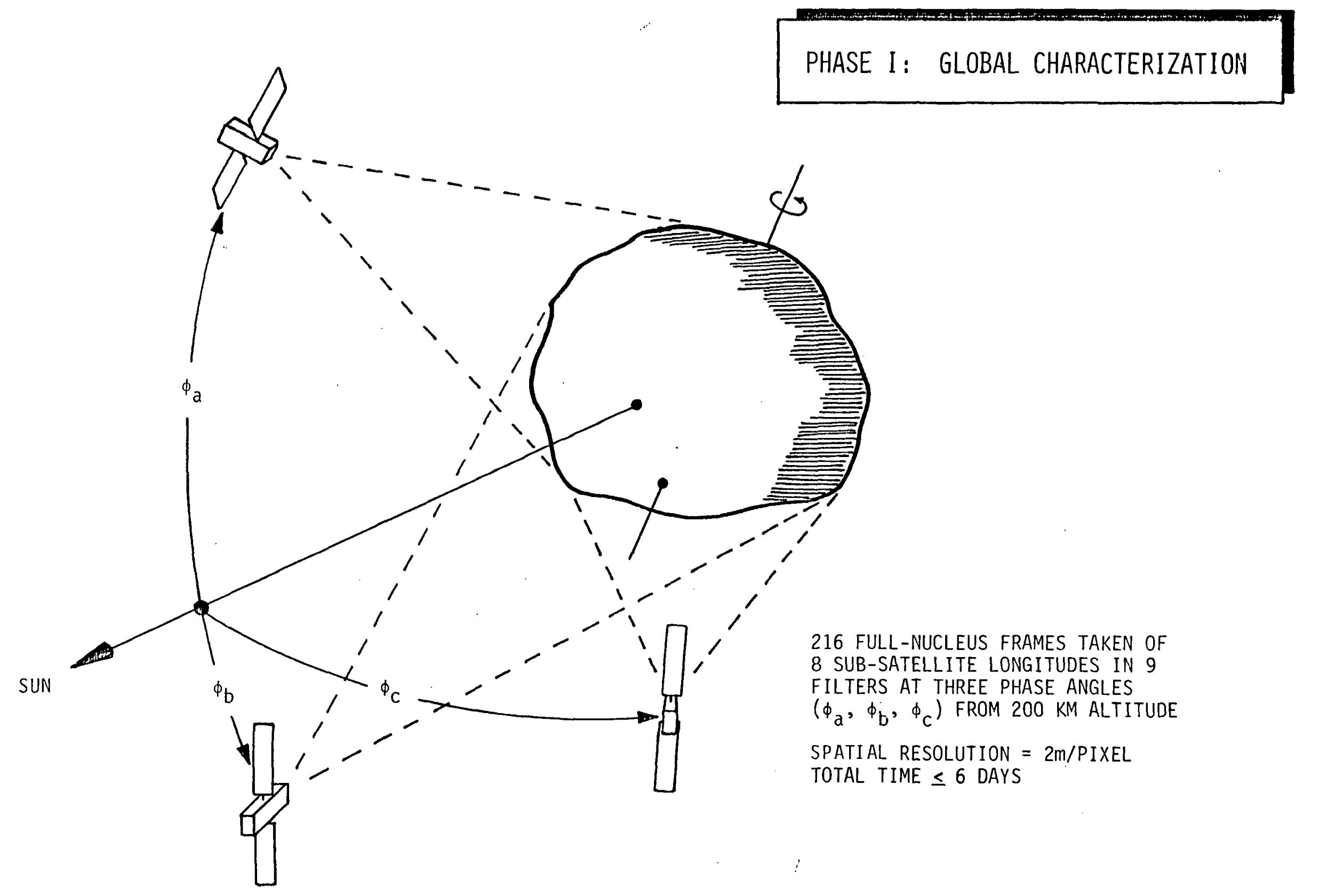




\section{PHASE II: MOSAIC SITING MAP}

The second major phase of the encounter strategy is devoted to mapping regions of the comet selected as candidate sampling sites. During the 7 days allowed for this phase, the spacecraft would be stationed at a $50 \mathrm{~km}$ altitude at a selected phase angle and would provide a global mosaic consisting of 96 stereo images (192 frames) in four filter color. The spatial resolution at this altitude is $50 \mathrm{crl} / \mathrm{pixel}$ (100 cm per line pair).

This phase represents the most critical period with regard to protection of optical surfaces from the dust hazard. Once the phase is over, the spacecraft would be transferred to a safer $100 \mathrm{~km}$ altitude to await the site selection decision. 


\section{PHASE II: MUSAIC SITIIIG MAP}

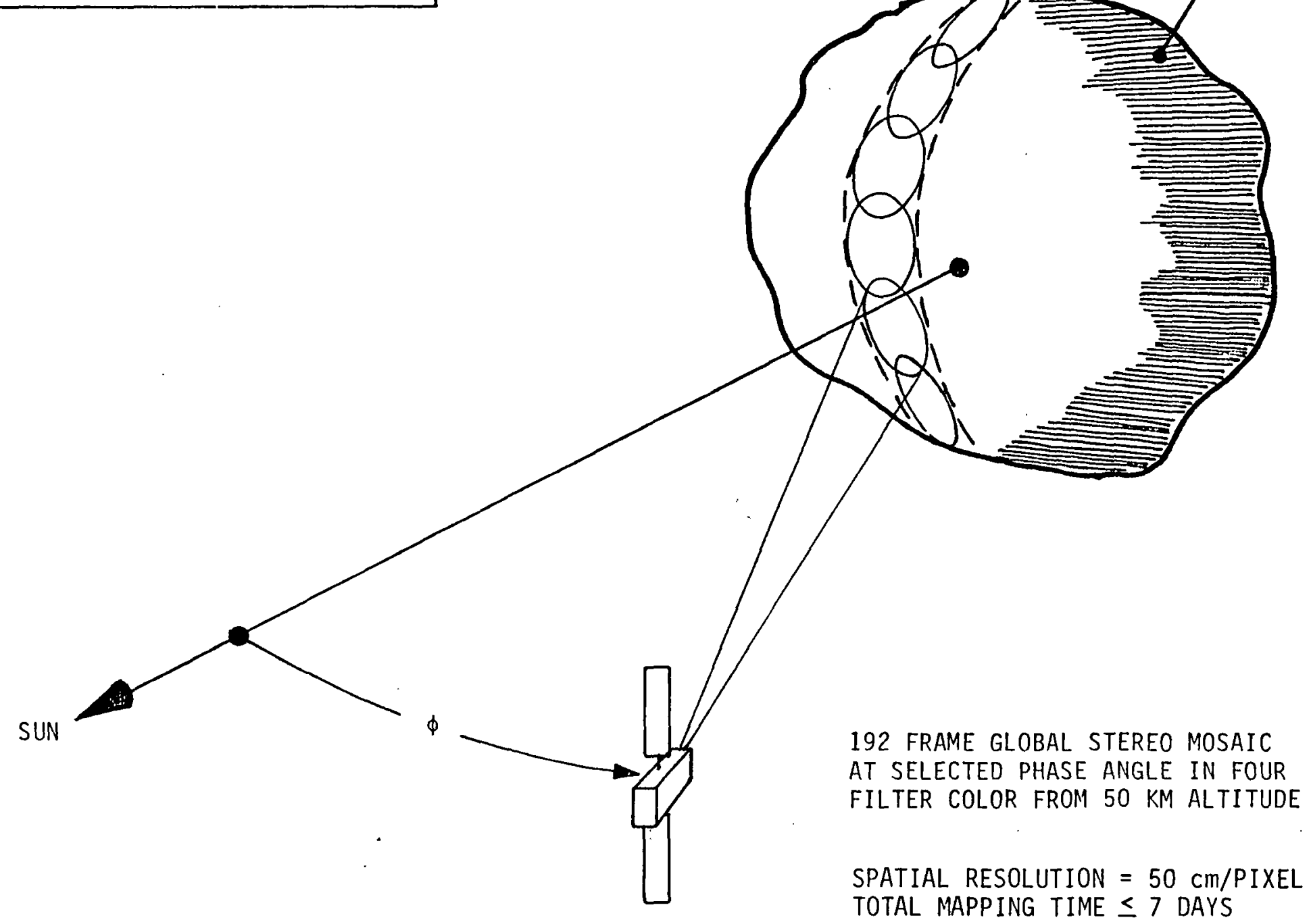




\section{PHASE III: SAMPLE COLLECTION AND SITE CHARACTERIZATION}

A total of 5 days is allowed for selection of the first sample site. At the end of that time the spacecraft would be committed to that site and begin a transfer to a $10 \mathrm{~km}$ altitude. After reaching that altitude it would stationkeep at a fixed location until it achieved the proper phase relationship with the sample site (requiring up to $1 / 4$ of a nucleus rotation). It would at that point begin a "forced-synchronous" orbit and thus maintain a fixed position over the sampling site. At the terminator it would deploy the sampler, whose own attitude control system would take over and maintain the appropriate orientation and direction needed to impact/land at the selected site. Throughout the period when the sampling site is on the dark side of the comet, the spacecraft would remain directly above it in its forced orbit, and when the site is again illuminated, the spacecraft would begin the site characterization phase of the encounter, taking images at spatial resolutions of $10 \mathrm{~cm} / \mathrm{pixel}$ (20 $\mathrm{cm}$ per line pan) at phase angles from $90^{\circ}$ to $0^{\circ}$. At the end of one complete revolution, a launch signal would be sent to the sampler to initiate its vertical ascent.

Recovery of the sampler would require implementation of automated rendezvous and docking procedures by the spacecraft. Once docked, the sample would be transferred to the protective canister and auxiliary sampler electronics and structure would be jettisoned. The spacecraft would then be free to depart.

The entire sample collection and site characterization phase requires approximately 1.5 nucleus rotations which in the case of Tempel 2 could be as little as 7.2 hours or in the case of Wild 2 as much as 15 hours (assumed).

After the first sample is collected the spacecraft would return to an attitude of $100 \mathrm{~km}$ and await a decision on the second sampling site. Three days is allowed for that decision. The sample collection and site characterization phase would then be repeated.

The "forced-synchronous" orbit referred to above is required because the comet's low gravity places the natural synchronous orbit at too low an altitude. Higher altitude synchronous orbits are attained by downward thrusting to create an artificial "gravity" force. The thrust accelerations needed for this application are generally greater than that available from low-thrust systemis (see Supporting Data Appendix), therefore it has been assumed that the necessary thrust acceleration is supplied by auxiliary chemical systems. 


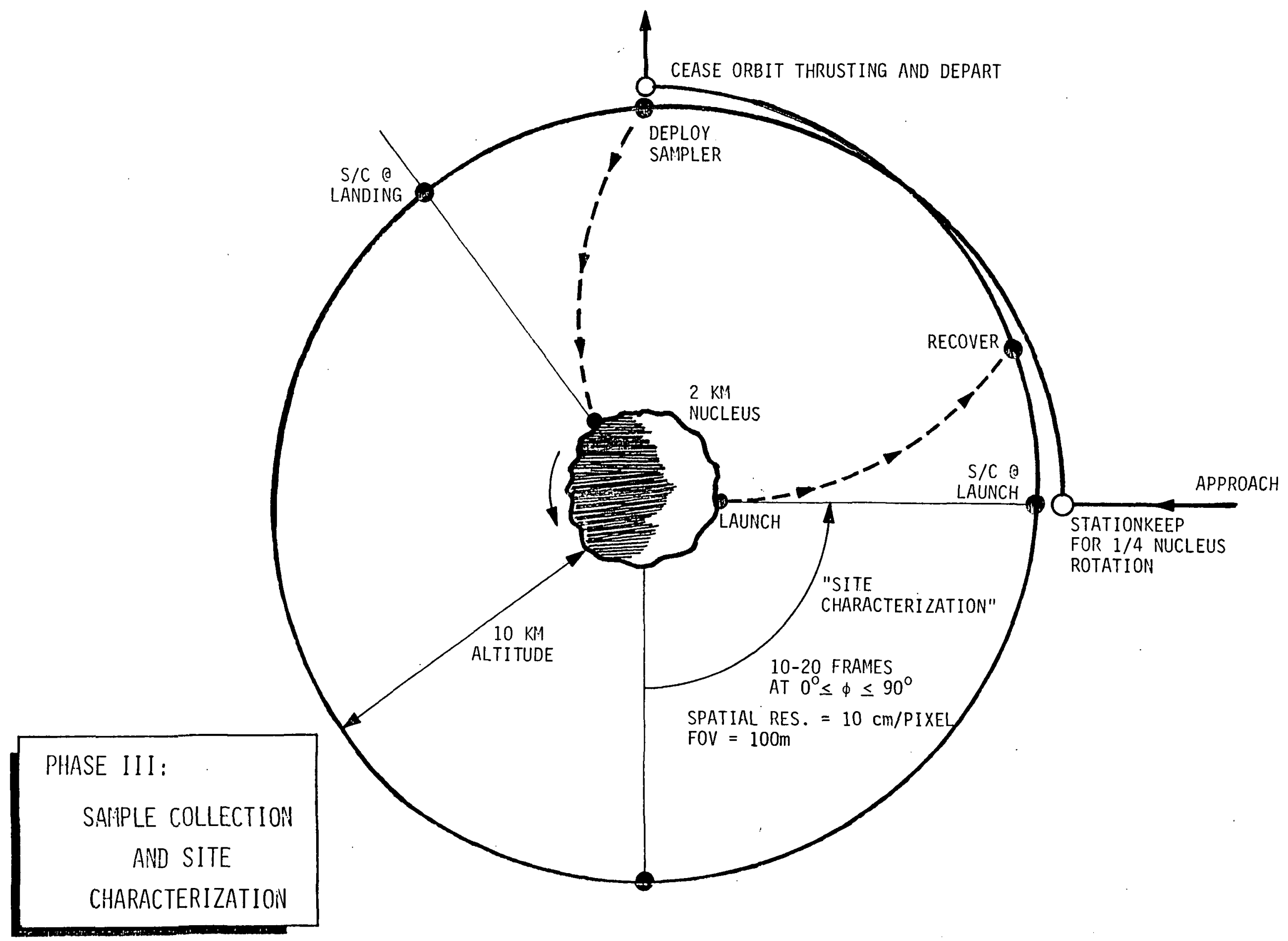




\section{EVENT TIMING PROFILE}

The figure shown on the facing page illustrates the timing of the various events and phases that comprise the near-encounter strategy outlined in the preceding pages. Essentially, the total time spent at near encounter is approximately 27 days. However, if 3 days are allowed at the start to accomodate the transfer to $200 \mathrm{~km}$ and 2 days are allowed at the end for departure, the minimum total stay time at the comet would be approximately 32 days.

To see how the dust hazard impacts the arrival and departure times at the three comets of interest, refer to the table above the graph. Here it is seen that departure from Encke can be no sooner than 51 days after perihelion since the encounter can start no earlier the $t_{p}+19$. At Tempel-2 it is seen that arrival can be no later than 66 days before perihelion since departure must occur before $t_{p}$ - 34d. Similarly at Wild-2, arrival can be no later than $t_{p}$ - $209 d$ because of the departure constraint at $t_{p}-177$. Detailed timing profiles for each comet are included in the Appendix. 
EVENT TIMING PROFILE

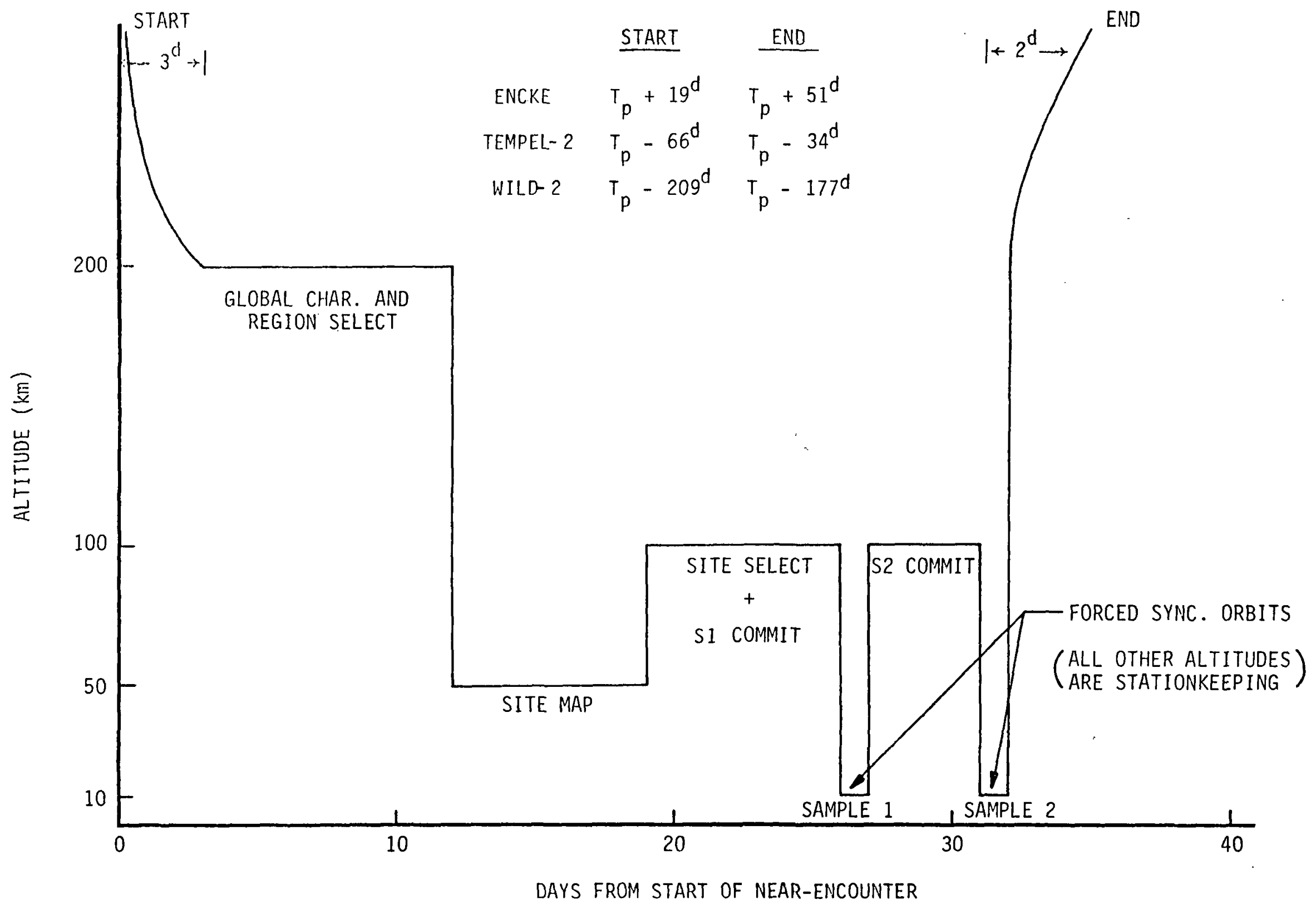




\section{Page intentionally left blank}

Page intentionally left blank 


\section{SAMPLING STRATEGY}

Because the physical properties of a comet nucleus are presently unknown, this study has considered two different sampling devices whose development and use would depend on further knowledge gained through a precursor rendezvous mission. One device is an open-core penetrator that would obtain a sample by impacting the surface under controlled conditions (attitude and velocity). Such a device would be suitable for a softer, less consolidated surface such as snow (from soft to packed). The second device is a hollow-core drill similar to those developed for sampling frigid regions here on Earth and would be suitable for compact, hard surfaces such as crystalline ice.

Since two samples are to be collected and since optimally a long-lived lander could be attached to either device, four different sampling strategies were examined:

1) Two open-core penetrators

2) Two open-core penetrators, one with a long-lived lander

3) Two hollow-core drills

4) Two hollow-core drills, one with a long-lived lander

In strategies involving a long-lived lander, it is assumed that it will always be attached to the second sampler deployed. Since the first sampler would relay surface information back to the spacecraft, deployment of the second sampler could be "fine-tuned" and thus reduce the risk involved in both collecting the second sample and in properly anchoring the lander. 


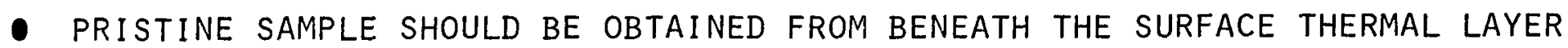
OF THE NUCLEUS

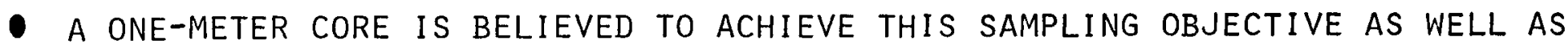
PROVIDE A STRATIGRAPHIC RECORD BETWEEN THE SAMPLE AND THE SURFACE

- if the nuCleus surface haRdness is similar to snow (from soft to packed) a CONTROLLED IMPACT OPEN-CORE PENETRATOR IS PROPOSED

- if the NUCLEUS SURFACE haRDNESS is SIMILAR TO OR GREATER THAN ICE, AN ANCHOR-LANDED HOLLOW-CORE DRILL IS PROPOSED

- optionally, a long-lived lander is attachable to either of these devices

- hence, four sampling strategy concepts are considered

CONCEPT 1: TWO OPEN-CORE PENETRATORS

CONCEPT 2: TWO OPEN-CORE PENETRATORS, ONE WITH A LONG-LIVED LANDER

CONCEPT 3: TWO HOLLOW-CORE DRILLS

CONCEPT 4: TWO HOLLOW-CORE DRILLS, ONE WITH A LONG-LIVED LANDER 


\section{PENETRATOR SAMPLER/LANDER}

\section{PENETRATOR SAMPLER}

The major subsystems of this vehicle consist of a three layer sampling tube, a support electronics package and a reaction control system (RCS). The core tube has an outer surface of stainless steel, a middle layer of insulating material, and an inner liner of composite material. The outer layer is attached to a terrabrake and these two components will remain on the surface when the sample is returned to the orbiter. If the speed at impact is too high for the local conditions (soil too soft, subsurface voids, etc.) then the terrabrake is large enough to stop the penetrator within a few centimeters of the surface. If the speed at impact is too low then a cold gas $\left(N_{2}\right)$ RCS is available to try to force the sampler further into the surface. But conditions which are strong enough to stop the penetrator probably cannot be overcome by the RCS. The primary purpose of the RCS is to provide reaction mass for a guidance and control system which is part of the support electronics. 0ther capabilities of the electronics package include two way communication with the orbiter and monitoring the condition of the sample. Power is provided by a remotely activated primary battery.

\section{LANDER}

The lander vehicle has been designed to support a scientific package over the course of one entire orbit period. To accomplish this, the RTG has been sized to provide $150 \mathrm{~W}$ (BOL) of power. This RTG has been placed on a mast 1.5 - 2.0 meters above the surface so that the waste heat radiated by this device will not exceed the heat load seen by the comet fron the Sun at aphelion. In addition, since the lander sits on the surface, the base of the lander has been sealed and protected by multilayer insulation (MLI) to prevent heat flow to the surface. The communication systell will use $X$ band and a high gain antenna with hemispherical pointing capability to connunicate with either the orbiter or with Earth. This system has been sized to provide a data rate of 1000 BPS at a distance of 1 AU. The additional base area of this lander will be able to stop the combined mass of both the sampler and lander should the impact velocity be too high. Once the sample has been returned to the orbiter, the outer sleeve of the penetrator will provide an anchor for the lander. 


\section{PENETRATOR SAMPLER/LANDER}

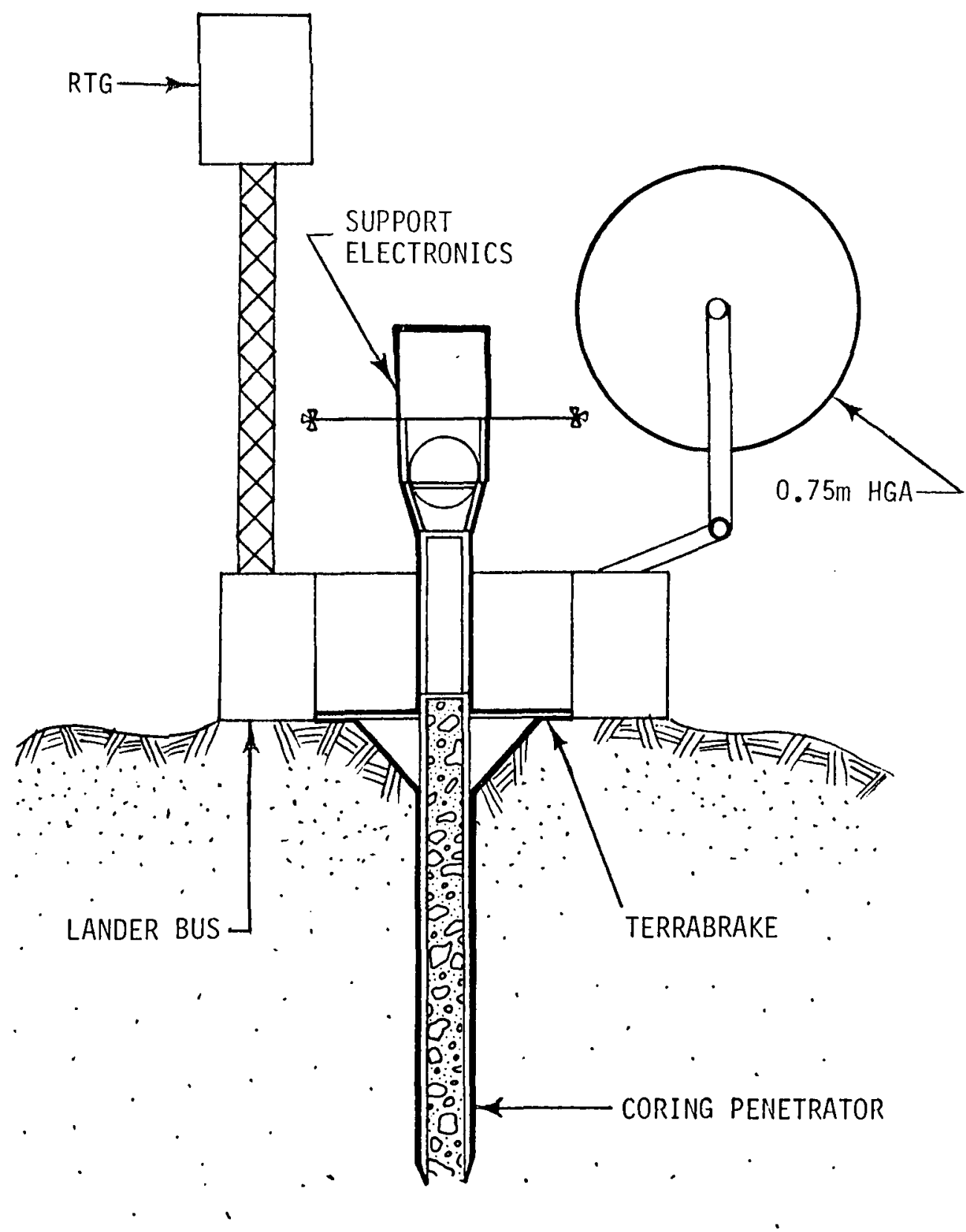

SAMPLER $\quad$ LANDER

SCIENCE

COMMAND/DATA HANDLING

TELECOMMUNICATION

AACS

REACTION CONTROL SYSTEM

POWER/PYRO

STRUCTURE

THERMAL CONTROL

CABL ING

DEVICES

SUBTOTAL

CONTINGENCY

$\mathrm{N}_{2}$ PROPELLANT

TOTAL

TOTAL (BOTH VEHICLES)
$1.0 \quad 10.0$

$2.0 \quad 16.0$

$1.2 \quad 11.2$

$1.6 \quad 0$

2.4. 0

$1.9 \quad 13.5$

$6.2 \quad 46.2$

$0.6 \quad 9.0$

$0.3 \quad 5.0$

1.28 .0

$18.4 \quad 118.9$

$\begin{array}{llll}(30 \%) & 5.7 & (15 \%) & 17.8\end{array}$

$0.7 \quad 0$

$24.8 \mathrm{~kg} \quad 136.7 \mathrm{~kg}$

$161.5 \mathrm{~kg}$ 


\section{DRILLING SAMPLER}

\section{RETURN VEHICLE}

This vehicle has a breakdown of subsystems similar to that of the penetrator sampler. The RCS system is basically the same except for an increase in the propellant load to account for the larger vehicle. The support electronics provide the same functions with the addition of event sequencing during the drilling operation. The core barrel is constructed of composite materials and is attached to a metal cutting head. This device is patterned after an ice drill developed by the Cold Regions Research and Engineering Laboratory in cooperation with the Shell 0il Company. The core barrel and sample will be isolated from the outside environment and the support electronics (including the drill motors) by multilayer insulation.

\section{LANDING SYSTEM}

Since it has been assumed that a drill would only be used on harder materials, the landing/anchoring system must be modified accordingly. For this system, the lander legs are assumed to be rigid penetrators each containing a shaped charge in the end. These charges would be activated if the surface resistance exceeded a specified level and have the capability of creating a hole with a depth 10 to 20 times its diameter. Once in place, a leveling device on each leg would compensate for any uneven landing leg penetration, and at the same time provide a compressive force to the legs to induce their expansion in "moly-bolt" fashion and thus provide anchoring. 


\section{DRILLING SAMPLER}

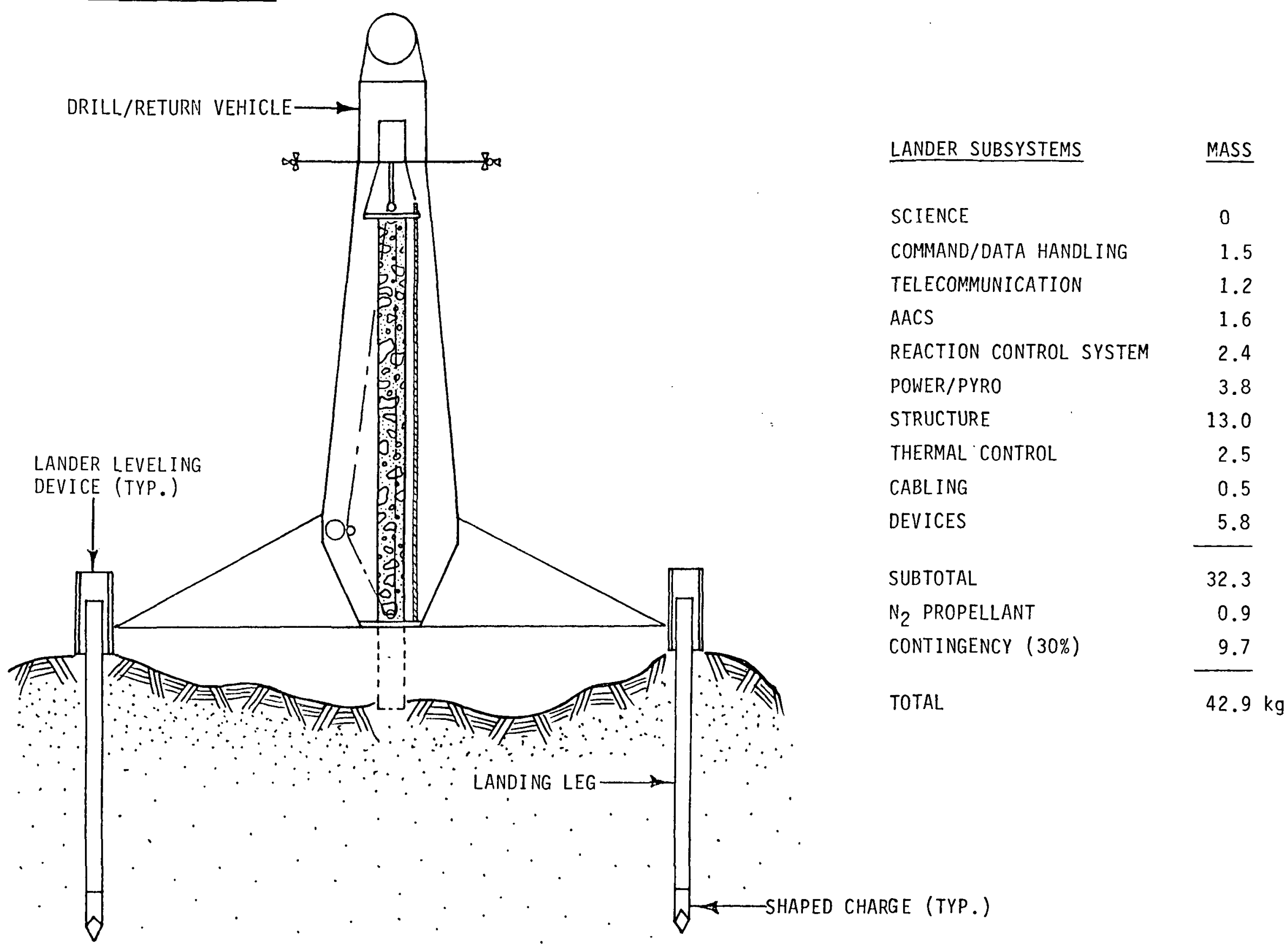




\section{DRILLING SAMPLER/LANDER}

This vehicle is made up of components and systems already discussed. The landing legs and drill/return vehicle remain unchanged, while the lander structure has been reconfigured to accommodate the drill and the landing legs. 


\section{DRILLING SAMPLER/LANDER}

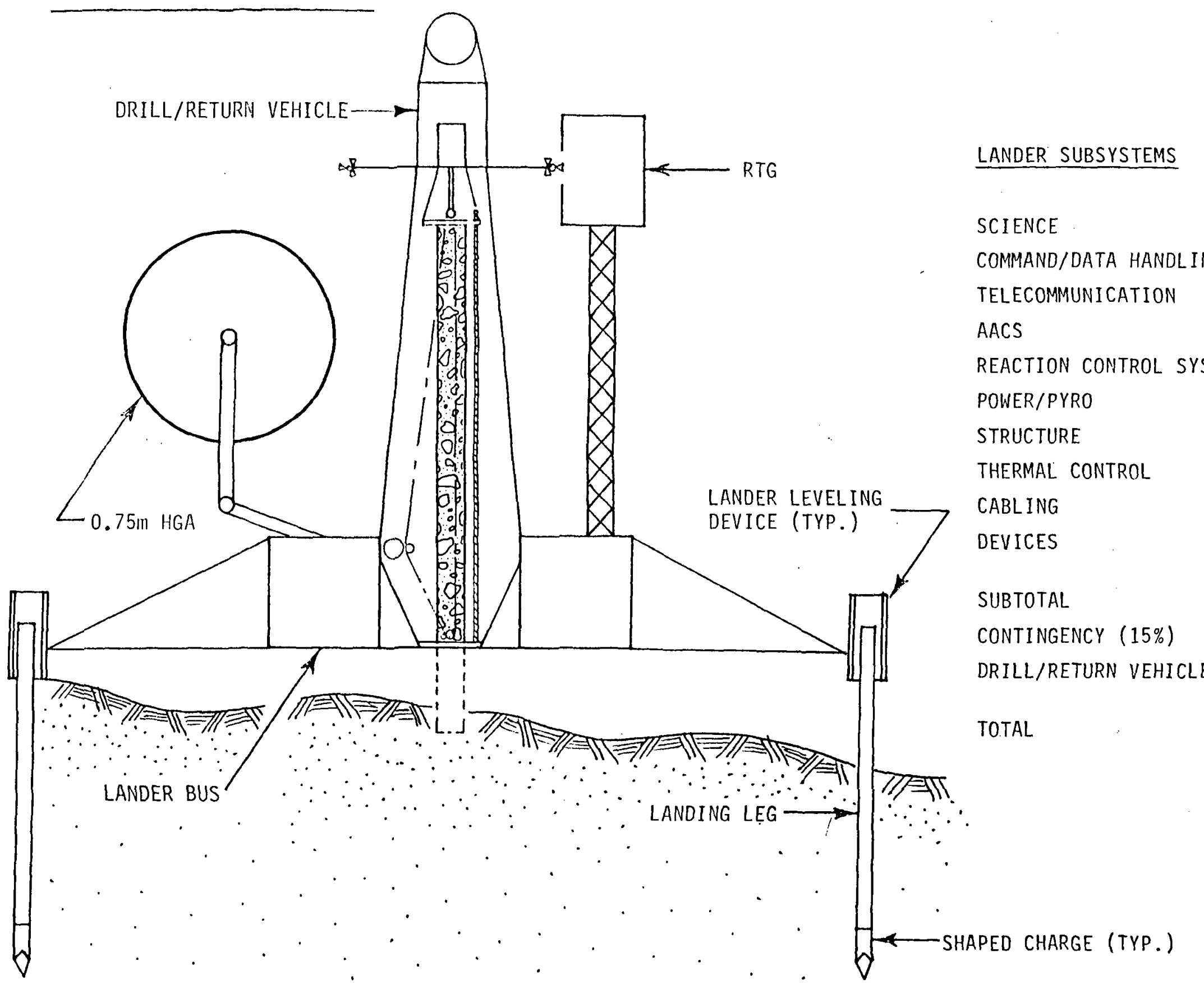

MASS

14.0

16.0

11.2

0

0

30.0

42.5

9.6

5.0

10.5

138.8

20.8

29.1

188.7 


\section{Page intentionally left blank}

\section{Page intentionally left blank}




\section{THERMAL PROTECTION OF COMET SAMPLE}

Thermal protection of the comet sample is one of the key mission requirements. Ideally, the sample should be kept at or below the acquisition temperature, i.e. the subsurface temperature at the maximum collection depth, in order to protect its volatile inventory. For design purposes, this temperature was assumed to be $100^{\circ} \mathrm{K}$ which is expected to be less than the surface temperature at aphelion for the short period comets of interest.

The approach taken to the thermal control design was to first examine strictly passive techniques under postulated worst case conditions and if these were unable to perform adequately, then to resort to active cooling methods where needed. Results obtained from the first-cut analyses appear however, to indicate that passive techniques alone are sufficient to keep the samples within 5 to 10 degrees of the design goal and therefore active methods were no longer considered.

There are four phases of the mission that present unique thermal protection problems for the sample. They are: (1) the sampling process itself, (2) the ascent from the comet to the spacecraft, (3) the long return transit to Earth, and (4) the time spent in Earth orbit awaiting Shuttle recovery. The table on the facing page presents the various techniques and accomodations proposed to control the thermal environment of the sample during these mission phases.

During the sampling phase, thermal control of the sampler core would be provided by multi-layer insulation (MLI) surrounding the core tube or drill enclosure. The fact that the stay time at the surface is short with most of it spent in (relative) darkness, also helps prevent subsurface heating through conduction.

During the recovery phase, the sample would continue to be protected by the MLI insulation, which could be made highly solar-reflective. However, the IR background temperature of the comet can be expected to raise the skin temperature of the insulated package to values near $200^{\circ} \mathrm{K}$. Fortunately with an ascent rate of $5 \mathrm{~m} / \mathrm{sec}$, the time to recovery would be only on the order of $1 / 2$ hour, and the thermal inertia of the sample itself would prevent the internal temperature from rising more than $5^{\circ} \mathrm{K}$ at worst. (See Supporting Data Appendix) After recovery, the sample core would be transferred to a protective canister and hermetically sealed.

Thermal control measures employed during the Earth return transit phase and in Earth orbit are described in the following pages. 
MISSION PHASE

SAMPLING

RECOVERY

EARTH RETURN TRANSIT

EARTH ORB IT
THERMAL CONTROL TECHNIQUES/ACCOMODATIONS

MLI INSULATED CORE SLEEVE (CORE SAMPLER)

MLI INSULATED TENT (DRILL)

SHORT STAY TIME/DARK SIDE SAMPLING

MLI INSULATION

THERMAL INERTIA

MLI INSULATED, HERMETICALLY SEALED CANISTER SHIELDED ENCLOSURE WITH THERMAL CONTROL SURFACES SPACECRAFT SHIELDING AND RADIATION TO DEEP SPACE SPACECRAFT ATTITUDE CONTROL

NADIR POINTING（LONG-AXIS） ATTITUDE CONTROL

MLI INSULATED SHIELDED CANISTER

RADIATION TO SPACE

THERMAL INERTIA 


\section{EARTH RETURN CONFIGURATION}

The sample canister is considered to be tubular in shape with dimensions of $125 \mathrm{~cm} \times 30 \mathrm{~cm}$ (dia.). It would be thermally insulated by MLI (placed either internally or externally) and have a low emissivity film (e.g. goldized Kapton, $\varepsilon=0.03$ ) over its external surface. Throughout its return to Earth the capsule would be shielded completely by thermal control surfaces which reflect solar radiation but during the return transit act primarily as radiators to deep space.

As shown on the facing page, the shielding enclosure consists of three plane surfaces surrounding the length of the tubular canister, and two triangular end plates (not shown). The shields could be constructed of lightweight aluminum with thermal control films on their internal and external surfaces. Internally, goldized Kapton could again be used for its low emissivity properties, while externally, silver/Teflon appears suitable because its a/ $\varepsilon$ can be as low as 0.1 .

During the return transit to Earth, it is important to maintain a spacecraft attitude that permits the package to view deep space while avoiding direct solar illumination. Since this might not always be possible, a rotatable sun shield and turntable arrangement, as shown in the figure, could provide the needed flexibility.

A thermal analysis of the configuration described above, indicates the potential for maintaining the sample at or below its encapsulation temperature throughout the Earth return phase of the mission. 


\section{EARTH RETURIN CONFIGURATION}

SOLAR ILLUMINATION

(NOMINAL DIRECTION)
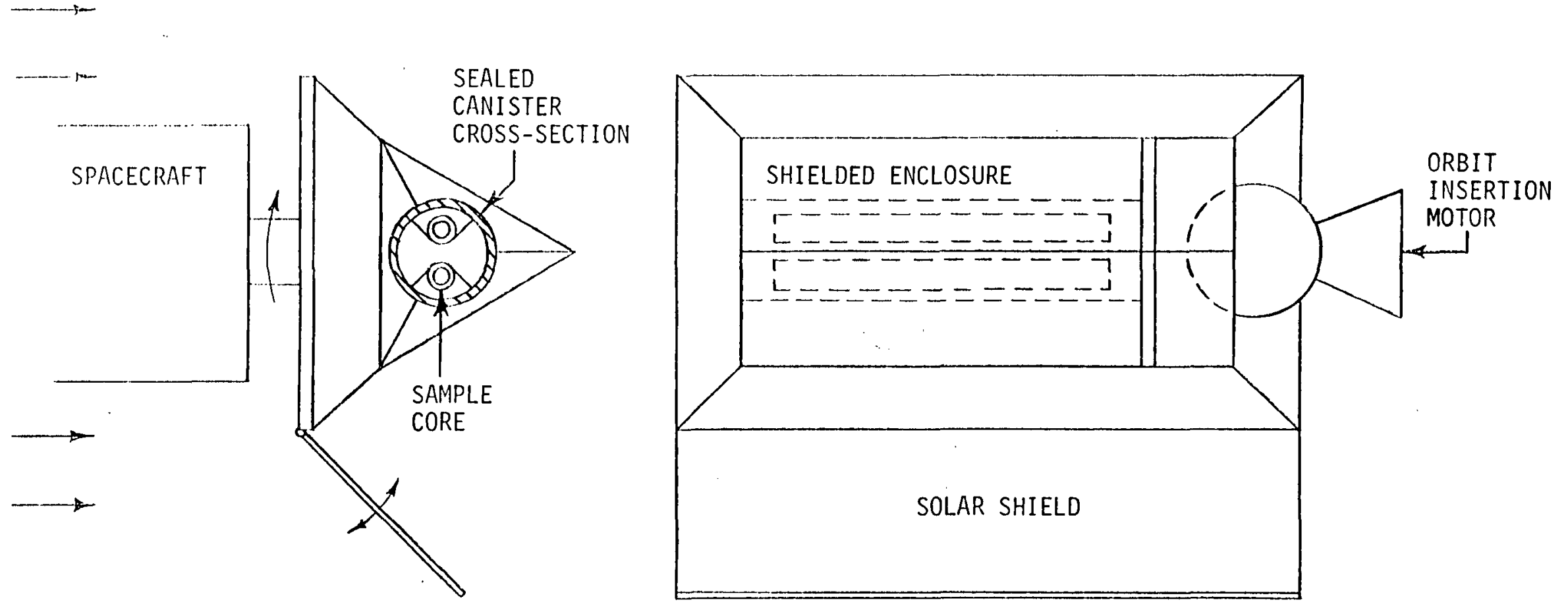

MLI ON CORE SLEEVES AND WITHIN CANISTER DOUBLE WALL (EFFECTIVE $\varepsilon=0.001$ )

THERMAL CONTROL COATINGS/FILMS ON ALL SHIELD SURFACES
$\alpha / \varepsilon \simeq 0.1$
SOLAR RADIATION
(SILVER/TEFLON)
$\varepsilon \simeq 0.03$
INTERNAL SURFACES
(GOLDIZED KAPTON) 


\section{TEMPERATURE PROFILE OF SAMPLE PAYLOAD IN EARTH ORBIT}

While in a nominal $370 \mathrm{~km}$ Shuttle recovery orbit, the injected payload faces a heat load arising from three sources: direct solar radiation, Earth-reflected solar radiation, and longer wave thermal radiation from the Earth. Furthermore, from this low Earth orbit, the payload surfaces have a greatly diminished capability for radiating to deep space. Use of nadir-pointing attitude control, as illustrated in the figure, can help mitigate the problem by increasing the radiating surface area with respect to the area receiving radiation. However since the heat load would still be greater than the heat radiated away, the payload package and its contents would in time still reach an equilibrium teriperature of about $185^{\circ} \mathrm{K}$.

The solution to the thermal control problem is extensive insulation of the core samples, and their container, which produces a large thermal time constant; and timely recovery of the package by the Shuttle. As can be seen from the graph on the facing page, Shuttle recovery within a week would prevent the sample temperature from rising above $110^{\circ} \mathrm{K}$ (assuming its initial temperature were $100^{\circ} \mathrm{K}$ ).

The thermal control analysis performed in this study was necessarily simplified because of the many unknowns that presently exist. Consequently there are a number of thermal control issues that have not been addressed. These include performance of thermal control surfaces after impact or layering by cometary dust, potential thermal contamination sources in the sampling process, and methodology for capping and thermally protecting the open core end prior to ascent. A more extensive 1 ist of open thermal performance issues is provided as supporting data in the Appendix. 
TEMPERATURE PROFILE OF SAMPLE PAYLOAD IN EARTH ORBIT

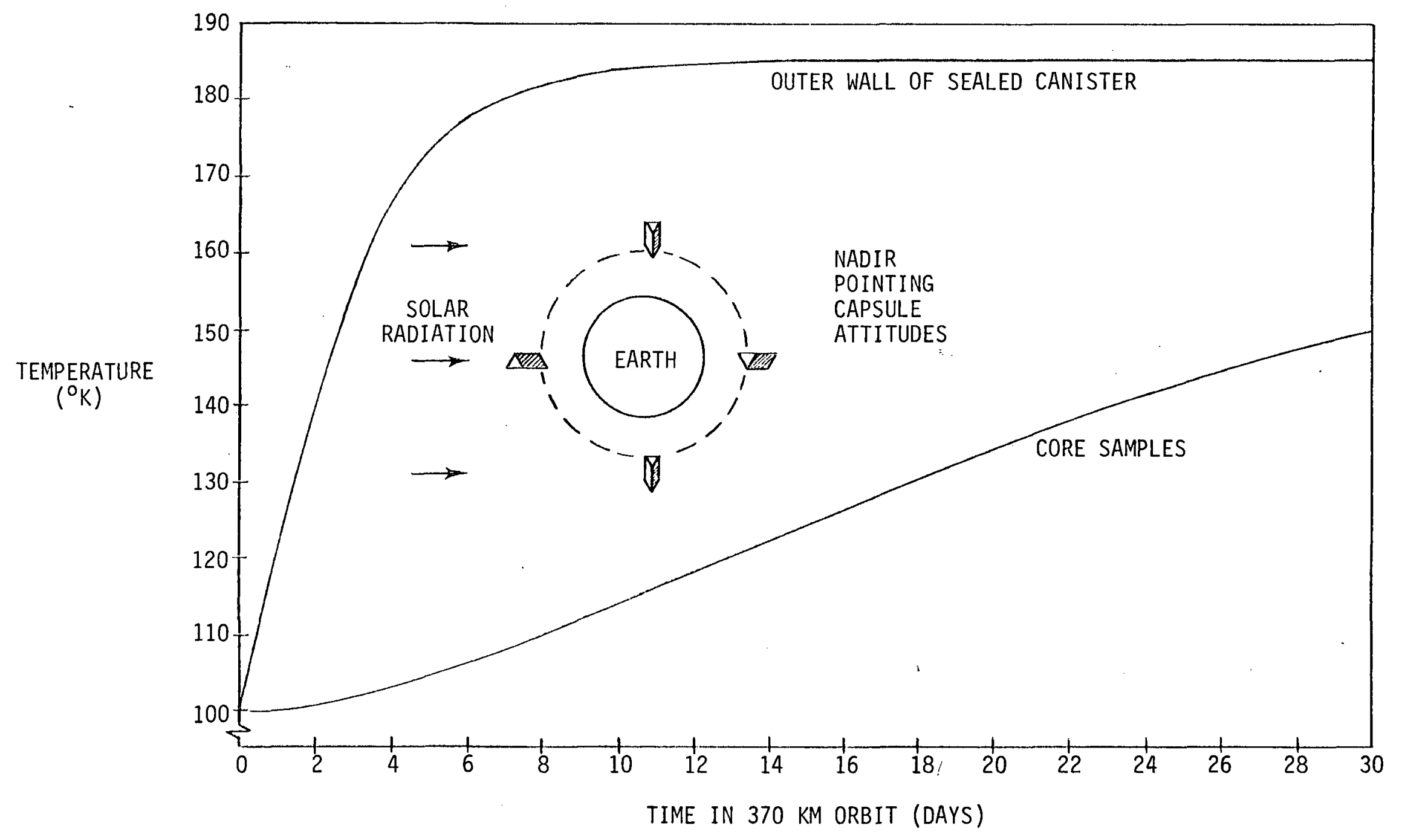


Page intentionally left blank

Page intentionally left blank 


\section{FLIGHT}

PERFORMANCE 


\section{FLIGHT MODE OPTIONS}

Three distinct flight modes were analyzed for Comet Sample Return missions: 1) ballistic using chemical propulsion, 2) Solar Electric Propulsion (SEP), and 3) Nuclear Electric Propulsion (NEP). The analyses entailed the derivation of trajectory and performance data for each flight mode/target combination for the purpose of identifying launch requirements and performance margins.

In the missions investigated, emphasis was placed on comet rendezvous near perihelion in accordance with the previously stated advantages of such encounters for comet sampling and science. However, in order to also assess the performance implications of aphelion rendezvous, two such missions were examined as ballistic flight mode options; one to Wild-2 arriving in January 2000 , and one to Kopff arriving in January 2007. These, in fact, were found to be the only opportunities in the (approximate) time period of interest that provide Earth-comet geometries appropriate to aphelion transfer.

Direct trajectories, both outbound and return, were taken as basic to all three flight modes. Consideration was also given to $\triangle V E G A$ trajectories, in the analysis of ballistic missions, as a potential means of capturing missions whose injection mass $-C_{3}$ requirements for direct transfers exceed projected launch capabilities. Ballistic mode performance gains resulting from use of Space-storable retro propulsion ( $I_{S p}=370 \mathrm{sec}$ ) was also accounted for in these analyses.

While direct trajectories were assumed for both low-thrust flight modes, NEP missions provided further options with respect to spiral escape and capture at Earth. Performance for the NEP flight mode was computed both with an without Earth-escape spirals. The spiral escape option presumed the spacecraft to be first carried to a $700 \mathrm{~km}$ circular orbit by the shuttle and then released from the cargo bay. From that point on, the NEP systems would be used to accelerate the spacecraft to escape velocity in ever-increasing spiral orbits away from the Earth.

Spiral capture is almost the inverse of the above process, ie., the NEP ion energies would apply continuous deceleration forces to the spacecraft during its inbound spiral. However, to avoid excessive irradiation of the sample during a relatively slow spiral passage through the .Van Allan belts, the spiralling process would be terminated prior to reaching regions of significant radiation and the return capsule would be jettisonned and transferred to a low-Earth recovery orbit by a series of solid rocket motor burns.

The spiral capture mode was invoked for all NEP missions in this study regardless of the technique used for Earth escape. The other two flight modes depend exclusively on a solid rocket motor (staged as necessary) for Earth capture and orbit insertion of the return capsule. In all cases, the final low-Earth orbit was assumed to be circular and Shuttle-compatible to facilitate quick sample recovery. 


$\begin{array}{cllll}\begin{array}{c}\text { FLIGHT } \\ \text { MODE }\end{array} & \begin{array}{c}\text { RENDEZVOUS } \\ \text { MODE }\end{array} & \begin{array}{c}\text { TRAJECTORY } \\ \text { TYPE }\end{array} & \begin{array}{c}\text { SPACECRAFT } \\ \text { PROPULSION }\end{array} & \begin{array}{c}\text { EARTH CAPTURE* } \\ \text { MODE }\end{array} \\ \text { BALLISTIC } & \text { PERIHELION } & \text { DIRECT \& } \triangle V E G A & \text { SPACE-STORABLE } & \text { SOLID ROCKET } \\ & \text { APHELION * } & \text { DIRECT } & \text { SPACE-STORABLE } & \text { SOLID ROCKET } \\ \text { SEP } & \text { PERIHELION } & \text { DIRECT } & \text { ION ENGINES } & \text { SOLID ROCKET } \\ \text { NEP } & \text { PERIHELION } & \text { SPIRAL ESCAPE/DIRECT } & \text { ION ENGINES } & \text { SPIRAL CAPTURE } \\ & \text { PERIHELION } & \text { DIRECT } & \text { ION ENGINES } & \text { SPIRAL CAPTURE }\end{array}$

* Sample return to shuttle retrieval orbit

* SPECial case for selected comets 


\section{LAUNCH INJECTION STAGE OPTIONS}

The launch/injection stage options considered in this study run the gamut from a single standard shuttle launch without an upper stage to multiple shuttle launches for on-orbit assembly of stacked Centaurs. These options and their respective flight mode applications, as determined by performance analyses of the comet mission set, are as follows:

1) Only a single Shuttle launch is needed to capture missions employing either of the lowthrust flight modes. SEP missions require the services of a Centaur(G') upper stage whereas NEP missions using an Earth-escape spiral can be launched from the Shuttle alone. Without spiralling, the NEP missions require on-orbit fueling of a Centaur $\left(G^{\prime}\right)$ and therefore two Shuttle launches.

2) On-orbit assembly or fueling is a technique utilized to gain the performance advantage of the fully-loaded Centaur upper stage unconstrained by Shuttle cargo mass limitations. One option requiring two Shuttle launches is to mate the Centaur stage with the payload in orbit. Another option is to complete the propellant loading of Centaur in orbit. This higher performance Centaur $\left(G^{\prime}\right)$ is necessary for NEP missions injected to $C_{3}>0$. The more difficult ballistic missions require two fully-loaded Centaurs, either stacked Centaur(G')'s or the Centaur(G')/Centaur(G).

For purposes of this study, the SEP system size is defined by a $38 \mathrm{kw}$ solar array (beginning of life, at $1 \mathrm{AU}$, unconcentrated) with the addition of array concentrators. The ion thrusters operating at $3560 \mathrm{sec}$ specific impulse utilize a maximum input power of $36 \mathrm{kw}$. The SEP dry mass is $1741 \mathrm{~kg}$. The NEP system has an input power level of $100 \mathrm{kw}$, its ion thrusters operate at 5500 sec specific impulse, and its dry mass is $4367 \mathrm{~kg}$. 
- standard shuttLe launch

SHUTTLE, $\ldots \ldots \ldots \ldots \ldots \ldots$ NEP $W /$ ESCAPE SPIRAL

SHUTTLE/CENTAUR $\left(G^{\prime}\right) \ldots \ldots \ldots \ldots \ldots \ldots$, $\ldots \ldots$, $\ldots \ldots$

- ON-ORBIT ASSEMBLY/FUELING

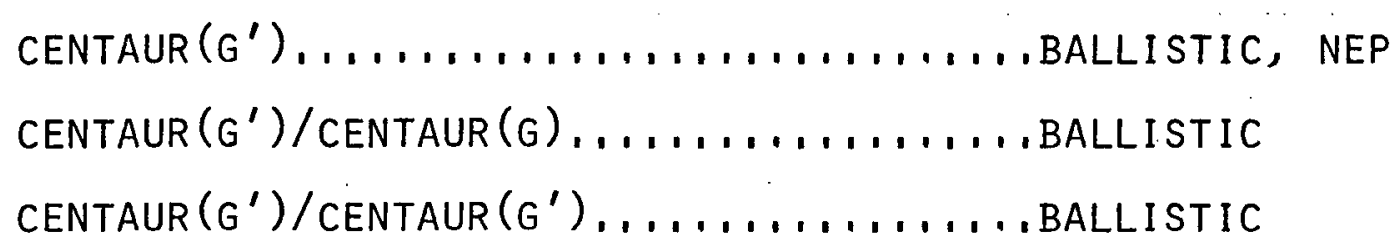

- LOW THRUST SYSTEMS

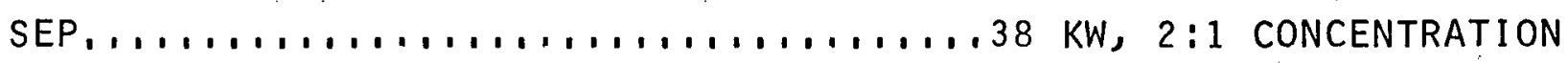

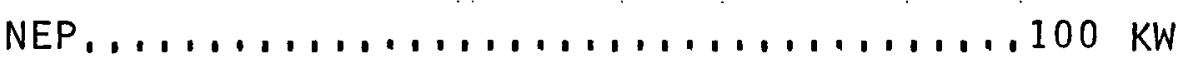




\section{TEMPEL 2 SAMPLE RETURN MISSION CAPTURE DIAGRAM}

The mission capture diagram for comet Tempel-2 is shown on the facing page. This example is for missions utilizing Sampler Concept \#1, ie, two penetrator samplers without a lander/station. It can be seen that the NEP mission employing an Earth escape spiral $\left(C_{3}=0\right)$ can be launched by the Shuttle alone with a performance margin of approximately $8000 \mathrm{~kg}$. In addition to eliminating the need for an upper stage, performance delivered by this flight mode far exceeds the capabilities of the other flight modes examined. The diagram shows that the same NEP system, if injected directly at $\mathrm{C}_{3}>4 \mathrm{~km}^{2} / \mathrm{sec}^{2}$, would require a fully loaded Centaur(G') stage (ie, on-orbit delta fueling) to capture the mission and would still not provide as great a performance margin $(\approx 5000 \mathrm{~kg})$.

The SEP mission, with a smaller injected mass requirement (the dry NEP system is 3 times heavier than SEP and also uses more propellant) can be captured by the Shuttle/Centaur(G') without the need for on-orbit fueling. Its performance margin is approximately $1000 \mathrm{~kg}$.

Ballistic missions are the most difficult missions to capture and therefore require the most capable launch vehicles. In fact, the diagram illustrates that the direct ballistic mission to Tempel-2 cannot be captured even by two fully-loaded stacked Centaur(G')'s. In order to capture the mission ballistically, a $\triangle$ VEGA trajectory is needed and requires on-orbit assembly of at least a Centaur(G')Centaur(G) stack. The performance margin for such a mission would be approximately $1600 \mathrm{~kg}$. 
SAMPLER CONCEPT 1: TWO CORE PENETRATORS, NO LANDER/STATION

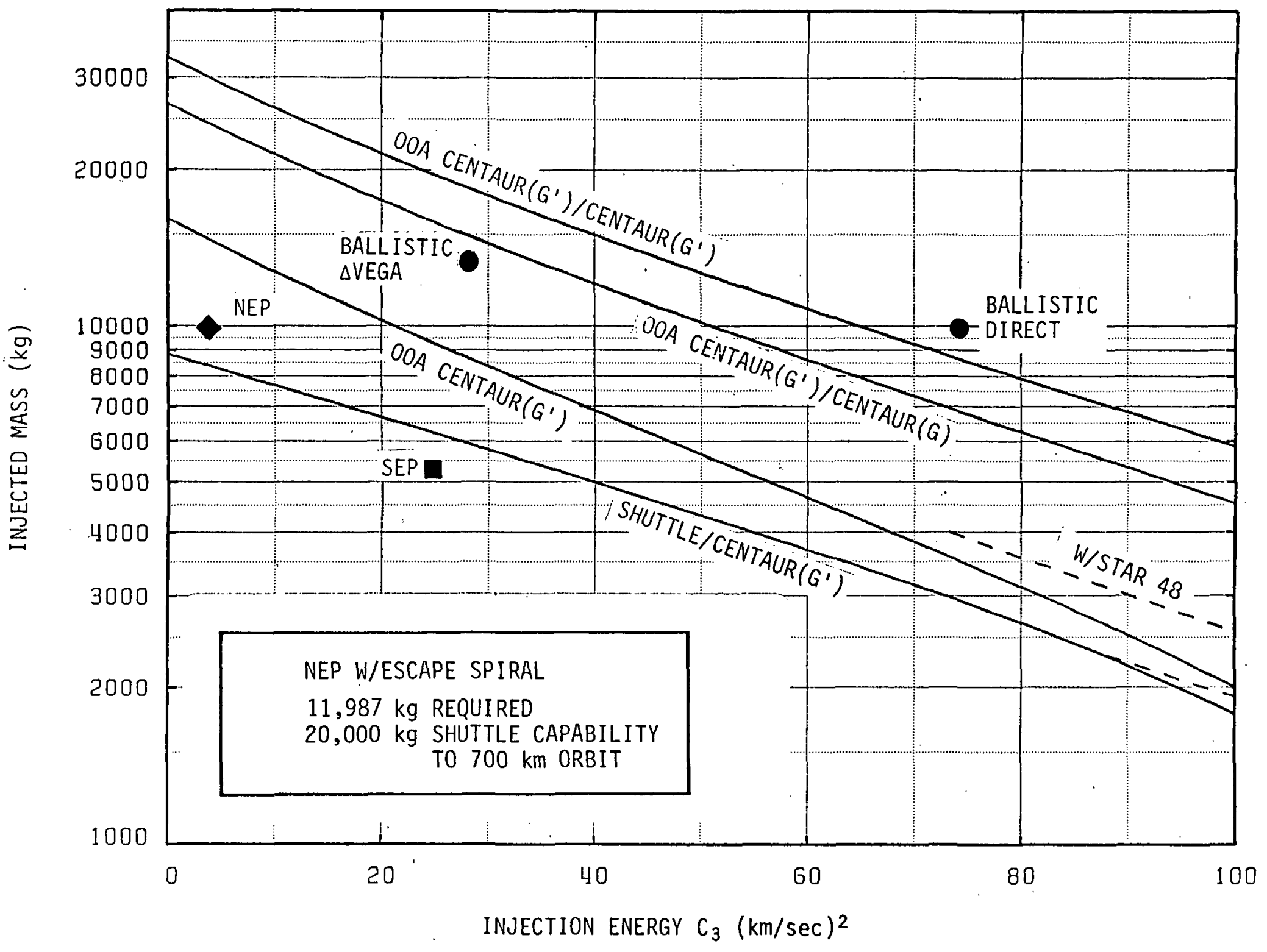

TEMPEL 2 SAMPLE RETURN MISSION CAPTURE DIAGRAM 


\section{MISSION OPTIONS - PERFORMANCE}

The "Mission Options" table has been presented previously in a less complete form. It now contains information derived from performance analyses of the listed options. Several conclusions may be drawn from these results:

- Using mass margin and round trip time as performance discriminators, it is clear that NEP is the most capable system; SEP generally provides good capability; and ballistic/chemical propulsion generally provides very poor capability.

- NEP with an escape spiral requires Shuttle delivery to a nuclear safe altitude $(\simeq 700 \mathrm{~km})$ but provides the largest Shuttle cargo margins $(5200-7600 \mathrm{~kg})$ with round trip times of approximately 7 years.

- NEP without an escape spiral requires a fully loaded Centaur(G') (on-orbit delta-fueling) and provides somewhat less mass margin $(2800-4300 \mathrm{~kg})$ but with somewhat reduced trip times of approximately 6 years.

- SEP requires a large solar array $(\simeq 38 \mathrm{k})$ with concentrators and its injected mass margins are smaller than NEP $(500-1500 \mathrm{~kg})$. Its round trip times range from 5 to 6 years.

- The ballistic flight mode cannot capture most mission opportunities. The exceptional cases are those listed in the table and they require on-orbit assembly of Centaur stages and space-storable retropropulsion. The round trip times for perihelion encounter are also very long at 8 to 11 years.

When comparing flight mode capabilities as above, note should be taken of the fact that the NEP results in the Table reflect the most difficult (heaviest) sampling concept, while the ballistic cases presume the simplest (1ightest) concept. The SEP results are based on the Penetrator/Lander concept which is slightly lighter than the Drill/Lander considered for the NEP missions. 
MISSION OPTIOAS

\begin{tabular}{|c|c|c|c|c|c|c|c|c|c|c|c|c|}
\hline \multirow{2}{*}{ OPTION } & \multirow{2}{*}{ COMET/YR } & \multicolumn{2}{|c|}{ TOTAL $T_{M}$} & \multirow{2}{*}{$\begin{array}{l}\text { FLIGHT } \\
\text { MODE }\end{array}$} & \multicolumn{3}{|c|}{ SAMPLER CONCEPT } & \multirow{2}{*}{$\begin{array}{c}\text { LAUNCH } \\
\& \\
\text { INJ. STACK }\end{array}$} & \multicolumn{2}{|c|}{ INJECTED MASS (KG) } & \multicolumn{2}{|c|}{ COSTS (' 84 \$M) } \\
\hline & & $R_{p}$ & $\mathrm{R}_{\mathrm{A}}$ & & PEN. & DRL. & LDR. & & REQ'D & MARGIN & PROJECT & TOTAL \\
\hline 1 & ENCKE/03 & $6.1^{\gamma}$ & & SEP & $x$ & & & $\begin{array}{l}\text { SHUTTLE } \\
\text { CENT }\left(G^{\prime}\right)\end{array}$ & 5,260 & 950 & & \\
\hline 2 & ENCKE/03 & $6.1^{Y}$ & & SEP & $x$ & & $x$ & $\begin{array}{l}\text { SHUTTLE } \\
\text { CENT }\left(G^{\prime}\right)\end{array}$ & 5,540 & 660 & & \\
\hline 3 & ENCKE/03 & $7.0 Y$ & & NEP & & $x$ & $x$ & SHUTTLE & 14,760 & 5,240 & & \\
\hline 4 & TEMPEL-2/05 & $11.1^{Y}$ & & $\begin{array}{l}\text { BAL. } \\
\triangle V E G A\end{array}$ & $x$ & & & $\begin{array}{l}\text { OOA } \\
\operatorname{CENT}\left(G^{\prime}\right) /(G) \\
\end{array}$ & 13,320 & 1,590 & & \\
\hline 5 & TEMPEL-2/05 & $5.0^{Y}$ & & SEP & $x$ & & & $\begin{array}{l}\text { SHUTTLE } \\
\text { CENT }\left(G^{\prime}\right)\end{array}$ & 5,220 & 980 & & \\
\hline 6 & TEMPEL-2/05 & $5.0^{\gamma}$ & & SEP & $x$ & & $x$ & $\begin{array}{l}\text { SHUTTLE } \\
\text { CENT }\left(G^{\prime}\right)\end{array}$ & 5,290 & 910 & & \\
\hline 7 & TEMPEL - $2 / 05$ & $6.7 Y$ & & NEP & & $x$ & $x$ & SHUTTLE & 12,410 & 7,590 & & \\
\hline 8 & WILD-2/03 & $6.0^{Y}$ & & SEP & $x$ & & & $\begin{array}{l}\text { SHUTTLE } \\
\text { CENT }\left(G^{\prime}\right)\end{array}$ & 4,670 & 1,530 & & \\
\hline 9 & WILD-2/03 & $6.0^{\gamma}$ & & SEP & $x$ & & $x$ & $\begin{array}{l}\text { SHUTTLE } \\
\operatorname{CENT}\left(G^{\prime}\right)\end{array}$ & 4,740 & 550 & & \\
\hline 10 & WILD-2/03 & $7.0^{\gamma}$ & & NEP & & $x$ & $x$ & SHUTTLE & 13,870 & 6,130 & & \\
\hline 11 & WILD-2/03 & $8.9^{\gamma}$ & & $\begin{array}{l}\text { BAL. } \\
\text { DIR. }\end{array}$ & $x$ & & & $\begin{array}{l}00 A \\
\text { CENT }\left(G^{\prime}\right) /\left(G^{\prime}\right)\end{array}$ & 10,310 & 440 & & \\
\hline 12 & WILD-2/03 & & $6.1^{Y}$ & $\begin{array}{l}\text { BAL. } \\
\text { DIR. }\end{array}$ & $x$ & & & $\begin{array}{l}00 A \\
\text { CENT }\left(G^{\prime}\right) /\left(G^{\prime}\right)\end{array}$ & 8,260 & 490 & & \\
\hline
\end{tabular}


The large injected mass margins available for NEP missions provide the opportunity to select trajectories that can use the "excess" margin for mission enhancement, ie.

(1) stay time at the comet can be extended thus permitting a more relaxed encounter profile with more time available for remote science and site selection decision-making;

(2) hazards due to comet activity can be alleviated by arriving/departing at times further removed from perihelion, thus providing an added degree of confidence in mission success;

(3) total mission trip time can be reduced; or

(4) any combination of the above can be accomplished.

The figure on the facing page illustrates how the injected mass margin varies for NEP missions to Tempel 2 as values of stay time, arrival time and trip time are adjusted. Comparisons are shown for both spiral escape and direct injection $\left(C_{3}=4 \mathrm{~km}^{2} / \mathrm{sec}^{2}\right)$ trajectories.

The oversize points plotted in the figure reference a "nominal" mission characterized by a mininum stay time requirement of approximately 32 days with outbound and return trajectories optimized to provide maximum mass margins. Furthermore, comet arrival/departure dates for the "nominal" mission permit cometary dust coverage of up to $20 \%$ of the spacecraft surfaces during the encounter phase. NEP trajectories which satisfy these criteria were found to provide margins of approximately $7600 \mathrm{~kg}$ for the spiral escape made and $4300 \mathrm{~kg}$ for the direct injection mode with trip times of 6.7 years and 5.5 years respectively.

Changing the arrival/departure dates at Tempel 2 from $T_{p}-66 d / T_{p}-34 d$ to $T_{p}-136 d / T_{p}-74^{d}$, essentially doubles the stay time (from $32 \mathrm{~d}$ to $60 \mathrm{~d}$ ) and reduces the dust hazard by a factor of 10 (from an expected coverage of $20 \%$ to $2 \%$ ). With these new dates, the available performance margins for the two NEP flight modes still remain high at $6900 \mathrm{~kg}$ for the spiral mode and $3900 \mathrm{~kg}$ without spiralling; and the mission durations are not appreciably affected.

As shown by the curves plotted in the figure, the mission durations can also be reduced to a limited extent by trading-off some of the remaining margin. It is seen for example, that extended stay time missions employing an Earth escape spiral can be reduced in total time to about 5.8 years and still retain approximately $4900 \mathrm{~kg}$ of margin. However, attempting to reduce the duration of such missions much beyond this point is shown by the graph to be clearly unrealistic; and for such applications it becomes preferrable to dispense with the time consuming escape spiral and employ the more direct, Centaur-based injection. With that approach, the mission could be performed in as little as 4.2 years with an injected mass margin of approximately $2600 \mathrm{~kg}$. Beyond this point, the trade-off of mass margin for trip time reduction becomes excessive. 


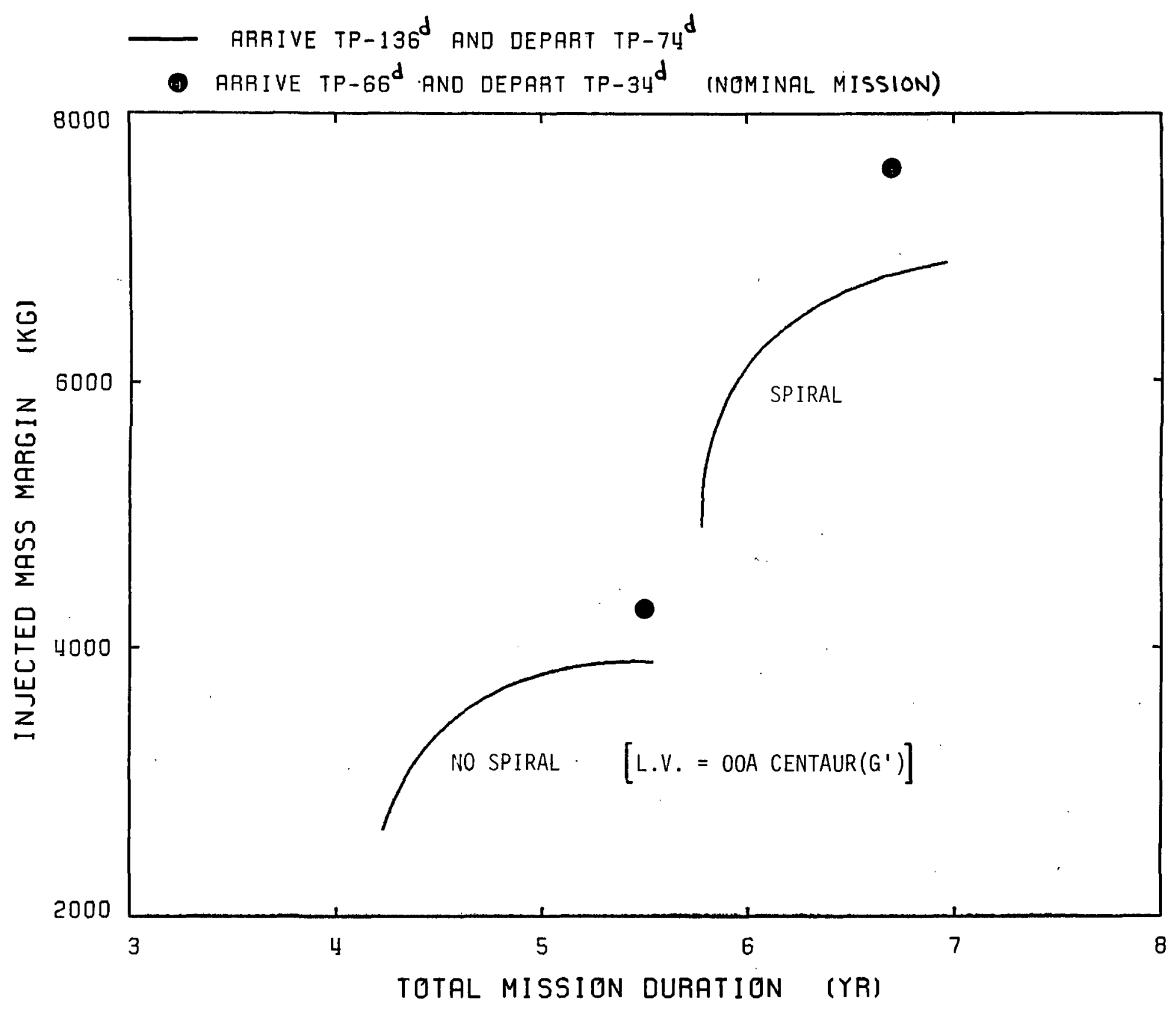

TEMPEL 2 NEP PERFORMANCE COMPARISON 


\section{Page intentionally left blank}

Page intentionally left blank 


\section{COSTING ASSUMPTIONS}

The proposed comet sample return mission would most certainly be a major new start involving development of hardware elements never before designed or tested. The only major exception would be the spacecraft bus, for which significant heritage has been assumed from ongoing projects in the core program of planetary exploration. This inheritance is applied at the engineering subsystem level and varies depending upon the flight delivery mode. Specifically, moderate structural configuration changes and certain box-level interface modifications to the spacecraft have been assumed for interfacing to a low thrust delivery system. For the ballistic cases, the space-storable propulsion system for deep-space maneuvers is assumed to be an essentially new development and is costed as an integral part of the spacecraft. Conversely, for the low thrust cases, the SEP and NEP system unit costs are included under transportation. Although the sample return capsule design should not require any new technologies, and certain subsystem components (e.g. a beacon transponder) may benefit from heritage, the capsule is costed as entirely new because of the uncertainties in sample pretection and recovery requirements. Both the sampler devices and long-lived landers are costed as entirely new developments which would require extensive proof of concept feasibility testing.

Mission operations are assumed to be conducted via a multi-mission operations system with minimum activities during both the outbound and return legs of the interplanetary cruise. Nominal encounter operations are assumed to require two months, allowing one month for target acquisition and approach maneuvering. An additional month is assumed for an aphelion encounter to allow increased difficulty in target acquisition. For mission options that carry a lander, its operations are costed assuming a nominal duration of $60 \%$ of the comet's orbit period in order to encompass both the perihelion and aphelion portions of the orbit.

Costs for retrieving, storing and analyzing the physical sample have not been estimlated, implying an assumption that such activities would be funded separately from the sample return project.

Transportation is defined as the recurring or "use" cost of Shuttle launches, upper stages and on-orbit assembly operations. SEP and NEP are treated as special cases of a high-cost, extended upper stage and included separately as part of the transportation systenl. The itemized costs shown are based on current NASA estimates for Shuttle launches and Centaur stages, and on preliminary SAI estimates for SEP, NEP and OOA. 
- ENGINEERING DESign heritage

SPACECRAFT BUS: MARINER MARK II (COMET RENDEZVOUS)

RETURN CAPSULE: NEW

LONG-LIVED LANDER: NEW

SAMPLER: NEW

- MULTI-MISSION OPERATIONS SYSTEM

MINIMUM ACTIVITY CRUISE OPERATIONS

TWO MONTHS INTENSIVE ACTIVITY AT ENCOUNTER ( 3 MONTHS FOR APHELION ENC, )

LANDER OPERATION DURING $60 \%$ OF COMET ORBIT PERIOD

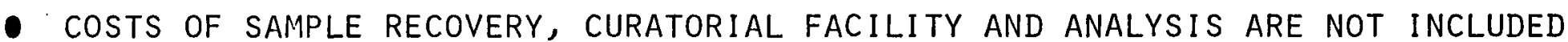

- tRANSPORTATION-RELATED UNit COSTS

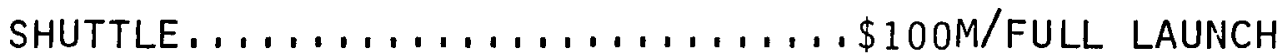

CENTAUR $G \ldots \ldots \ldots \ldots \ldots \ldots \ldots \ldots \ldots, \$ 35 M$

CENTAUR $G^{\prime} \ldots \ldots \ldots \ldots \ldots \ldots \ldots \ldots \ldots, \ldots 45 M$

SOLAR ELECTRIC PROPULSION, , , ,,$\$ 70 \mathrm{M}$

NUCLEAR ELECTRIC PROPULSION, , . .\$175M

ON-ORBIT-ASSEMBLY $\ldots \ldots \ldots \ldots \ldots \ldots, \$ 10 M / F L I G H T$ ASSEMBLY 


\section{COST ESTIMATE FOR TEMPEL-2 MISSION OPTION \#6}

Cost estimates for the individual elements which comprise Mission Option \#6 are shown as an example of the method used for cost estimation. Hardware development refers to the design, fabrication, assembly and test of a fully flight-qualified spacecraft, i.e. cost of the vehicle prior to launch stack integration. Each vehicle is treated as an independent development project, with its own project management, hardware development and spacecraft-level integration and test cost elements. Further details may be found in the Appendix to this report.

The program-level elements consist of activities which apply either only before launch, as in subcontracting and vehicle integration, only after launch for science data analysis, or throughout the entire mission program, as in operations and management. For this costing scenario, it has been presumed that all hardware elements except the spacecraft are developed via the major system contract mode. Thus, subcontracting refers to costs associated with monitoring and administering these systell contracts. Vehicle integration refers to costs associated with assembling the various hardware eleinents into a launch/flight stack. Mission operations includes costs for mission design, launch operations and cruise and encounter operations. Data analysis encompasses the costs of cataloging and analyzing the returned science data and, in general, is a function of the number and complexity of science investigations and the nominal encounter duration. Program management includes costs for integrating and managing the various other elenents into a cohesive program. Finally, because of the preliminary yet ambitious concept for such a mission as this to Tempel-2, a liberal contingency of $30 \%$ has been applied to the net cost estimate, leading, in the case of Mission Option \#6, to a total cost estimate of nearly $\$ 625$ million. 
HARDWARE DEVELOPMENT PROJECTS

SPACECRAFT

RETURN CAPSULE

PENETRATOR SAMPLERS（2）

LANDER

PROGRAM-LEVEL ELEMENTS

SUBCONTRACTING

VEHICLE INTEGRATION

MISSION OPERATIONS

DATA ANALYSIS

PROGRAM MANAGEMENT

CONTINGENCY $\quad(30 \%)$

TOTAL
330.3

144.2

49.4

43.9

92.8

149.0

27.9

17.0

83.1

16.0

5.0
143.8

623.1

SHUTTLE, CENTAUR AND SEP UNIT COSTS ARE NOT INCLUDED 


\section{MISSION OPTIONS - COST}

The "Mission Options" table is now presented in completed form with the addition on the project and total program costs.

Project costs are seen to primarily reflect cost differences in sampling hardware (addition of a lander) and round trip time (particularly evident in the ballistic missions). The project costs range from a minimum of 455 million dollars for the 5 year SEP mission to Tempel-2 carrying only penetrators to a maximum of 740 million dollars for the 7 year NEP inission to Wild-2 carrying the drill samplers plus a lander.

To arrive at the total cost of a program, the transportation cost must be added to the project incurred cost for each of the options. Note that in this set only the ballistic options require more than a single Shuttle launch and on-orbit assembly. (NEP missions without an Earth escape spiral would require on-orbit fueling, but those mission options were not included in this set). However, not all those launches require the full cargo bay. For those cases we have assumed a cost sharing policy and very roughly estimated its effect.

The total cost of transportation elements over the set of mission options range from 215 to 275 million dollars. Adding these to the project costs, brings the total program cost for a comet nucleus sample return mission to the range 670 million to slightly over 1 billion dollars. The minimum and maximum cost options remain the same. 
MISSION OPTIOHS

\begin{tabular}{|c|c|c|c|c|c|c|c|c|c|c|c|c|}
\hline \multirow{2}{*}{ OPTION } & \multirow{2}{*}{ COMET/YR } & \multicolumn{2}{|c|}{ TOTAL $T_{M}$} & \multirow{2}{*}{$\begin{array}{l}\text { FLIGHT } \\
\text { MODE }\end{array}$} & \multicolumn{3}{|c|}{ SAMPLER CONCEPT } & \multirow{2}{*}{ 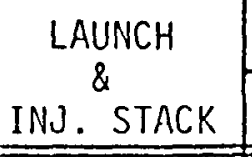 } & \multicolumn{2}{|c|}{ INJECTED MASS (KG) } & \multicolumn{2}{|c|}{ COSTS (' $84 \$ M)$} \\
\hline & & $R_{p}$ & $R_{A}$ & & PEN. & DRL. & LDR. & & REQ'D & MARGIN & PROJECT & TOTAL \\
\hline 1 & ENCKE/03 & $6.1^{Y}$ & & SEP & $x$ & & & $\begin{array}{l}\text { SHUTTLE } \\
\operatorname{CENT}\left(G^{\prime}\right)\end{array}$ & 5,260 & 950 & 470 & 685 \\
\hline 2 & ENCKE $/ 03$ & $6.1^{Y}$ & & SEP & $x$ & & $x$ & $\begin{array}{l}\text { SHUTTLE } \\
\text { CENT }\left(G^{\prime}\right)\end{array}$ & 5,540 & 660 & 635 & 850 \\
\hline 3 & ENCKE $/ 03$ & $7.0 Y$ & & NEP & & $x$ & $x$ & SHUTTLE & 14,760 & 5,240 & 730 & 1,005 \\
\hline 4 & TEMPEL - $2 / 05$ & $11.1^{Y}$ & & $\begin{array}{l}\text { BAL. } \\
\triangle V E G A\end{array}$ & $x$ & & & $\begin{array}{l}00 A \\
\operatorname{CENT}\left(G^{\prime}\right) /(G)\end{array}$ & 13,320 & 1,590 & 660 & 900 \\
\hline 5 & TEMPEL - 2/05 & $5.0^{Y}$ & & SEP & $x$ & . & & $\begin{array}{l}\text { SHUTTLE } \\
\text { CENT }\left(G^{\prime}\right)\end{array}$ & 5,220 & 980 & 455 & 670 \\
\hline 6 & TEMPEL-2/05 & $5.0^{Y}$ & & SEP & $x$ & & $x$ & $\begin{array}{l}\text { SHUTTLE } \\
\text { CENT }\left(G^{\prime}\right)\end{array}$ & 5,290 & 910 & 625 & 840 \\
\hline 7 & TEMPEL - 2/05 & $6.7 Y$ & & NEP & & $x$ & $x$ & SHUTTLE & 12,410 & 7,590 & 735 & 1,010 \\
\hline 8 & HILD-2/03 & $6.0^{Y}$ & & SEP & $x$ & & & $\begin{array}{l}\text { SHUTTLE } \\
\operatorname{CENT}\left(G^{\prime}\right)\end{array}$ & 4,670 & 1,530 & 470 & 685 \\
\hline 9 & HILD-2/03 & $6.0^{Y}$ & & SEP & $x$ & & $x$ & $\begin{array}{l}\text { SHUTTLE } \\
\text { CENT (G') }\end{array}$ & 4,740 & 550 & 640 & 855 \\
\hline 10 & HILD-2/03 & $7.0^{Y}$ & & NEP & & $x$ & $x$ & SHUTTLE & 13,870 & 6,130 & 740 & 1,015 \\
\hline 11 & HILD-2/03 & $8.9^{Y}$ & & $\begin{array}{l}\text { BAL. } \\
\text { DIR. }\end{array}$ & $x$ & & & $\begin{array}{l}00 A \\
\text { CENT(G') }\left(G^{\prime}\right)\end{array}$ & 10,310 & 440 & 615 & 865 \\
\hline 12 & WILD-2/03 & & $6.1^{Y}$ & $\begin{array}{l}\text { BAL. } \\
\text { DIR. }\end{array}$ & $x$ & & & $\begin{array}{l}\text { OOA } \\
\text { CENT }\left(G^{\prime}\right) /\left(G^{\prime}\right)\end{array}$ & 8,260 & 490 & 545 & 795 \\
\hline
\end{tabular}




\section{Page intentionally left blank}

Page intentionally left blank 


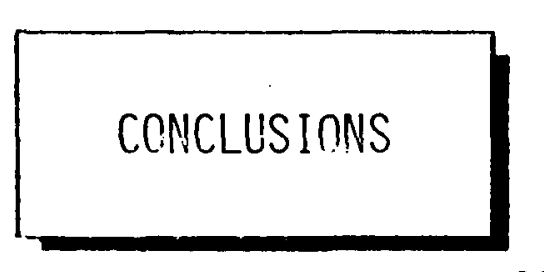


- a pRecursor comet RendezVous mission is neEded for nuCleus characterization; COMET SELECTED FOR SAMPLE RETURN SHOULD HAVE SIMILAR PROPERTIES

- Site characterization/SELEction CAN BE DONE by REMOTE SPACECRAFt With SAMPLing ACCOMPLISHED IN SHORT PERIOD OF TIME BY RECOVERABLE NUCLEUS SAMPLER

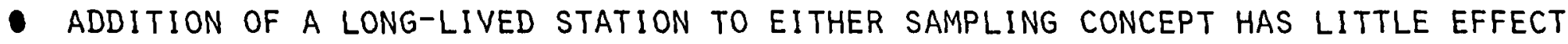
ON LAUNCH MARGINS AND NO EFFECT ON THE MISSIONS CAPTURED

- RETURNed SAMPLES SHOULD Be INJECTEd InTO A SHUTtLe-COMPATIBLE RECOVERY ORBIT WHERE THEY CAN BE QUICKLY RETRIEVED

- one-meter length nuCleus cores can be thermally maintained by passive techniques AT LESS THAN $120 \mathrm{~K}$ FROM TIME OF SAMPLING UNTIL SHUTTLE RECOVERY

- LOW THRUST PROPULSION (SEP OR NEP) IS ENABLING TECHNOLOGY ON THE BASIS OF MASS MARGIN, REASONABLE TRIP TIME, AND TARGET SELECTION FLEXIBILITY

- total mission cost is estimated to be in the RANGe 455-740M (Fy' 84\$) OR 670-1015M WITH TRANSPORTATION COSTS INCLUDED 
- open Issues

- DEFINITION OF COMET NUCLEUS PROPERTIES

- REFINED CHARACTERIZATION OF COMA ENVIRONMENT/HAZARDS

- SAMPLING DEPTH

- APHELION MISSION OPTIONS/DESIGN IMPLICATIONS

- SAMPLE CONTAMINATION DURING SAMPLING PROCESS

- CRitical technologies/design

- LOW THRUST PROPULSION

- AUTOMATED RENDEZVOUS, DOCKING, \& SAMPLE TRANSFER

- SAMPLER DESIGN \& HARDWARE

- ENVIRONMENTAL（THERMAL \& RADIATION） PROTECTION FOR SAMPLE 


\section{Page intentionally left blank}

Page intentionally left blank 


\section{SUPPORTING DATA APPENDIX}




\section{Page intentionally left blank}

Page intentionally left blank 


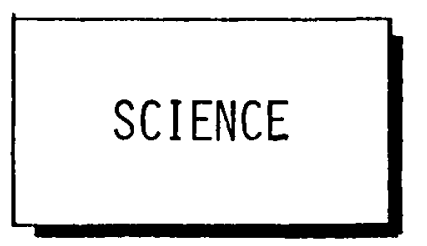


- primary objective

O TO COLLECT A PRISTINE SAMPLE OF A COMET FROM BENEATH THE SURFACE THERMAL BOUNDARY LAYER OF ITS NUCLEUS AND RETURN IT TO EARTH IN A MINIMALLY ALTERED STATE

- secondary objectives

0 TO CHARACTERIZE THE COMET TO A LEVEL CONSISTENT WITH A PRECURSOR RENDEZVOUS MISSION (IF DONE TO A DIFFERENT COMET)

O TO MONITOR COMET DYNAMICS THROUGH PERIHELION AND APHELION WITH A LONG-LIVED LANDER

- TO DETERMINE THE SUBSURFACE PROPERTIES OF THE NUCLEUS IN AN AREA LOCAL TO THE SAMPLED CORE 


\begin{tabular}{|c|c|c|c|}
\hline & RENDEZVOUS & $\begin{array}{l}\text { PER I HELION } \\
\text { CSR }\end{array}$ & $\begin{array}{l}\text { APHELION } \\
\text { CSR }\end{array}$ \\
\hline SOLID STATE IMAGING (NARROW \& WIDE ANGLE) & $\mathrm{x}$ & $\mathrm{x}$ & $x$ \\
\hline THERMAL IR RADIOMETER & $x$ & $x$ & $x$ \\
\hline IR REFLECTANCE MAPPER & $x$ & $x$ & $\mathrm{x}$ \\
\hline GAMMA-RAY SPECTROMETER (EXCEPT W/NEP) & $x$ & $x$ & $x$ \\
\hline X-RAY SPECTROMETER & $x$ & $x$ & \\
\hline NEUTRAL MASS SPECTROMETER & $x$ & $x$ & $x$ \\
\hline ION MASS SPECTROMETER & $x$ & $x$ & $x$ \\
\hline DUST COUNTER & $x$ & $x$ & \\
\hline DUST COLLECTOR/ANALYZER & $x$ & & \\
\hline RADAR ALTIMETER & $x$ & $x(1)$ & $\times(1)$ \\
\hline EUV SPECTROPHOTOMETER & $x$ & & \\
\hline NEAR UV-VISIBLE SPECTROPHOTOMETER & $x$ & & \\
\hline MAGNETOMETER & $x$ & & \\
\hline FAST ION ANALYZER & $x$ & & \\
\hline ELECTROMAGNETIC SOUNDER & $x$ & $x(1)$ & $x(1)$ \\
\hline PLASMA WAVE ANALYZER & $x$ & & \\
\hline ELECTRON ANALYZER & $\mathrm{x}$ & & \\
\hline
\end{tabular}

(1) IF ELECTROMAGNETIC SOUNDER IS SELECTED IT COULD PERFORM ALTIMETER FUNCTION 


\begin{tabular}{|c|c|c|c|c|}
\hline & & $\begin{array}{c}\text { MASS } \\
(\mathrm{KG})\end{array}$ & $\begin{array}{l}\text { POWER } \\
(W)^{\prime}\end{array}$ & $\begin{array}{l}\text { DATA RATE } \\
(\text { KBPS })\end{array}$ \\
\hline * & SOLID STATE IMAGING (NARROW \& WIDE ANGLE) & 31 & 26 & 15 \\
\hline & THERMAL IR RADIOMETER & 10 & 6 & 1 \\
\hline * & IR REFLECTANCE MAPPER & 18 & 12 & 6 \\
\hline * & GAMMA-RAY SPECTROMETER（EXCEPT W/NEP） & 14 & 4 & 3 \\
\hline & $X$-RAY SPECTROMETER & 14 & 5 & 2 \\
\hline & NEUTRAL MASS SPECTROMETER & 5 & 12 & 2 \\
\hline * & ION MASS SPECTROMETER & 9 & 10 & $<1$ \\
\hline & DUST COUNTER & 5 & 10 & 0.1 \\
\hline * & RADAR ALTIMETER & 10 & 15 & 0.2 \\
\hline & TOTAL（PERIHELION CSR） & 116 & 100 & 30.3 \\
\hline & TOTAL (APHELION CSR) & 97 & 85 & 27.9 \\
\hline
\end{tabular}




\begin{tabular}{|c|c|c|c|}
\hline & $\begin{array}{l}\text { MASS } \\
(\text { KG })\end{array}$ & $\begin{array}{l}\text { POWER } \\
(W)^{2}\end{array}$ & $\begin{array}{l}\text { DATA RATE } \\
\text { (BPS) }\end{array}$ \\
\hline SOLID STATE IMAGING & 2 & 6 & 500 \\
\hline MASS SPECTROMETER & 5 & 12 & 200 \\
\hline TEMPERATURE TRANSDUCER & $<0.5$ & 1 & 10 \\
\hline PHOTOMETER & $<0.5$ & - & - \\
\hline SE I SMOMETER & 2 & 3 & 200 \\
\hline TRACKING & - & - & - \\
\hline TOTAL (2)(3) & 10 & 22 & 910 (1) \\
\hline
\end{tabular}

NOTES:

(1) WHEN COMET IS INACTIVE, DATA RATE CAN BE REDUCED TO $\simeq 100 \mathrm{BPS}$

(2) PENETRATOR SAMPLER ALSO INCLUDES TEMPERATURE TRANSDUCER AND ACCELEROMETER

(3) INSTRUMENTS TO PERFORM SURFACE COMPOSITION ANALYSIS HAVE NOT BEEN INCLUDED IN THE BASELINE PAYLOAD, BUT MAY BE ADDED IF CORE HOLE LOGGING IS DESIRED (APPLIED TO DRILL SAMPLER ONLY) 
- temperatURE CONTROL:

- environmental RECORD:

- INSTRUMENT REQUiREMENTS (TOTALS):
100 TO $120 \mathrm{~K}$

\section{TEMPERATURE}

PRESSURE

ENERGETIC PARTICLE DOSE

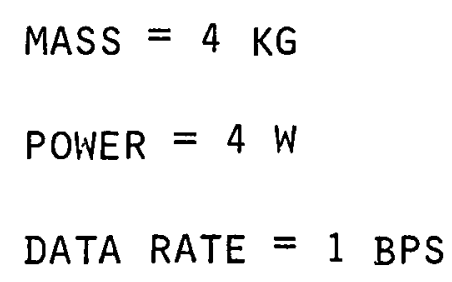




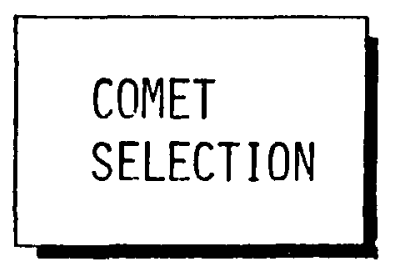


- the sample RETURN COMET SHOULd BE JUDGED USiNg the SAME CRITERIA ESTABLISHED FOR THE SELECTION OF A RENDEZVOUS TARGET

- these CRITERIA INCLUDE the FOLLOWING CONSIDERATIONS:

- BE CURRENTLY ACTIVE WITH A CLEARLY RETAINED VOLATILE INVENTORY, I.E, A GOOD GAS PRODUCER

O HAVE A WELL-IDENTIFIED NUCLEUS

- HAVE A LOW-INCLINATION ORBIT, I,E, < 15 DEgREES

0 HAVE A SHORT ORBIT PERIOD, I,E, $<7$ YEARS

0 GOOD EARTH-BASED VIEWING DURING ENCOUNTER, WHILE NOT NECESSARY, WOULD CERTAINLY BE AN ADVANTAGE

- ideally, the sample return target could be the same comet as selected for THE RENDEZVOUS MISSION; THIS HOWEVER IS CONSIDERED UNDULY RESTRICTIVE IF PROGRAM PLANNING FLEXIBILITY IS TO BE MAINTAINED 


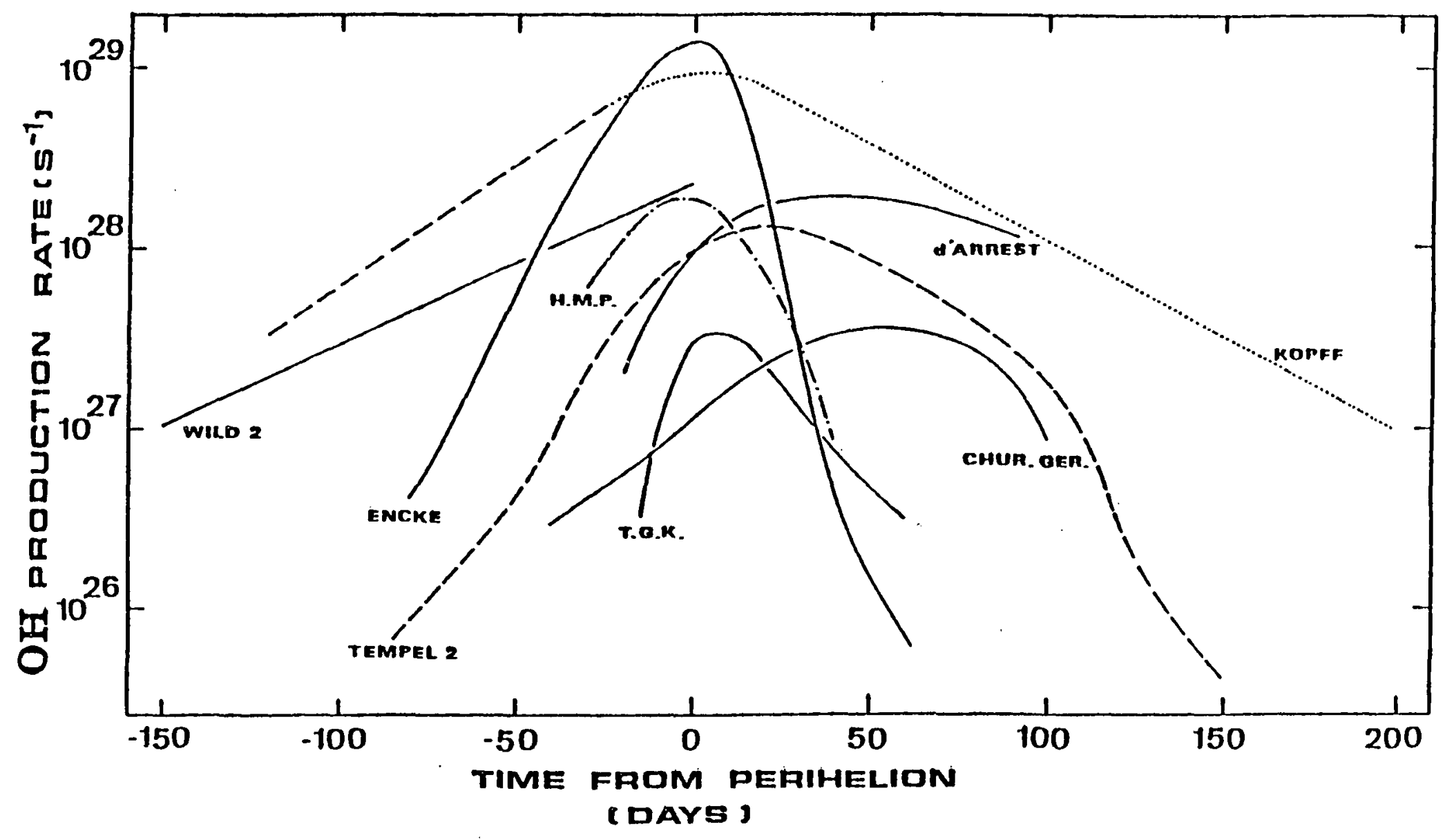

GAS PRODUCTION IN SHORT PERIOD COMETS (FESTOU, 1933) 


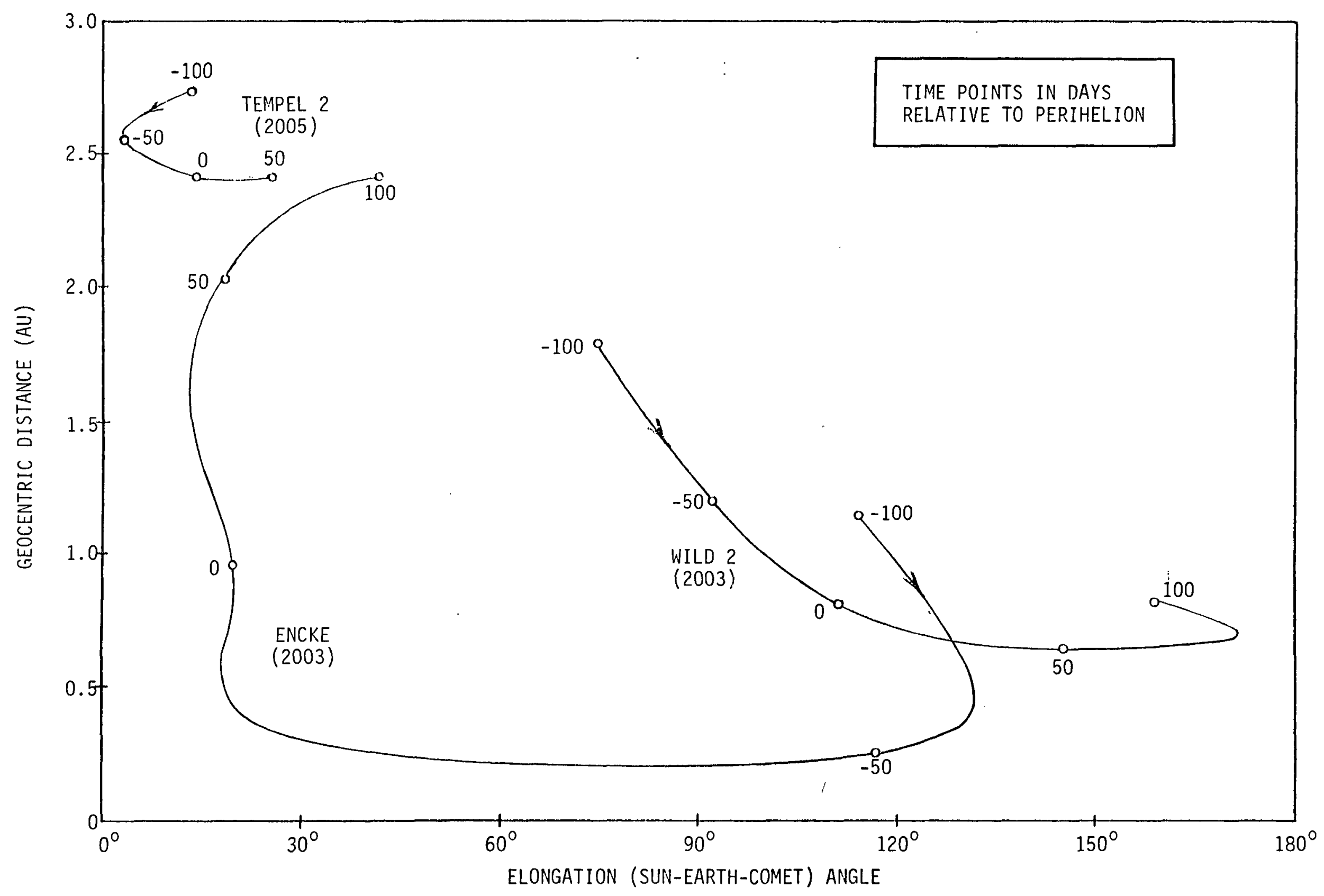




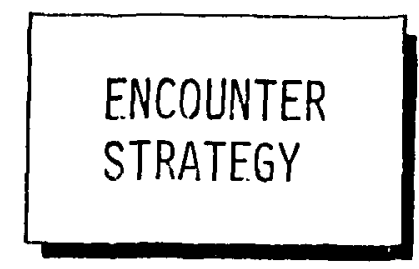


- globally characterize the nucleus (2M resolution a 200 kM altitude)

- evaluate and select candidate regions for sampling

- map siting regions at 4X global resolution (50 CM Resolution a 50 kM alt)

- Select sample sites

- establish "Forced-synchronous" orbit and commit sampler no. 1

- characterize site 1 at 5x Regional resolution (10 CM RESOlution @ 10 kM alt)

- recover sample no, 1 and return to safe altitude

- Reestablish "Forced-synchronous" ORBit and COMmit SAMPler no, 2

- characterize site 2 at 5x Regional resolution (10 CM Resolution a 10 kM alt)

- recover samiple no, 2 and leave

- complete encounter strategy as fast as possible tO Minimize DUST/gas/thermal ENVIRONMENTAL HAZARDS OF COMA 


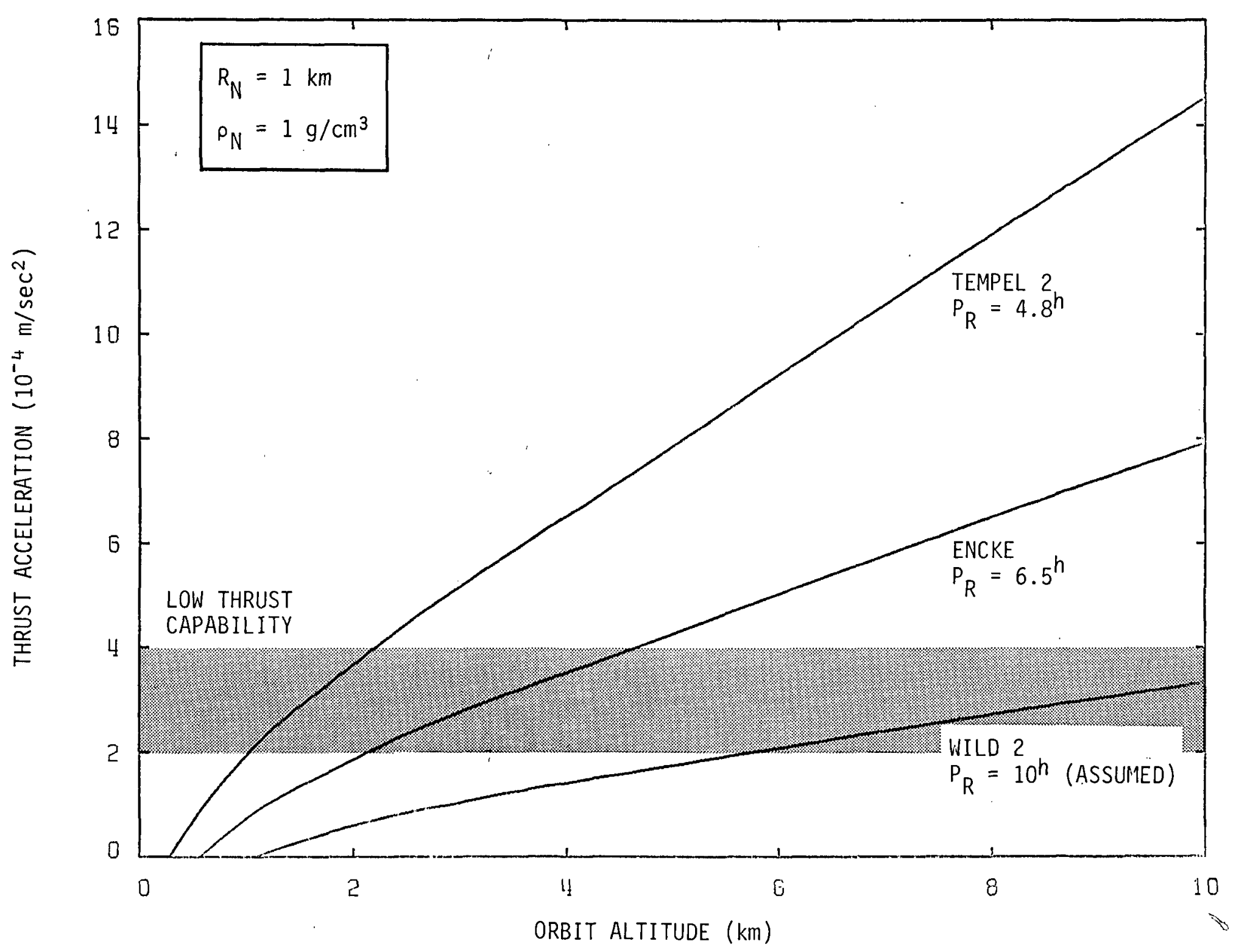

STATIONKEEPING TO MATCH COMET ROTATION IN FORCED CIRCILAR ORBIT 


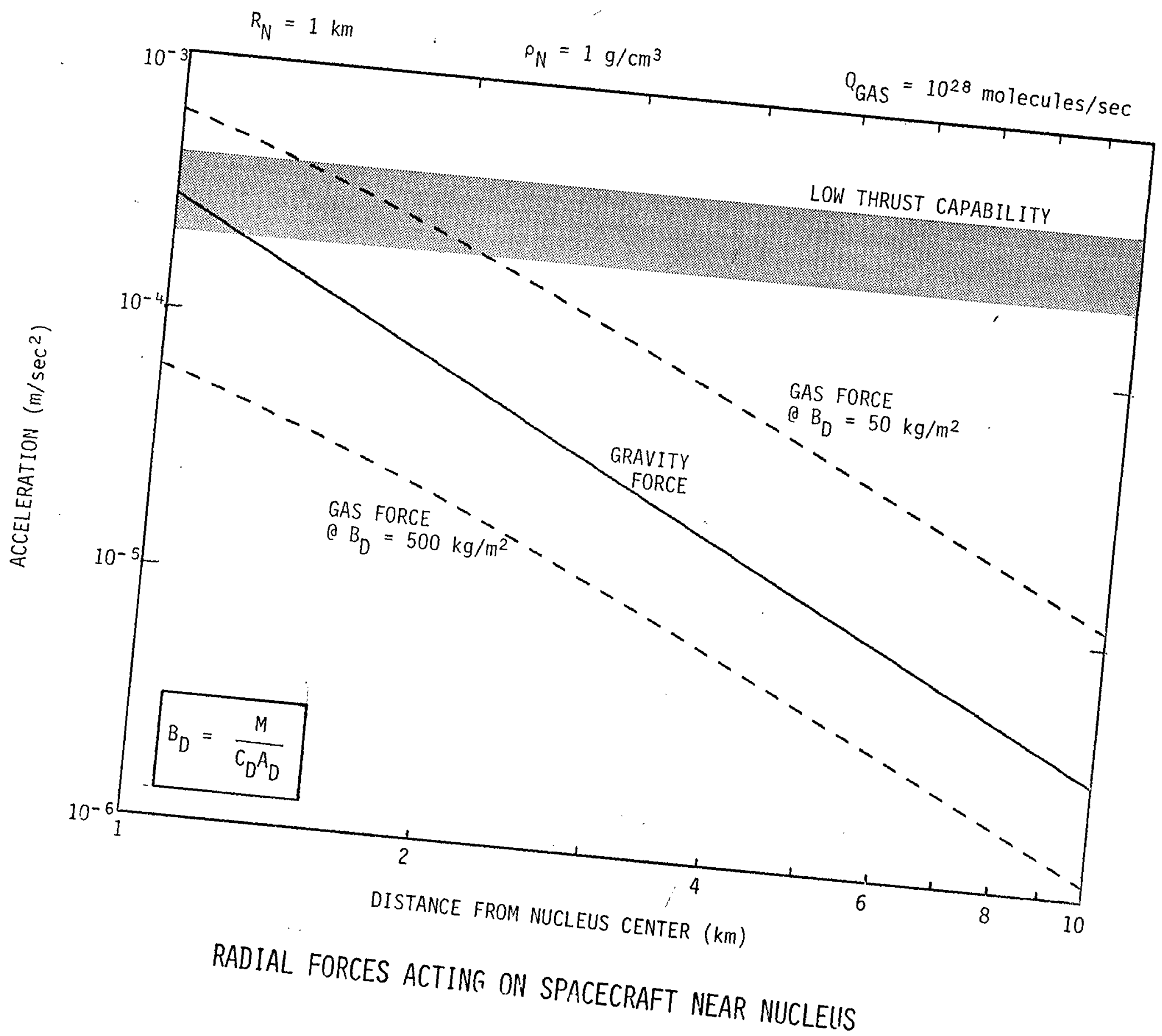




\section{ENCKE NEAR ENCOUNTER PROFILE}

\begin{tabular}{|c|c|c|c|c|c|c|}
\hline \multirow{2}{*}{\multicolumn{2}{|c|}{ PHASE }} & \multicolumn{2}{|c|}{ TIME } & \multirow[b]{2}{*}{ DURATI ON (DAYS) } & \multirow[b]{2}{*}{ ALTITUDE (KM) } & \multirow[b]{2}{*}{$\Delta V(M / S E C)$} \\
\hline & & BEG IN & END & & & \\
\hline GLOBAL & CHARACTER I ZATI ON & $T_{p}+22.2^{d}$ & $\mathrm{~T}_{\mathrm{p}}+28.2^{\mathrm{d}}$ & 6.0 & 200 & $\simeq 0$ \\
\hline REGION & SELECT & $T_{p}+28.2^{d}$ & $T_{p}+30.2^{d}$ & 2.0 & 200 & $\simeq 0$ \\
\hline TRANS & SFER & $T_{p}+30.2^{d}$ & $\mathrm{~T}_{\mathrm{p}}+31.2^{\mathrm{d}}$ & 1.0 & $200 \rightarrow 50$ & 3.5 \\
\hline REGION & MAP & $T_{p}+31.2^{d}$ & $\mathrm{~T}_{\mathrm{p}}+38.2^{\mathrm{d}}$ & 7.0 & 50 & $\simeq 0$. \\
\hline TRANS & SFER & $T_{p}+38.2^{d}$ & $T_{p}^{+}+38.5^{d}$ & 0.3 & $50 \rightarrow 100$ & 3.5 \\
\hline SITE SE & ELECT & $T_{p}+38.5^{d}$ & $T_{p}+43.6^{d}$ & 5.1 & 100 & $\simeq 0$ \\
\hline TRANS & SFER & $T_{p}+43.6^{d}$ & $T_{p}+44.2^{d}$ & 0.6 & $100 \rightarrow 10$ & 3.5 \\
\hline SAMPLIN & NG NO, 1 & $T_{p}+44.2^{d}$ & $T_{p}+44.6^{d}$ & 0.4 & 10 & 29.1 \\
\hline TRANS & SFER/HOLD/TRANSFER & $T_{p}+44.6^{d}$ & $T_{p}+48.6^{d}$ & 4.0 & $10 \rightarrow 100 \rightarrow 10$ & 14.0 \\
\hline SAMPLIN & NG NO. 2 & $T_{p}^{+}+48.6^{d}$ & $T_{p}+49.0^{d}$ & 0.4 & 10 & 29.1 \\
\hline$-\cdots$ & $----\cdots-\cdots$ & --- & --- & $---\cdots-$ & $-\cdots-\cdots$ & ----- \\
\hline TOTALS & & & & 26.8 & & 82.7 \\
\hline
\end{tabular}




\section{TEMPEL 2 INEAR ENCOUNTER PROFILE}

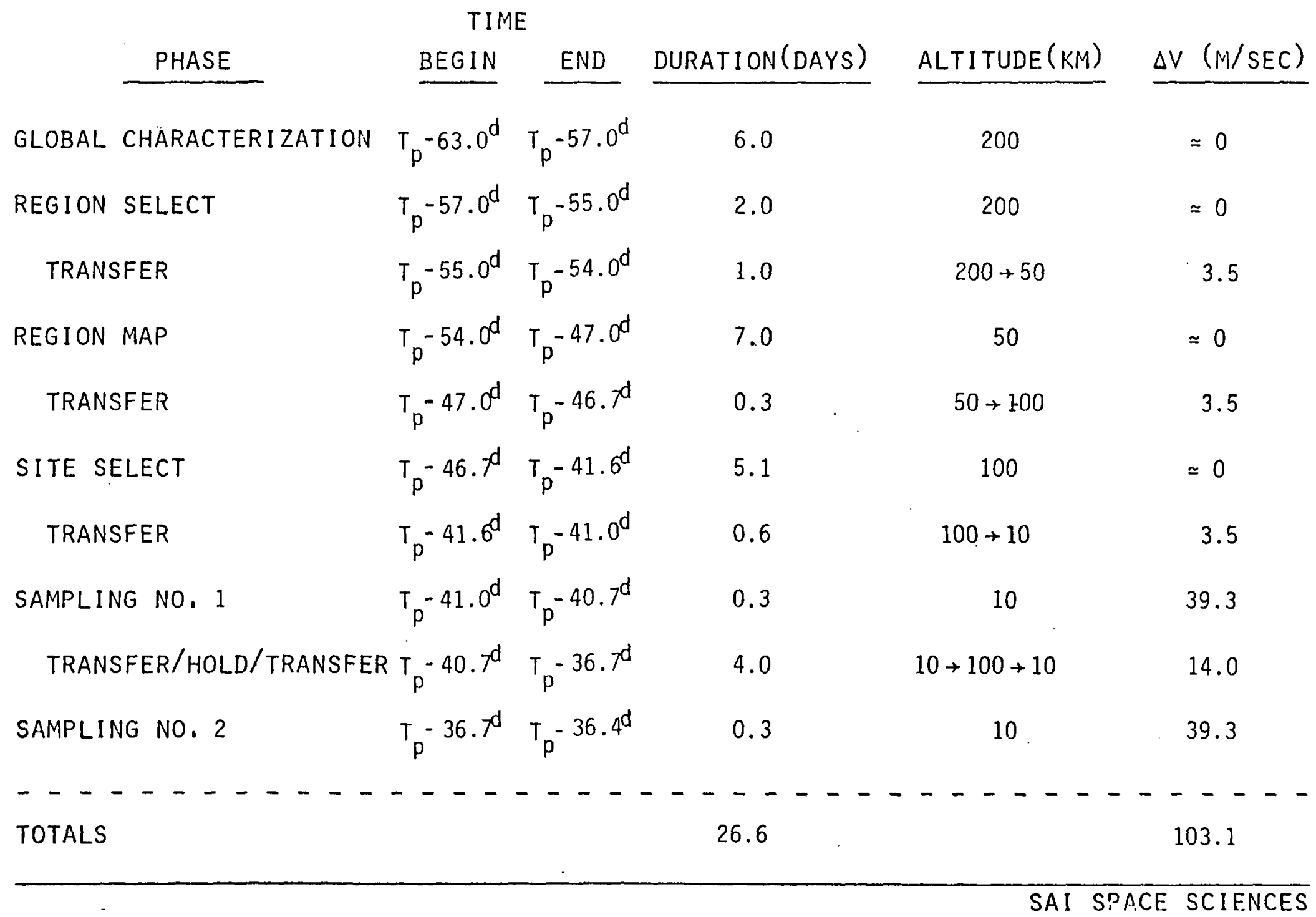




\begin{tabular}{|c|c|c|c|c|c|c|}
\hline \multirow{2}{*}{\multicolumn{2}{|c|}{ PHASE }} & \multicolumn{2}{|c|}{ TIME } & \multirow{2}{*}{ DURATION (DAYS) } & \multirow[b]{2}{*}{ ALTI I TUDE (KM) } & \multirow[b]{2}{*}{$\Delta V(M / S E C)$} \\
\hline & & BEG IN & END & & & \\
\hline GLOBAL & CHARACTERIZATION & $T_{p}-206.0^{d}$ & $T_{p}-200.0^{d}$ & 6.0 & 200 & $\simeq 0$ \\
\hline REG I ON & SELECT & $T_{p}-200.0^{d}$ & $T_{p}-198.0^{d}$ & 2.0 & 200 & $\simeq 0$ \\
\hline TRANS & SFER & $T_{F}-198.0^{d}$ & $T_{p}-197.0^{d}$ & 1.0 & $200 \rightarrow 50$ & 3.5 \\
\hline REGION & MAP & $T_{p}-197.0^{d}$ & $T_{p}-190.0^{d}$ & 7.0 & 50 & $\simeq 0$ \\
\hline TRANS & SFER & $T_{p}-190.0^{d}$ & $T_{p}-189.7^{d}$ & 0.3 & $50+100$ & 3.5 \\
\hline SITE SE & ELECT & $T_{p}-189.7^{d}$ & $T_{p}-184.6^{d}$ & 5.1 & 100 & $\simeq 0$ \\
\hline TRANS & SFER & $T_{p}-184.6^{d}$ & $T_{p}-184.0^{d}$ & 0.6 & $100 \rightarrow 10$ & 3.5 \\
\hline SAMPLIN & NG NO, 1 & $T_{p}-184.0^{d}$ & $T_{p}-183.4$ & 0.6 & 10 & 18.8 \\
\hline TRANS & SFER/HOLD/TRANSFER & $T_{p}-183.4^{d}$ & $T_{p}-179.4^{d}$ & 4.0 & $10+100+10$ & 14.0 \\
\hline SAMPLIN & NG NO. 2 & $T_{p}-179.4^{d}$ & $T_{p}-178.8^{d}$ & 0.6 & 10 & 18.8 \\
\hline $\begin{array}{l}---- \\
\text { TOTALS }\end{array}$ & $-\cdots-\cdots-\cdots$ & $-\cdots$ & $-\cdots$ & $\begin{array}{c}--\cdots \\
27.2\end{array}$ & $-\cdots--$ & $\begin{array}{c}---\cdots \\
62.1\end{array}$ \\
\hline
\end{tabular}




\section{Page intentionally left blank}

Page intentionally left blank 


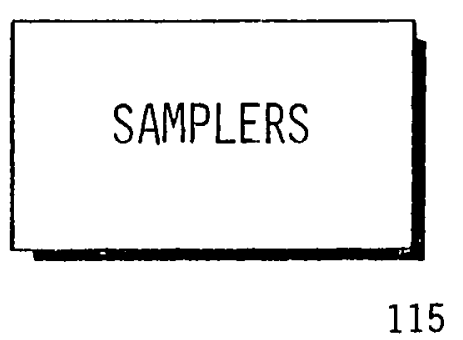




\section{CONCEPT CONSTRAINTS/GUIDELIMES}

- SAMPLing guidelines

- SUBSURFACE SAMPLE - CORE SAMPLE OF 1 METER LENGTH MINIMUM (ASSUMED $>1$ THERMAL SKIN DEPTH)

- ACQUIRE TWO SEPARATE SAMPLES PREFERABLY FROM TWO DIFFERENT SITES

- LIMITED IN SITU DOCUMENTATION OF SAMPLES - MONITOR TEMPERATURE, NOTE MAXIMUM PENETRATION DEPTH

- OPTIONAL EMPLACEMENT OF A LONG-LIVED（1 COMET PERIOD） STATION TO MONITOR AND PROVIDE MORE EXTENSIVE DOCUMENTATION OF SAMPLING SITE

- REMOTE SAMPLER - AVOID HAZARDS INVOLVED WITH EXTENDED CLOSE APPROACH OF SPACECRAFT

- AVOID THERMAL, CHEMICAL AND RADIATION CONTAMINATION OF SAMPLER

- CANDIDATE CONCEPTS

- IMPACT SAMPLER - SOFT LOOSE SURFACE MATERIAL

$\checkmark$ SELECTED CONCEPT

- DRILLING SAMPLER - HARD RIGID SURFACE

$\checkmark$ SELECTED CONCEPT

- MULTI-SEGMENTED CORE SAMPLER

- ZERO-IMPULSE CORING TECHNIQUES

- FLEXIBLE CORE TUBE 


\begin{tabular}{|c|c|c|}
\hline EVENT & TIME & COMMENTS \\
\hline DEPLOY & - & NOMINAL SEPARATION SPEED OF $12 \mathrm{~m} / \mathrm{s}$ \\
\hline COAST & 14 MIN & \\
\hline IMPACT & - & $\begin{array}{l}\text { NOTE IMPACT DECELERATION AND REPORT } \\
\text { TO SPACECRAFT }\end{array}$ \\
\hline SAMPLE & $192-400 \mathrm{MIN}$ & $\begin{array}{l}\text { CLOSE OFF SAMPLING TUBE; WAIT } 2 / 3 \\
\text { OF COMET REVOLUTION }\end{array}$ \\
\hline LAUNCH & - & RETURN AT NOMINAL SPEED OF $5 \mathrm{~m} / \mathrm{s}$ \\
\hline COAST & $30 \mathrm{MIN}$ & \\
\hline CAPTURE & - & SPACECRAFT IS ACTIVE PARTNER \\
\hline SAMPLE STORAGE & 5 MIN & $\begin{array}{l}\text { SEPARATE FROM SAMPLER SUPPORT; } \\
\text { STORE IN SAMPLE RETURN SYSTEM }\end{array}$ \\
\hline TOTAL & $251-459$ MIN & $\begin{array}{l}10 \text { MIN ADDED FOR ALL EVENTS WHICH } \\
\text { HAVE NO SPECIFIC TIME NOTED }\end{array}$ \\
\hline
\end{tabular}




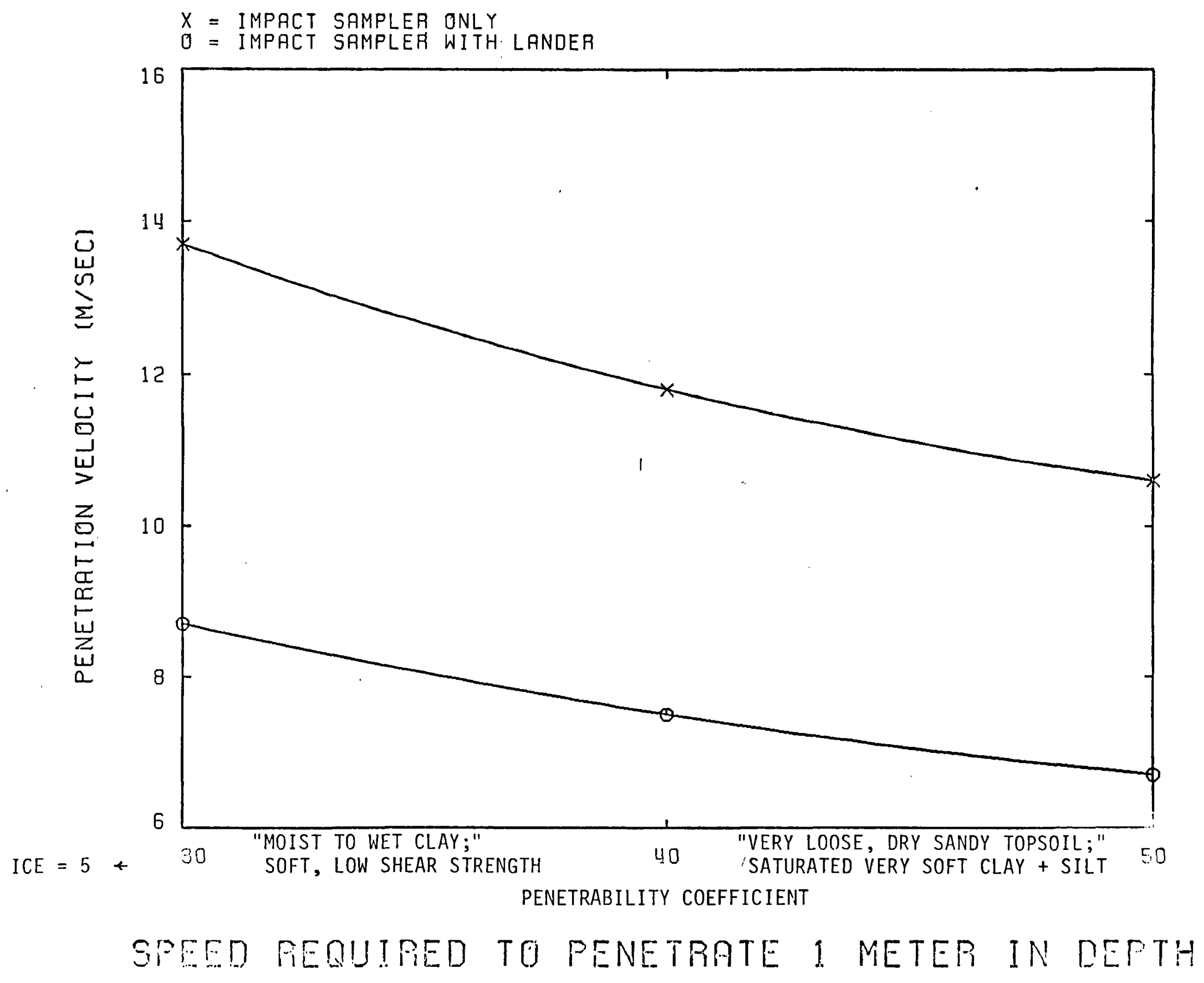



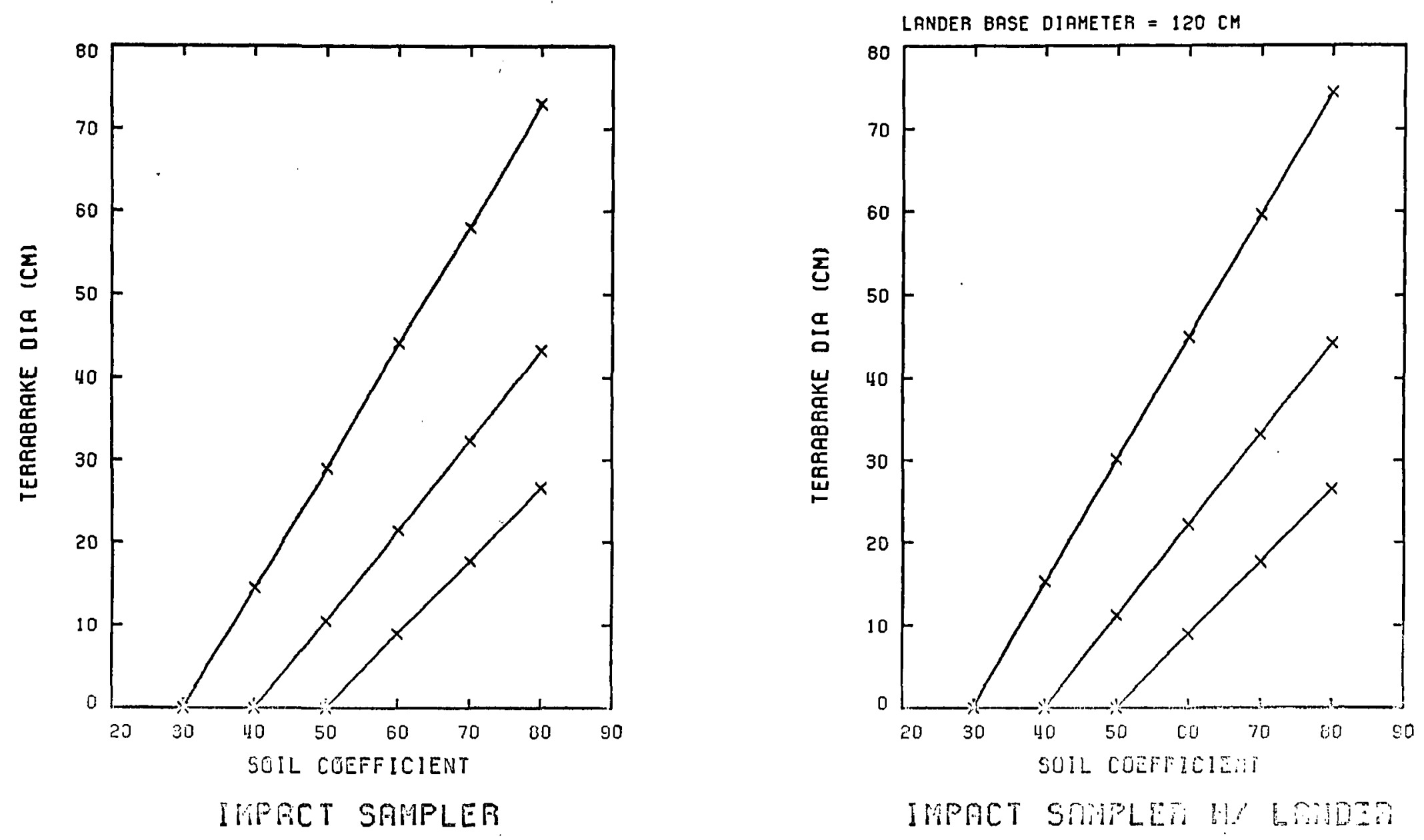

TERRABRAKE DIAMETER REQUJIRED TO STOP SAMPLER 


\begin{tabular}{|c|c|c|}
\hline EVENT & TIME & COMMENTS \\
\hline DEPLOY & - & NOMINAL SEPARATION SPEED OF $3 \mathrm{~m} / \mathrm{s}$ \\
\hline COAST & 60 MIN & \\
\hline IMPACT & - & $\begin{array}{l}\text { NOTE IMPACT DECELERATION AND REPORT } \\
\text { TO SPACECRAFT }\end{array}$ \\
\hline SAMPLE & $192-400 \mathrm{MIN}$ & $\begin{array}{l}\text { CLOSE OFF SAMPLING TUBE; WAIT } 2 / 3 \\
\text { OF COMET REVOLUTION }\end{array}$ \\
\hline LAUNCH & - & RETURN AT NOMINAL SPEED OF $5 \mathrm{~m} / \mathrm{s}$ \\
\hline COAST & $30 \mathrm{MIN}$ & \\
\hline CAPTURE & - & SPACECRAFT IS ACTIVE PARTNER \\
\hline SAMPLE STORAGE & 5 MIN & $\begin{array}{l}\text { SEPARATE FROM SAMPLER SUPPORT; } \\
\text { STORE IN SAMPLE RETURN SYSTEM }\end{array}$ \\
\hline TOTAL & 297-505 MIN & $\begin{array}{l}10 \text { MIN ADDED FOR ALL EVENTS WHICH } \\
\text { HAVE NO SPECIFIC TIME NOTED }\end{array}$ \\
\hline
\end{tabular}




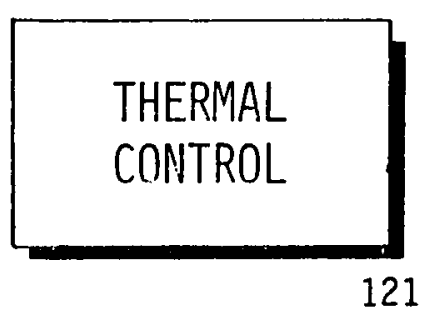




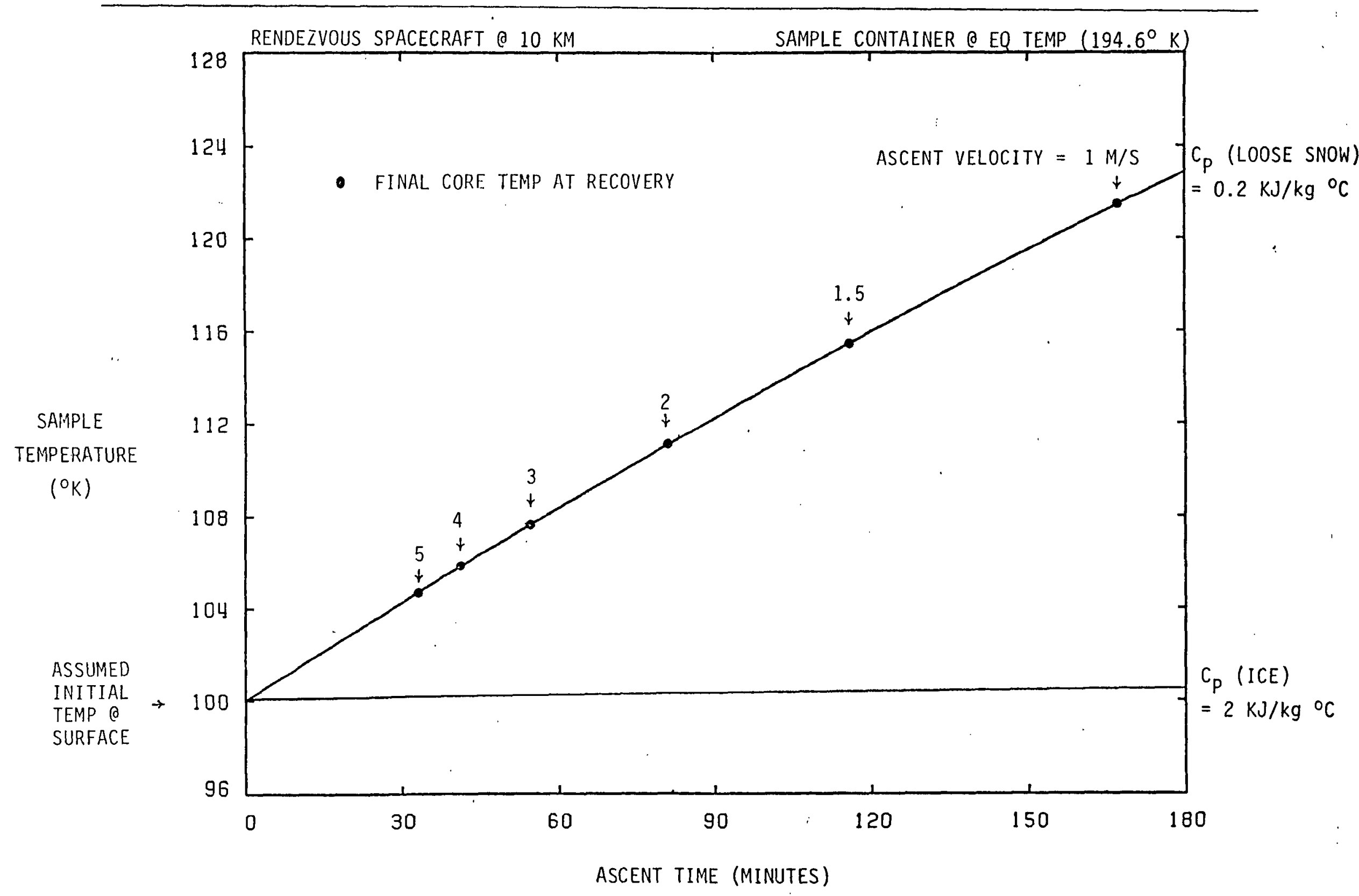


- PERFORMANCE OF THERMAL CONTROL SURFACES AFTER IMPACT OR LAYERING BY COMETARY DUST

- potential thermal CONTAMINATION SOURCES In SAMPLING PROCESSES

- heAT GENERATED BY CORING DRILL

- ENHANCED THERMAL CONDUCTION TO SUBSURFACE MATERIAL

- HEAT PRODUCED BY EXPLOSIVE CHARGES USED TO ANCHOR DRILL

- CORE TUBE TEMPERATURE PRIOR TO INSERTION

- NEED FOR DETAILED THERMAL ANALYSIS INCORPORATING CONFIGURATIONAL ASPECTS OF PROBLEM

- RADIATION HEAT TRANSFER BETWEEN SPACECRAFT/LANDER SUBSYSTEMS AND SAMPLE

- THERMAL PENETRATION CONDUCTANCES THROUGH MLI DUE TO STRUCTURE/SUPPORT

- SENSITIVITY OF ANALYSIS TO ASSUMED PHYSICAL AND THERMAL CHARACTERISTICS OF COMET MATERIAL

- METHODOLOGY FOR CORE RETENTION AND CAPPING PRIOR TO ASCENT

- active thermal CONTROL tRADEofFs

- SHOCK, VIBRATION, G-LOADING DURING EARTH ORBIT RETRO MANEUVER 


\section{Page intentionally left blank}

Page intentionally left blank 


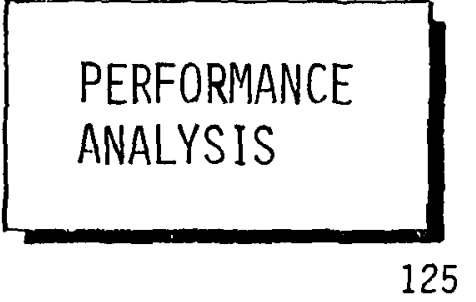




\section{MISSION FLIGHT CHARACTERISTICS}

\begin{tabular}{|c|c|c|c|c|c|c|c|c|c|}
\hline COMET & $\begin{array}{l}\text { FLIGHT } \\
\text { MODE }\end{array}$ & $\begin{array}{l}\text { TRAJ, } \\
\text { TYPE }\end{array}$ & $\begin{array}{l}\text { ROUND TRIP } \\
\text { TIME (YEARS) }\end{array}$ & $\begin{array}{l}\text { LAUN } \\
\text { DAT }\end{array}$ & $\begin{array}{l}\mathrm{NCH} \\
\text { IE }\end{array}$ & $\begin{array}{l}\text { ARRIVAL } \\
\text { DATE }\end{array}$ & $\begin{array}{l}\text { RETURN } \\
\text { DATE }\end{array}$ & $C_{3}\left(\begin{array}{l}\text { LUNCH } \\
(\mathrm{SEC})^{2}\end{array}\right.$ & $\begin{array}{c}\text { TOTAL SPACECRAFT* } \\
\text { CHEMICAL AV } \\
(\mathrm{KM} / \mathrm{SEC})\end{array}$ \\
\hline \multirow[t]{5}{*}{ ENCKE } & BALLISTIC & DIRECT & 8.0 & MAR & 2000 & DEC 2003 & MAR 2008 & 65.1 & 14.159 \\
\hline & BALLISTIC & $\triangle V E G A$ & 10.1 & JAN & 1998 & DEC 2003 & MAR 2008 & 28.7 & 14.572 \\
\hline & SEP & DIRECT & 6.1 & FEB & 2001 & DEC 2003 & MAR 2007 & 25.0 & 3.980 \\
\hline & NEP & SPIRAL ESC. & 7.0 & OCT & 1999 & DEC 2003 & NOV 2006 & $\longrightarrow$ & 0.222 \\
\hline & NEP & NO SPIRAL & 5.9 & JAN & 2.001 & DEC 2003 & NOV 2006 & 4.0 & 0.222 \\
\hline \multirow[t]{5}{*}{ TEMPEL 2} & BALLISTIC & DIRECT & 9.0 & JUL & 2000 & DEC 2004 & JUL 2009 & 74.3 & 11.381 \\
\hline & BALLISTIC & $\triangle V E G A$ & 11.1 & JUN & 1998 & DEC 2004 & JUL 2009 & 28.4 & 12.134 \\
\hline & SEP & DIRECT & 5.0 & AUG & 2002 & DEC 2004 & JUL 2007 & 25.0 & 4.000 \\
\hline & NEP & SPIRAL ESC. & 6.7 & MAY & 2001 & DEC 2004 & JAN 2008 & - & 0.242 \\
\hline & NEP & NO SPIRAL & 5.5 & JUL & 2001 & DEC 2004 & JAN 2008 & 4.0 & 0.242 \\
\hline \multirow[t]{5}{*}{ WILD 2} & BALLISTIC & DIRECT & 8.9 & APR & 1999 & JUL 2002 & MAR 2008 & 60.3 & 11.344 \\
\hline & BALLISTIC & APH, REND, & 6.1 & MAR & 1997 & JAN 2000 & APR 2003 & 73.4 & 10.863 \\
\hline & SEP & DIRECT & 6.0 & MAR & 1999 & JUL 2002 & APR 2005 & 25.0 & 3.959 \\
\hline & NEP & SPIRAL ESC, & 7.0 & $\mathrm{DEC}$ & 1998 & JUL 2002 & DEC 2005 & - & 0.201 \\
\hline & NEP & NO SPIRAL & 5.8 & MAR & 2000 & JUL 2002 & DEC 2005 & 4.0 & 0.201 \\
\hline KOPFF & BALLISTIC & APH, REND, & 6.0 & JUL & 2003 & JAN 2007 & JUL 2009 & 80.7 & 11.314 \\
\hline
\end{tabular}

* combined total of space-storable, hydrazine, and solid propellant maneuvers AV COMPONENTS APPLY TO DIFFERENT SYSTEM MASS VALUES THROUGHOUT MISSION SCENARIO 


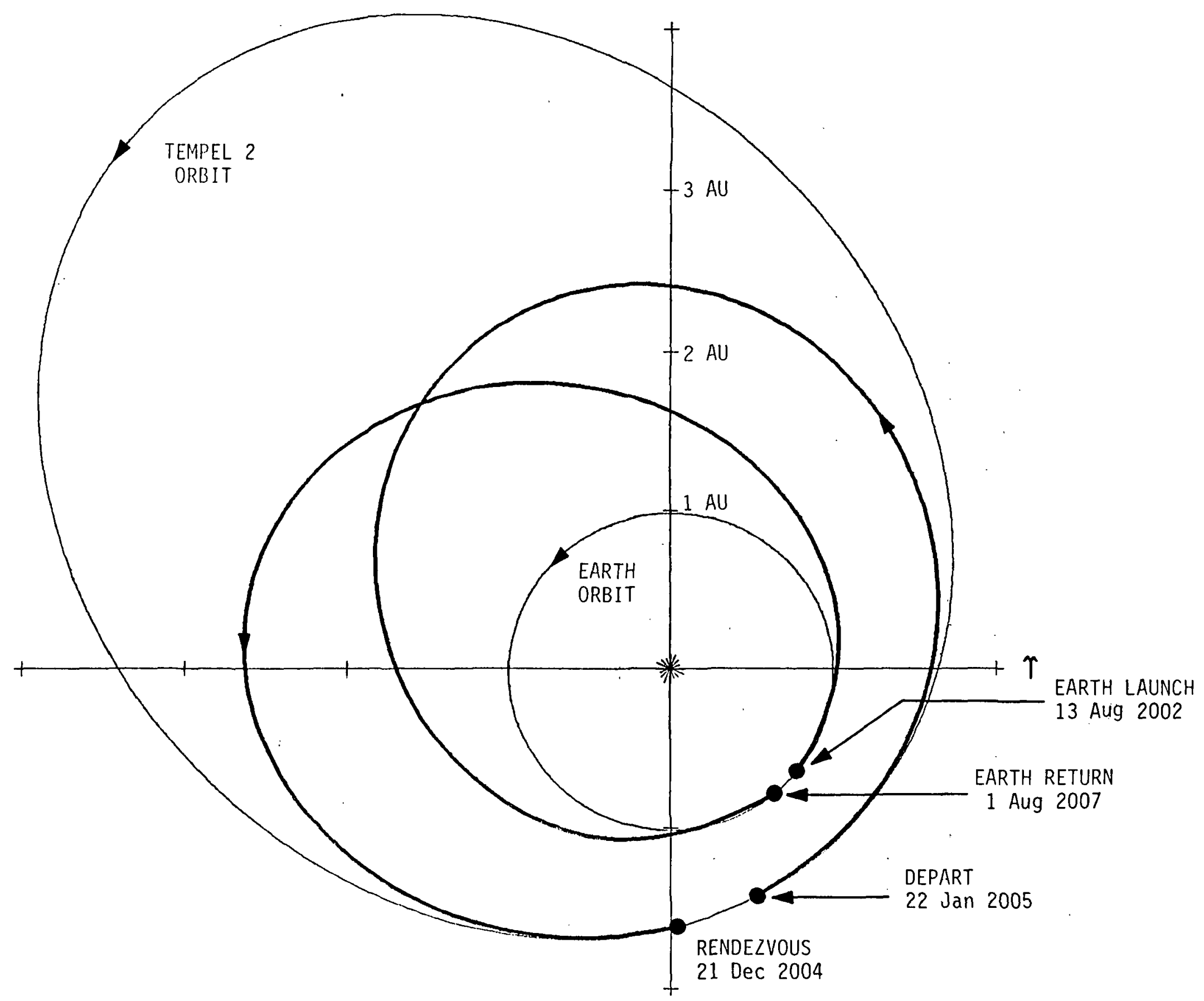

SEP FLIGHT PROFILE FOR COMET TEMPEL 2 SAMPLE RETURN 


\begin{tabular}{llccc} 
& & BALLISTIC & & SEP \\
\cline { 2 - 3 } (1) & SCIENCE & 106 & 106 & 106 \\
(2) & COMMAND/DATA HANDLING & 31.6 & 31.6 & 31.6 \\
(3) & TELECOMMUNICATION & 17.9 & 17.9 & 28.9 \\
(4) ATTITUDE AND ARTI CULATION CONTROL & 94.2 & 94.2 & 94.2 \\
(5) REACTION CONTROL SYSTEM & 39.3 & 39.3 & 39.3 \\
(6) POWER/PYRO & 70.9 & 25.9 & 25.9 \\
(7) STRUCTURE & 219.6 & 205.7 & 285.7 \\
(8) THERMAL CONTROL & 48.5 & 48.5 & 48.5 \\
(9) CABLING & 22.0 & 22.0 & 22.0 \\
(10) DEVICES & 34.6 & 34.6 & 34.6 \\
& SUBTOTAL (DRY) & & & \\
& CONTINGENCY (15\%) & 684.6 & 625.7 & 716.7 \\
& TOTAL & 102.7 & 93.9 & 107.5 \\
\end{tabular}




\section{MISSION OPTIOAS}

\begin{tabular}{|c|c|c|c|c|c|c|c|c|c|c|c|c|}
\hline \multirow{2}{*}{$\underset{\#}{\text { OPTION }}$} & \multirow{2}{*}{ COMET/YR } & \multicolumn{2}{|c|}{ TOTAL. TM } & \multirow{2}{*}{$\begin{array}{l}\text { FLIGHT } \\
\text { MODE }\end{array}$} & \multicolumn{3}{|c|}{ SAMPLER CONCEPT } & \multirow{2}{*}{$\begin{array}{c}\text { LAUNCH } \\
\& \\
\text { INJ. STACK } \\
\end{array}$} & \multicolumn{2}{|c|}{ INJECTED MASS (KG) } & \multicolumn{2}{|c|}{ COSTS (' $84 \$ M)$} \\
\hline & & $R_{p}$ & $\mathrm{R}_{\mathrm{A}}$ & & PEN. & DRL. & LDR. & & REQ'D & MARGIN & PROJECT & TOTAL \\
\hline 1 & ENCKE/03 & $6.1^{Y}$ & & SEP & $x$ & & & & 5,260 & & & \\
\hline 2 & ENCKE/03 & $6.1^{Y}$ & & SEP & $x$ & & $x$ & & 5,540 & & & \\
\hline 3 & ENCKE/03 & $7.0 Y$ & & NEP & & $x$ & $x$ & & 14,760 & & & \\
\hline 4 & TEMPEL-2/05 & $11.1^{Y}$ & & $\begin{array}{l}\text { BAL. } \\
\triangle V E G A\end{array}$ & $x$ & & & & 13,320 & & & \\
\hline 5. & TEMPEL -2/05 & $5.0^{Y}$ & & SEP & $x$ & & & & 5,220 & & & \\
\hline 6 & TEMPEL-2/05 & $5.0^{\gamma}$ & & SEP & $x$ & & $x$ & & 5,290 & & & \\
\hline 7 & TEMPEL-2/05 & $6.7 Y$ & & NEP & & $x$ & $x$ & & 12,410 & & & \\
\hline 8 & WILD-2/03 & $6.0^{Y}$ & & SEP & $x$ & & & & 4,670 & & & \\
\hline 9 & WILD-2/03 & $6.0^{Y}$ & & SEP & $x$ & & $x$ & & 4,740 & & & \\
\hline 10 & WILD-2/03 & $7.0^{\gamma}$ & & NEP & & $x$ & $x$ & & 13,870 & & & \\
\hline 11 & WILD-2/03 & $8.9^{Y}$ & & $\begin{array}{l}\text { BAL. } \\
\text { DIR. }\end{array}$ & $x$ & & & & 10,310 & & & \\
\hline 12 & WILD-2/03 & & $6.1^{Y}$ & $\begin{array}{l}\text { BAL. } \\
\text { DIR. }\end{array}$ & $x$ & & & & 8,260 & & & \\
\hline
\end{tabular}


- arRay pOWER............ 38 kW (bOL a 1 aU, unCONCENTRATEd)

- geOMETRIC CONCENTRATION, , $2: 1$

- thrust input power......36 kW (MAXimum \& 1 au)

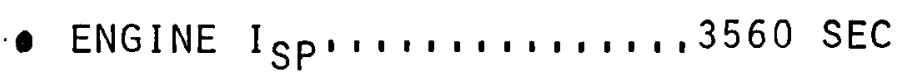

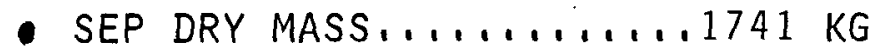

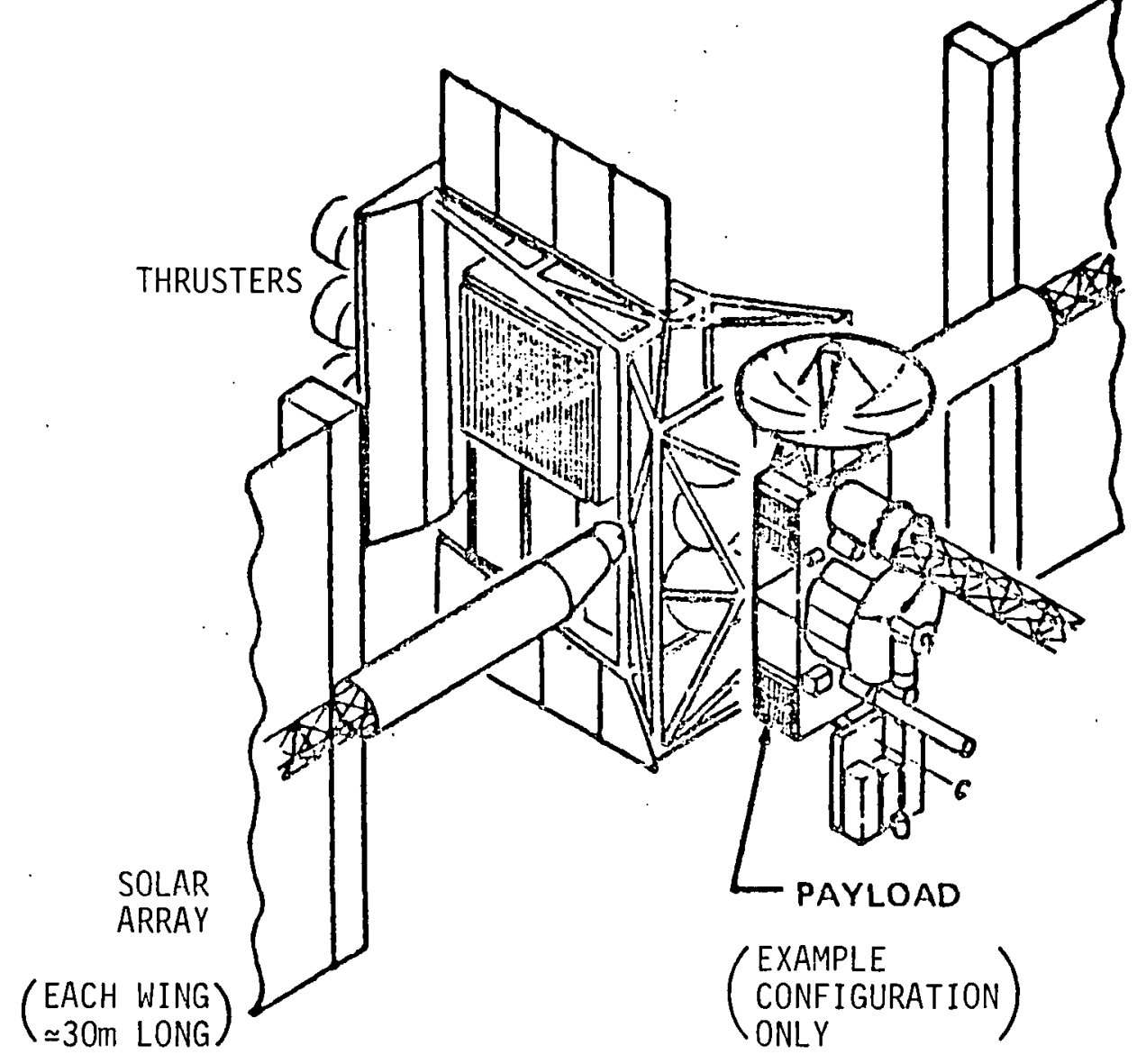




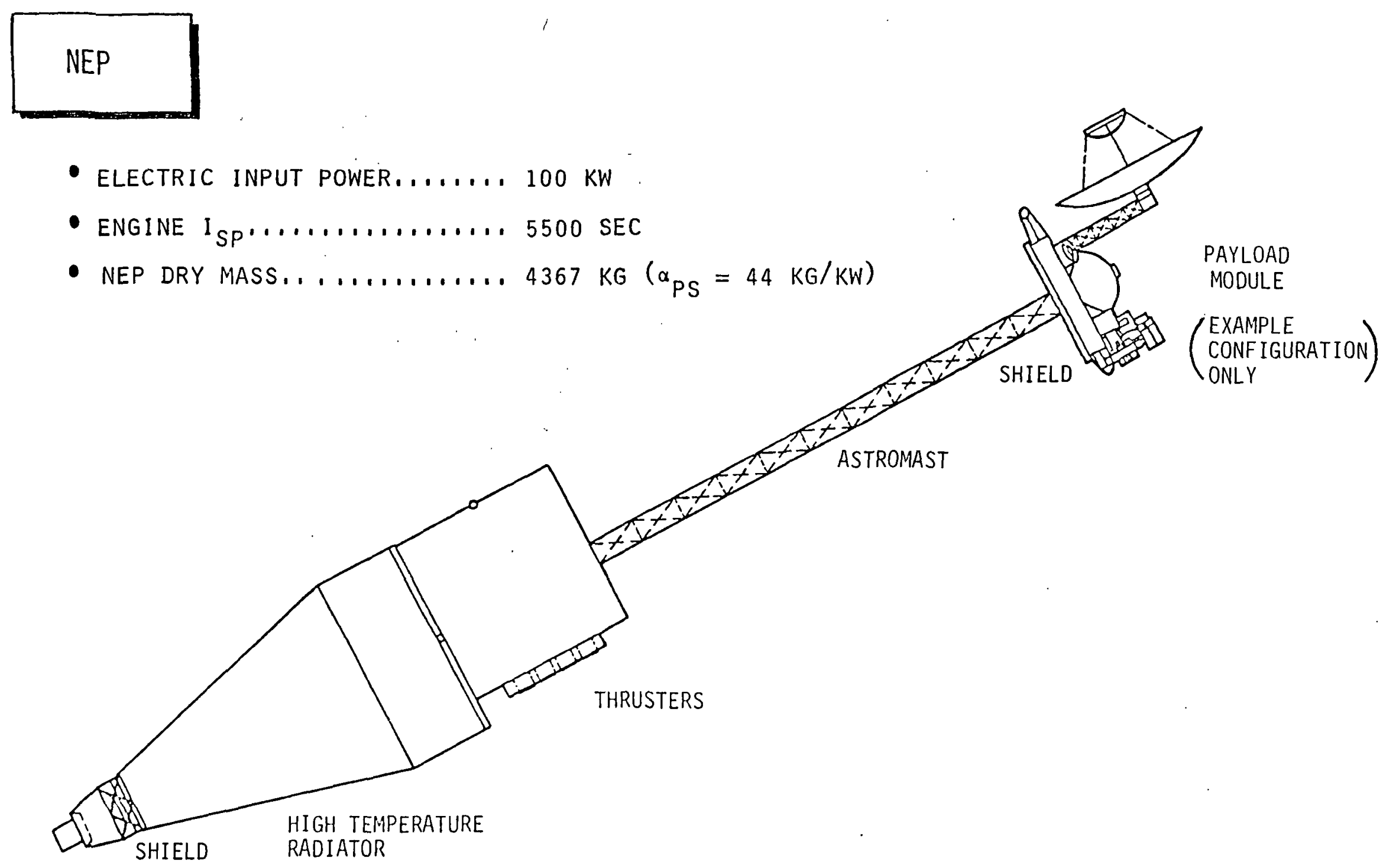

REACTOR 


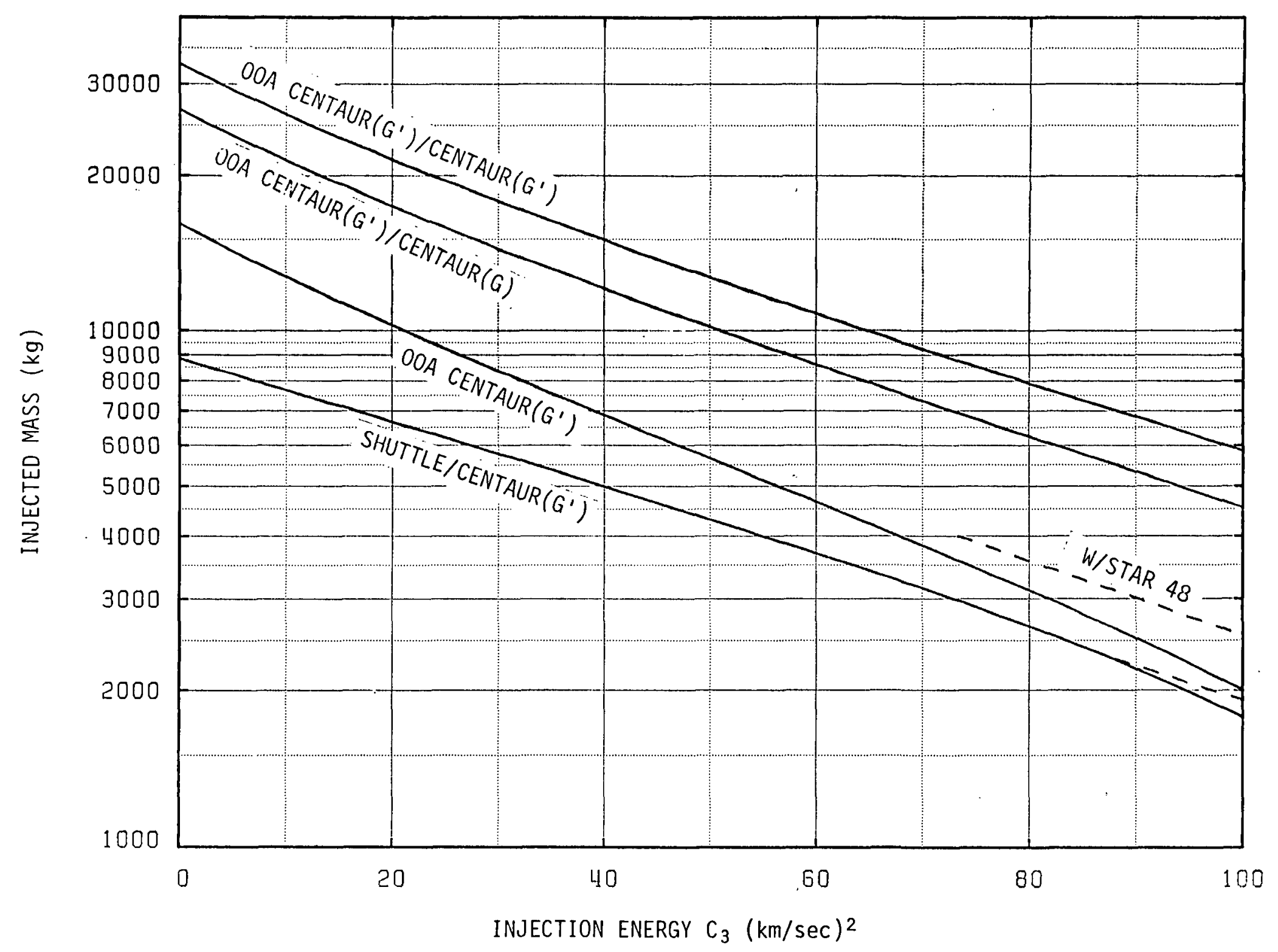

LAUNCH VEHICLE PERFORMANCE 
SAMPLER CONCEPT 1: TWO CORE PENETRATORS, NO LANDER/STATION

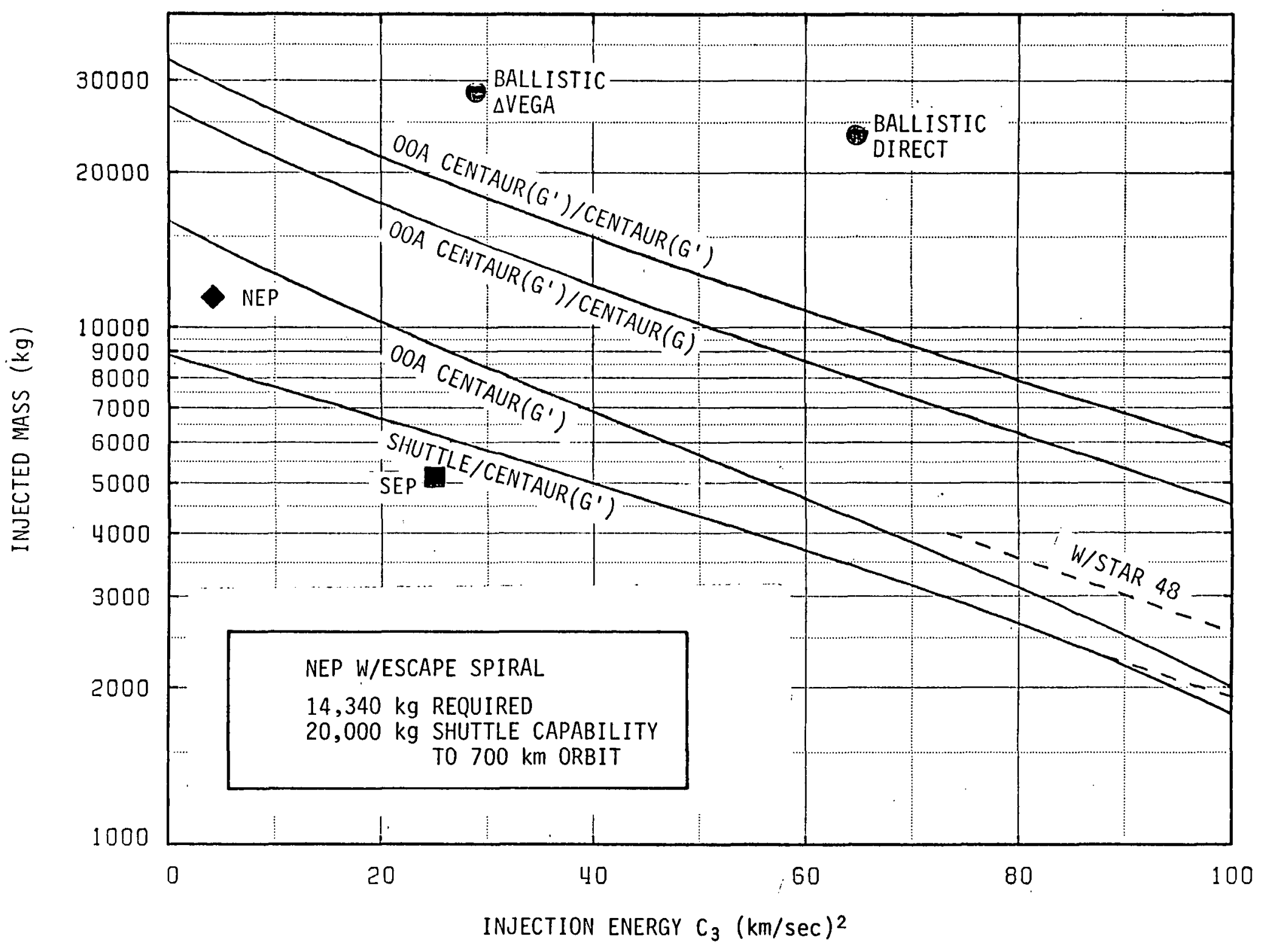

ENCKE SAMPLE RETURN MISSION CAPTURE DIAGRAM 
SAMPLER CONCEPT 1: TWO CORE PENETRATORS, NO LANDER/STATION

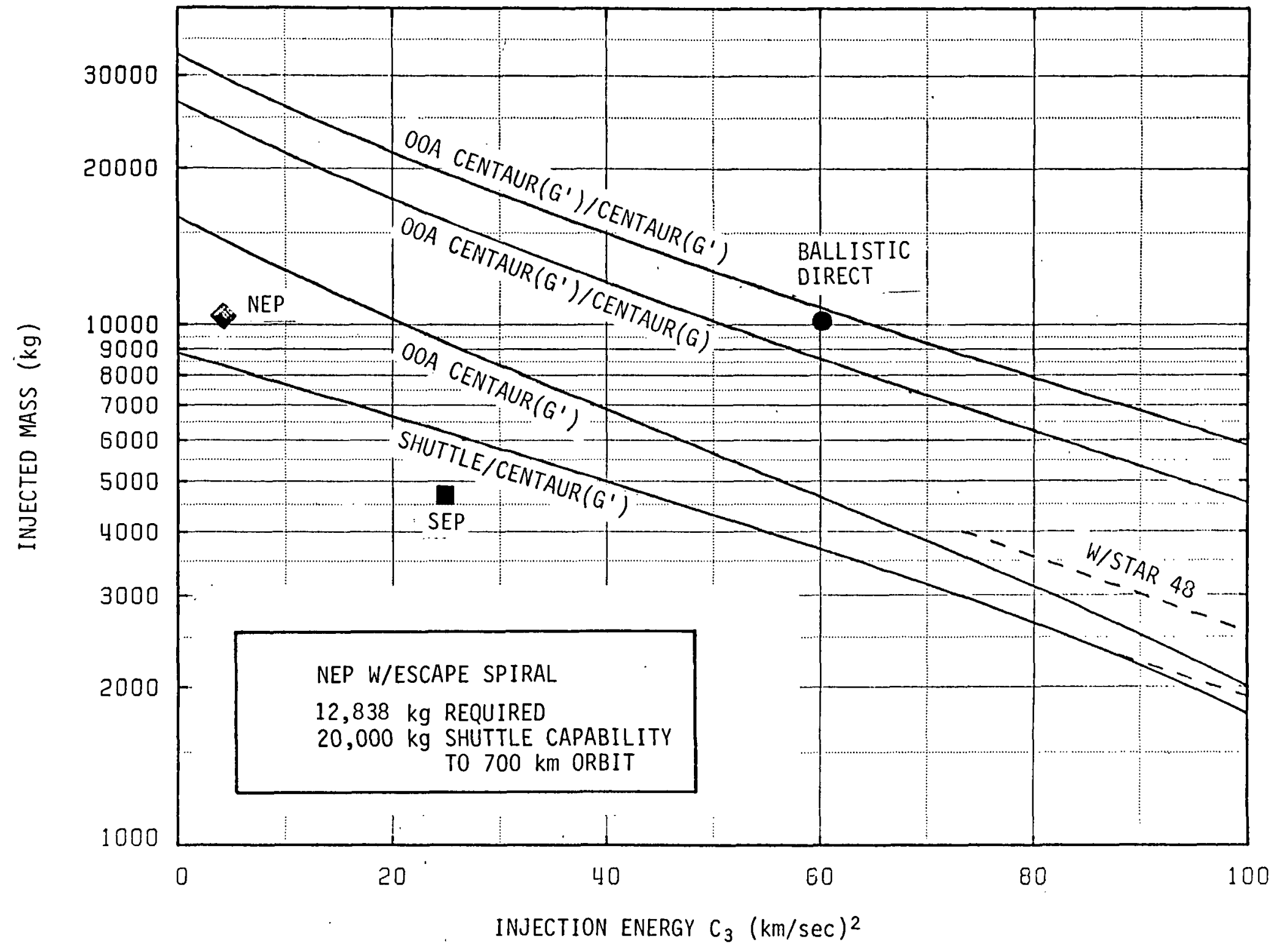

WILD 2 SAMPLE RETURN MISSION CAPTURE DIAGRAM 
SAMPLER CONCEPT 1: TWO CORE PENETRATORS, NO LANDER/STATION

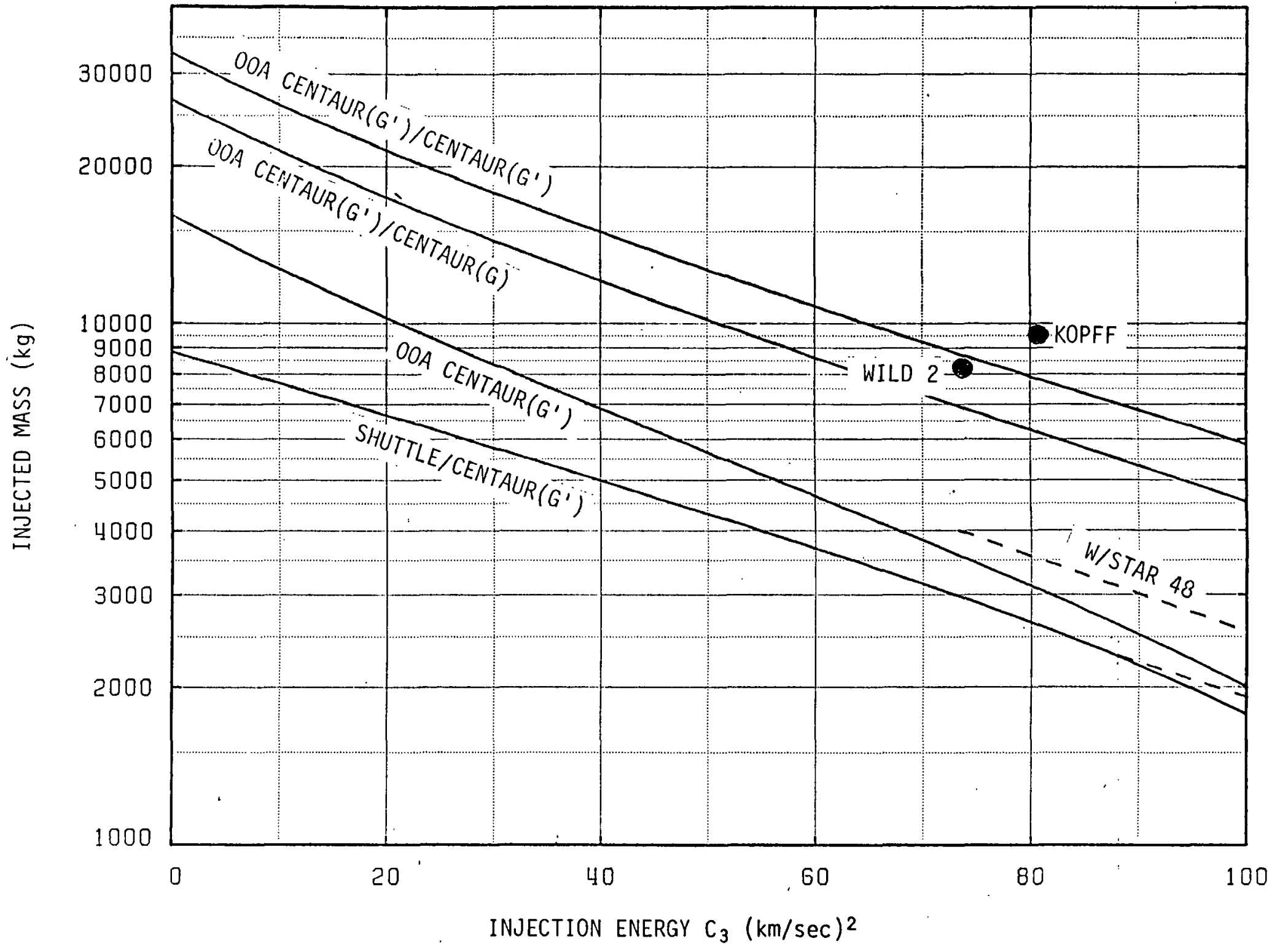

SAMPLE RETURN MISSION CAPTURE DIAGRAM FOR BALLISTIC APHELION RENDEZVOUS 


\section{BALLISTIC FLIGHT MODE PERFORMANCE FOR COMET SAMPLE RETURII}

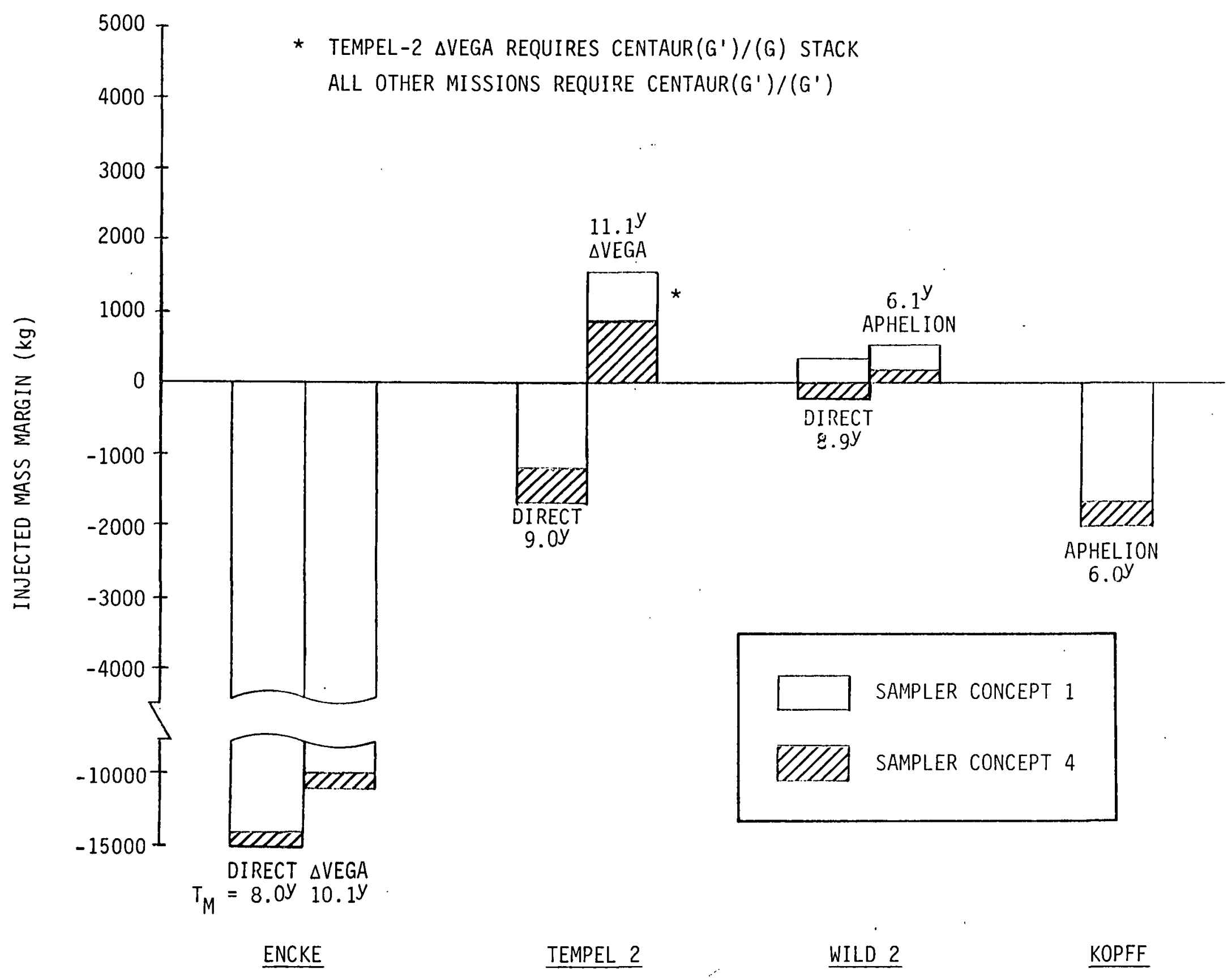




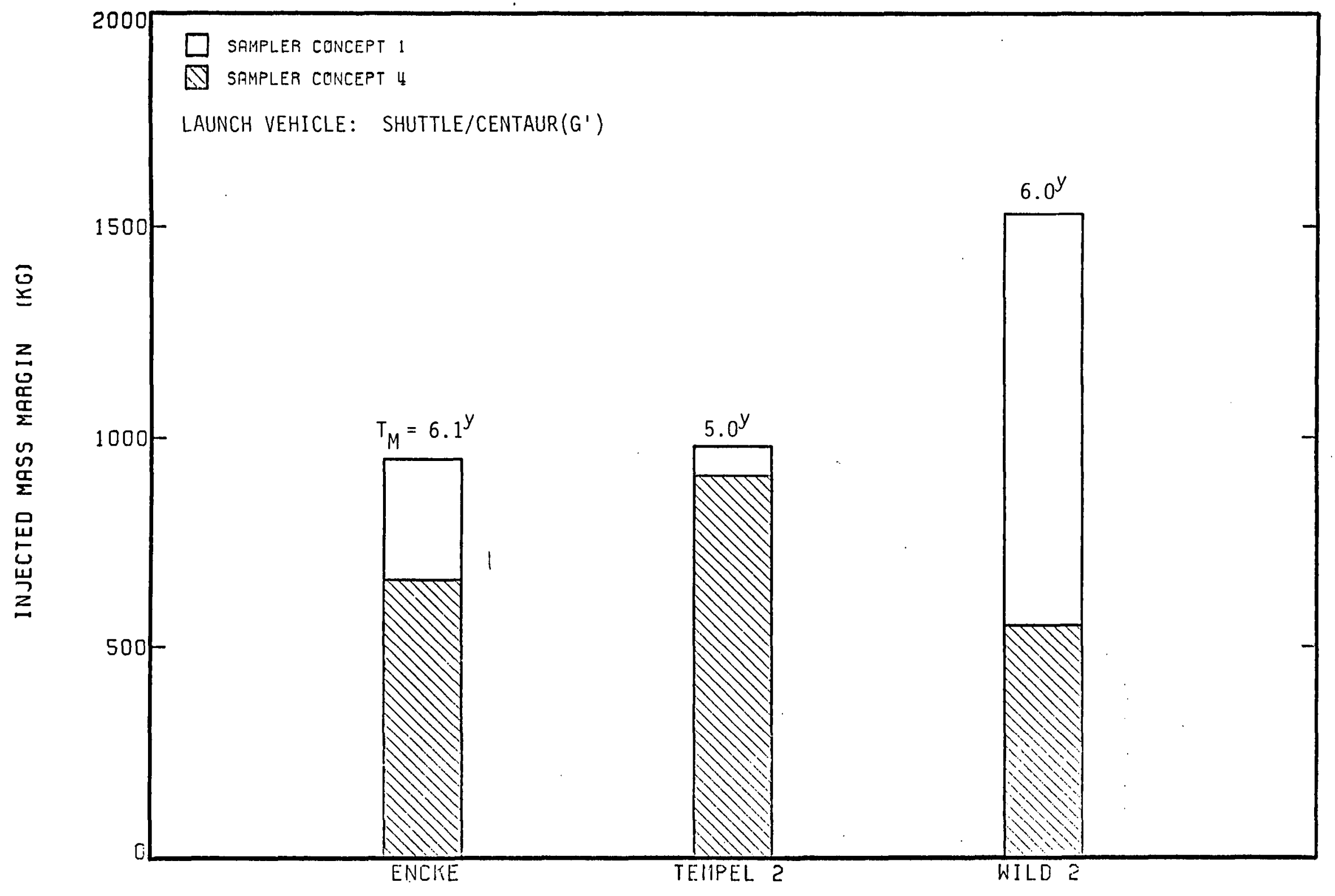

SEP FLIGIIT MODE PERFORMANCE FOR COMET SAMPLE RETURN 


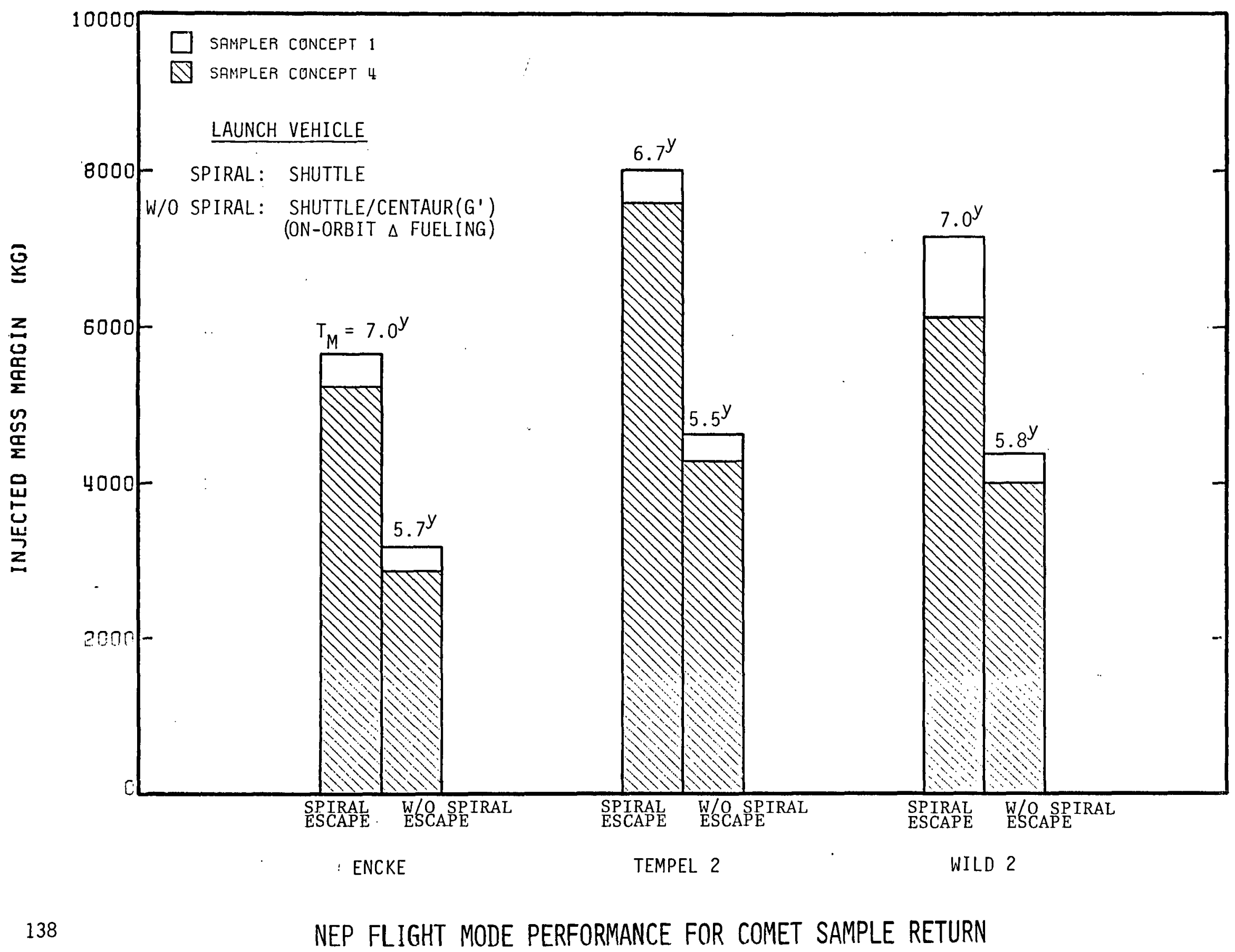


TEMPEL 2 NEP MISSION OPTIONS/PERFORMANCE COMPARISON

\begin{tabular}{|c|c|c|c|c|c|}
\hline \multirow{5}{*}{ 1.) } & \multirow[b]{4}{*}{$\begin{array}{l}\text { Arrive } T_{p}-66^{d} \\
\text { Depart } T_{p}-34^{d}\end{array}$} & \multicolumn{4}{|c|}{ MASS PERFORMANCE $(K G)^{(1)}$} \\
\hline & & \multicolumn{2}{|c|}{ SPIRAL ESCAPE } & \multicolumn{2}{|c|}{ INJECT $\& \mathrm{C}_{3}=4.0 \mathrm{~km}^{2} / \mathrm{sec}^{2(2)}$} \\
\hline & & REQ'D M INJ & MARGIN & REQ'D M INJ & MARGIN \\
\hline & & 12,410 & 7,590 & 10,310 & 4,290 \\
\hline & Total Mission Duration (YR) & \multicolumn{2}{|c|}{6.7} & \multicolumn{2}{|c|}{5.5} \\
\hline \multirow[t]{2}{*}{ 2.) } & $\begin{array}{l}\text { Arrive } T_{p}-136^{d} \\
\text { Depart } T_{p}-74^{d}\end{array}$ & 13,120 & 6,880 & 10,710 & 3,890 \\
\hline & Total Mission Duration (YR) & \multicolumn{2}{|c|}{7.0} & \multicolumn{2}{|c|}{5.5} \\
\hline \multirow[t]{2}{*}{ 3.) } & $\begin{array}{l}\text { Arrive } T_{p}-136^{d} \\
\text { Depart } T_{p}-74^{d}\end{array}$ & 14,020 & 5,980 & 11,310 & 3,290 \\
\hline & Total Mission Duration (YR) & \multicolumn{2}{|c|}{5.9} & \multicolumn{2}{|c|}{4.5} \\
\hline \multirow[t]{2}{*}{ 4.) } & $\begin{array}{l}\text { Arrive } T_{p}-136^{d} \\
\text { Depart } T_{p}-74^{d}\end{array}$ & 15,090 & 4,910 & 11,960 & 2,640 \\
\hline & Total Mission Duration (YR) & \multicolumn{2}{|c|}{5.8} & \multicolumn{2}{|c|}{4.2} \\
\hline
\end{tabular}

(1) Results for Sampler Concept \#4

(2) L.V. = OOA Centaur (G') 
- USing MASS MARgin AND ROUND tRIP tIME AS PERFORMANCE DISCRIMINATORS:

NUCLEAR ELECTRIC PROPULSION IS THE MOST CAPABLE SYSTEM

SOLAR ELECTRIC PROPULSION GENERALLY PROVIDES GOOD CAPABILITY

BALLISTIC/CHEMICAL PROPULSION GENERALLY PROVIDES VERY POOR CAPABILITY

- NEP With ESCAPE SPIRAL REQUIRES SHUTTLE DELIVERY TO NUCLEAR SAFE ALTITUDE ( $~ 700 k M)$ ROUND TRIP TIMES ARE APPROXIMATELY 7 YEARS

SHUTTLE CARGO MARGINS ARE $5200-7600 \mathrm{KG}$

NEP WITHOUT ESCAPE SPIRAL REQUIRES FULLY LOADED CENTAUR G' (ON-ORBIT DEL.TA-FUELING) ROUND TRIP TIMES ARE APPROXIMATELY 6 YEARS

INJECTED MASS MARGINS ARE $2200-4400 \mathrm{KG}$

- SeP requires large solar array ( $38 \mathrm{~kW}$ ) With concentrators

ROUND TRIP TIMES ARE 5 - 6 YEARS

INJECTED MASS MARGINS ARE $500-1500 \mathrm{KG}$

- the ballistic flight mode cannot capture most mission opportunities

EXCEPTIONAL CASES REQUIRE ON-ORBIT ASSEMBLY OF CENTAUR STAGES AND

SPACE-STORABLE RETROPROPULSION

ROUNDTRIP TIMES ARE VERY LONG AT 8 - 11 YEARS 


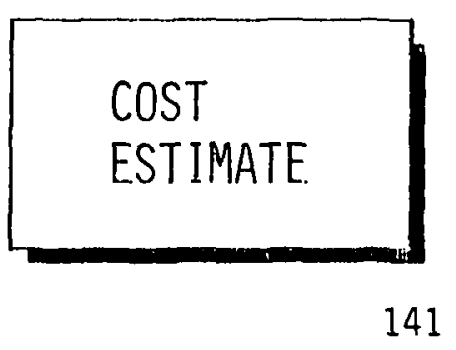




\begin{tabular}{|c|c|c|}
\hline & \multicolumn{2}{|c|}{ FY 1984 MILLION DOLLARS } \\
\hline & PENETRATOR & DRILL \\
\hline \multicolumn{3}{|l|}{ SAMPLER $^{*}(W / 0$ LANDER $)$} \\
\hline MANAGEMENT & 3.2 & 3.3 \\
\hline INSTRUMENTATION & 1.0 & - \\
\hline SUBSYSTEM DEVELOPMENT & 26.5 & 28.4 \\
\hline SYSTEM INTEGRATION/TEST & 13.2 & 13.6 \\
\hline TOTAL & 43.9 & 45.3 \\
\hline \multicolumn{3}{|l|}{ SAMPLER ${ }^{\star}(W / L A N D E R)$} \\
\hline MANAGEMENT & 3.2 & 3.3 \\
\hline INSTRUMENTATION & 1.0 & - \\
\hline SUBSYSTEM DEVELOPMENT & 26.5 & 27.4 \\
\hline SYSTEM INTEGRATION/TEST & 13.2 & 13.4 \\
\hline TOTAL & 43.9 & 44.1 \\
\hline \multicolumn{3}{|l|}{ LANDER } \\
\hline MANAGEMENT & 6.1 & 7.3 \\
\hline SCIENCE DEVELOPMENT & 18.7 & 28.6 \\
\hline SUBSYSTEM DEVELOPMENT & 34.0 & 35.5 \\
\hline SYSTEM INTEGRATION/TEST & 24.0 & 29.2 \\
\hline TOTAL & 82.8 & 100.6 \\
\hline
\end{tabular}




$\frac{\text { FY1984 MILLION DOLLARS }}{\text { BALLISTIC }} \frac{\text { LOW THRUST }}{\text { TEMPEL 2 }\left(R_{P}\right) \text { WILD 2 }\left(R_{P}\right) \text { WILD 2 }\left(R_{A}\right)}$ SEP NEP

SPACECRAFT

MANAGEMENT

SCIENCE DEVELOPMENT

SUBSYSTEMS DEVELOPMENT

SYSTEM INTEGRATION/TEST

TOTAL

RETURN CAPSULE
MANAGEMENT

SUBSYSTEMS DEVELOPMENT

SYSTEM INTEGRATION/TEST

TOTAL

4.3

4.3

44.0

44.0

12.6

60.9

60.9

INCLUDES CHEMICAL PROPULSION 


\section{DETAILED PROJECT COST ESTIMATE: TEMPEL-2 SEP MODE OPTION \#6}

FY 1984 MILLION DOLLARS

\begin{tabular}{|c|c|c|c|c|}
\hline SPACECRAFT & $\begin{array}{r}\text { RETURN } \\
\text { CAPSULE }\end{array}$ & $\begin{array}{c}\text { CORE } \\
\text { PENETRATOR }\end{array}$ & LANDER & TOTAL \\
\hline 10.3 & 3.5 & 3.2 & 6.1 & 23.1 \\
\hline 50.8 & - & 1.0 & 18.7 & 70.5 \\
\hline 53.6 & 35.6 & 26.5 & 34.0 & 149.7 \\
\hline 29.5 & 10.3 & 13.2 & 24.0 & 77.0 \\
\hline- & - & - & 10.0 & 10.0 \\
\hline 144.2 & 49.4 & 43.9 & 92.8 & 330.0 \\
\hline
\end{tabular}

SUBCONTRACTING

$\rightarrow \quad+\quad \rightarrow \quad 27.9$

VEHICLE INTEGRATION

17.0

OPERATIONS

83.1

DATA ANALYSIS

16.0

PROGRAM MANAGEMENT

5.0

NET TOTAL

479.3

APA/RESERVE $(30 \%)$

143.8

GRAND TOTAL

623.1 